\title{
Die Wachstumsperiode der Oocyte des Huhnes.
}

\author{
Von \\ Dr. med. vet. Sonnenbrodt,
}

Prosektor am anatom. Institut der Königl. Tierärztl. Hochschule zu Berlin.

Hierzu Tafel XIX-XXII.

Mein auf Anregung von Herrn Professor Dr. Schmalz ursprünglich gefasster Plan, den gesamten Geschlechtsapparat des Huhnes histologisch zu bearbeiten, machte mich mit den bisherigen Untersuchungen über diesen Gegenstand näher bekannt. Ich fand, dass hier noch grosse Lücken bestehen, die nur durch gründliche Untersuchungen ausgefüllt werden können. Die Literatur über das Ovarium und im besonderen über die Oocyte, welche hier ihre Wachstumsperiode durchmacht, wies Ergebnisse auf, welche eine neue Untersuchung notwendig erscheinen liessen. In den für die Hühneroocyte wichtigsten Arbeiten fiel mir (mit Ausnahme bei der Arbeit von d'Hollander), immer wieder auf, dass sie auf einem nur sebr geringen, zum Teil nicht ganz einwandfreien Materiale aufgebaut waren. Aus einigen Arbeiten geht klar hervor, dass für die Untersuchung nur eins, höchstens $z$ wei Hühner verarbeitet sind. Infolgedessen konnten gerade im letzten Teile der Wachstumsperiode sehr leicht Irrtümer vorkommen, da ein Huhn nur eine beschränkte Anzahl grosser Follikel besitzt. Geht nun noch der eine oder andere Follikel davon in Rückbildung über, so ist ein falsches Untersuchungsresultat selbstverständlich. Diese Umstände liessen in mir den Gedanken reifen, die Wachstumsperiode der Hühneroocyte an einem möglichst umfangreichen und allen Anforderungen entsprechenden Materiale zu untersuchen. Da die Oogenese und embryonale Entwicklung der Oocyte von d'Hollander neu bearbeitet war, konnte ich mich auf den postembryonalen Teil der Wachstumsperiode vom Augenblicke der Geburt an beschränken.

\section{Material und Technik.}

Das gesamte - allerdings ursprünglich nickt allein für diese Arbeit bestimmte - Material beläuft sich auf 93 Hühner in dem verschiedensten Alter, beginnend mit dem eben geborenen Hühnchen bis zur mehrere Jahre alten Legehenne. Hiervon scheiden jedoch für die vorliegende Arbeit un- 
berücksichtigt ca. 40 Hühner aus. Diese zeigten zum Teil Follikel in Rückbildung, oder waren doch verdächtig, zum Teil lieferten die damit angestellten Fixierungsversuche keine befriedigenden Resultate. Die jüngsten Stadien von bis zu drei Monate alten Hühnern verschaffte ich mir durch eigenen Brütversuch, zu deren Ergänzung ich noch einige mit ziemlich sicherer Geburtsangabe gekaufte Küken benutzte. Die sämtlichen älteren Hühner bekam ich in grosser Zahl bei Ankunft der russischen Geflügeitransporte hier in Berin. Unter den Opfern des Transports fanden sich fast immer mehrere noch lebendwarme tote Tiere. Die Geschlechtsorgane wurden - bei Hiihnern mit grossen Follikeln immer in situ an dem betreffenden Stücke der Wirbelsäule hängend - in reichlicher Fixierungsflüssigkeit fixiert.

Die besten Präparate erhielt ich bei Ovarien jüngerer Tiere durch Fixierung mit Sublimat-Eisessig. Diese war für grosse Follikel nicht besonders geeignet, da der Dotter weich blieb und leicht eine Loslüsung des Keimbläschens aus seiner Lage eintrat. Für Ovarien mit grossen Follikeln bildete eine Lösung von Calcium Bichromicum 20\%, Sublimat 20\% und Eisessig (20:10:1) die beste Fixierungsmethode, die auch für kleine Ovarien brauchbare Resultate ergab. Den stärkeren Sublimatzusatz zieje ich der einfachen Burchardtschen Flüssigkeit vor. Nachbehandlung mit Jod ist bei dieser Fixierungsflüssigkeit notwendig.

Die fixierten Organe wurden entsprechend weiter behandelt Die Überführung durch die Alkoholreihe wurde ganz allmäblich vorgenommen bis zum $80 \%$ igen Alkohol; in $96 \%$ kamen die betreffenden Stückchen erst unmittelbar vor der Einbettung auf höchstens 12 Stunden. Es wurde fast ausschliesslich in Paraffin eingebettet, nur einige Präparate in Celloidin. Die Paraffineinbettung geschah anfangs durch absoluten Alkohol, später durch Aceton. Das Aceton wurde vorher in der Wärme durch Cuprum sulfuric. wasserfrei gemacht. Für die Einbettung ergaben sich folgende Zeiten als die günstigsten. Die Organstückchen von etwa $1 / 2 \mathrm{~cm}$ Dicke, aber in dem ganzen Organ resp. den Follikeln entsprechender Grösse (mit Ausnahme der Follikel über $11 \mathrm{~mm}$ Grösse), blieben in Aceton bei Blattemperatur $1 / 4$ bis 1 Stunde, in Chloroform oder Xylol 10 Minuten bis $1 / 2$ Stunde, in einem Gemisch mit Paraffin $1 / 4$ Stunde, in dreimal gewechseltem Paraffin $1 / 2$ bis 3 Stunden. Eingebettet wurde in ganz festem Paraffin mit einem Schmelzpunkte von $56-58^{\circ} \mathrm{C}$. oder in einem aus ungefähr gleichen Teilen bestehenden Gemisch dieser Paraffinsorte mit der weicheren.

Von den in der beschriebenen Weise eingebetteten Stücken wurden ausschliesslich Schnittserien zuletzt als Bandserien angefertigt. Die Schnittdicke betrug bei den jüngsten Ovarien 2 bis $3 \mu$, bei grösseren 5 bis $7 \mu$; die über etwa $3 \mathrm{~mm}$ grossen Follikel resp. deren Kerne wurden $10, u$ dick geschnitten. Sämtliche Schnitte wurden auf Objektträgern durchschnittlich zu 5 bis 6 aufgeklebt. Die Schnitte kleinerer Ovarien und der kleineren Follikel wurden auf erwärmtes Wasser gebracht und hieraus anfgefangen. Diese Methode war jedoch für die grossen Follikel von etwa $\overline{5} \mathrm{~mm}$ an unsicher. Hier leistete mir mit einer kleinen Modifikation die Aufklebemethode mit Phenolgelatine (nach $01 \mathrm{t}$ ) gute Dienste. Das ron $01 \mathrm{t}$ angegebene 
Andrücken der Schnitte erwies sich für meine feinen Objekte misslich. Die verdünnte Phenolgelatinelösung hielt ich bei Bluttemperatur flüssig. Die darauf gebrachten Schnitte wurden wie aus warmem Wasser aufgefangen. Die überschüssige Gelatine wurde durch Fliesspapier abgesaugt und die Objektträger in einem geeigneten Halter auf der Kante stehend, bei Zimmertemperatur getrocknet. Dieses Aufstellen der Objektträger auf die Kante ist notwendig, damit die Gelatine nach einer Seite abläuft und nur in möglichst dünner Schicht unter den Schnitten zurückbleibt; eine zu dicke Gelatineschicht färbt sich immer mit. Nach dem vollständigen Trocknen wurden die Präparate mit $10 \%$ iger Formalinlösung nachbehandelt.

Zur Färbung der Präparate machte ich anfangs einige Versuche, ob und in wie weit die $\mathrm{Heidenhainsche} \mathrm{Eisenalaun-Hämatoxylinfärbung} \mathrm{von}$ einigen anderen Methoden übertroffen wurde. Die von Carnoy angegebene konz. Delafieldhämatoxylinfarbe befriedigte mich nicht. Die Mitochondrienfärbung nach Benda bot mir keine besonderen Vorteile. Die Cochenilletinktur-Dotterfärbung nach $\mathrm{Peter}$ gab mit Hämatoxylinnachfärbung gute Resultate, ist aber wegen der lange dauernden Doppelfärbung umständlich. Den grössten Teil der Präparate habe jch mit Eisenalaun-Hämatoxylin nach II. Heidenhain gefürbt. Diese Fürbung erwies sich für die Kernstrulturen immer als die sicherste und einfachste Methode. Zu Kontrastfürbungen benutzte ich am meisten Eosin, ausserdem aber auch Orcein, Rubin, Orange, Pikrinsäure und Pikrinsäure-Fuchsin S. Bei den Kernserien der grossen Follikel habe ich meistens keine Kontrastfürbung angewandt. Von sämtlichen Präparaten sind für die Untersuchung nur die besten berïcksichtigt worden.

Für die Abbildungen habe ich die Präparate mit dem Leitzschen Zeichenokular bei Ölimmersion selbst skizziert. An der Hand dieser Skizzen hat meine Schwester die einzelnen Abbildungen nach dem mikroskopischen Bilde ausgeführt.

Für die Technik wurden ausser den bekannten technischen Spezialwerken folgende Arbeiten benutzt:

B en d a : Die Mitochondrienfärbung und anderen Methoden zur Untersuchung der Zellsubstanzen. Verhandlungen der anatom. Gesellschaft, 15. Versammlung in Bonn 1901, pag. 1õõ.

Burchardt: Bichromate und Zellkern. La cellule XII, 2, pag. 337, 1897. Olt: Das Aufkleben mikroskopischer Schnitte. Zeitschr. für wissenschaftl. Mikroskopie, Bd. 23, pag. 323, Leipzig 1906.

Peter: Eine neue Dotterfärbung. Ebenda, Bd. 21, pag. 31t, Leipzig 1904.

\section{Untersuchungsbefunde.}

Das Ovar eines soeben ausgekrochenen Hühnchens ist ein links an der Aorta auf dem vordersten Nierenlappen liegendes flaches Hügelchen, welches sich von den benachbarten Organen durch seine hellrosa, fast weisse Färbung klar abbebt. Seine Länge beträgt $6-7 \mathrm{~mm}$, die Breite etwa $2 \mathrm{~mm}$ und in der 
Dicke misst es knapp $1 \mathrm{~mm}$. Das kraniale Ende ist abgerundet, am kaudalen Ende läuft es spitz zu, der mediale Rand ist wulstig gegenüber dem fast scharfen lateralen. Die Oberfläche ist glatt; einzelne ganz schwache Furchen springen besonders vom lateralen Rande her in das Organ ein. Eine starke wulstige Falte zieht vom Vorderende des medialen Randes schräg nach hinten und auswärts über das Ovar hinweg und geht hier in den lateralen Rand über. Hierdurch wird der Anschein erweckt, als ware del Eierstock mit seinem kaudalen Ende um $180^{\circ}$ gegen das kraniale Ende gedreht. Auf Schnitten zeigt sich, dass diese Falte eine tiefe, das Ovar fast ganz quer durchteilende Furche überdeckt. Diese Furche und die sie bedeckende Falte habe ich auch bei weiter entwickelten Eierstöcken immer gefunden, sie prägt sich oft noch an Ovarien aus, die schon mehrere Millimeter grosse gestielte Follikel tragen, die dann hüufig an dem freien Rande der Falte hängen. Diese Form und dies Aussehen behäl das Ovar bei seiner Weiterentwicklung bei. Seine Obertläche beginnt erst etwa nach einem Monat eine ganz feine Körnung zu zeigen, welche durch die sich vordrängenden Oocyten hervorgerufen wird. Die Grösse des Ovars eines Hühnchens von einem Monat beträgt etwa $1 \mathrm{~cm}$ in der Länge, $1 / 2 \mathrm{~cm}$ in der Breite und fast $2 \mathrm{~mm}$ in der Dicke. Bei dem weiteren Wachstum zerklüftet sich die Obertlăche des Eierstockes immer mehr. Die anfangs nur schwach angedeuteten Furchen dringen tiefer in das Orarialgewebe ein und zerlegen das ganze Organ in mehr oder weniger starke Wülste und Falten, an denen sich die Oocyten schon schwach perlenartig vorwölben. Das Ovar erinnert dann sehr an das Aussehen des Gehirns mit seinen Gyri und Sulci. Bei diesen grösseren Ovarien bei Hühnern von vier Monaten an Maße anzugeben, ist zwecklos, da sie sehr verschieden sind. Die Oocyten heben sich immer mehr aus dem Ovarialgewebe heraus. Die Furchen werden nun mehr oder weniger verdeckt. Wir erhalten Bilder vom Ovar, die an Kugelhaufen erinnern, die Grösse der Follikel beträgt jetzt schon bis zu $2 \mathrm{~mm}$. Nun heben sich die Follikel ganz aus den Ovarien heraus und sind nur durch ganz kurze Stiele damit verbunden. Das Bild der Weintraube ist vollendet. $\mathrm{Zu}$ mehreren Hundert drängt sich Beere an Beere. Die grösseren bis etwa $5 \mathrm{~mm}$ Durchmesser zeigenden Follikel haben ein helles weisslich durchscheinendes Aussehen, während die kleineren mehr grau 
gefärbt sind. Als helle Linie zeigt sich schon an allen Follikeln die Narbe. Eine wundervolle farbige Abbildung eines schönen traubigen Ovars vom Huhne gibt Lereboullet in seiner Fig. 42. Dieses Bild einer Weintraube wird zum Teil wieder gestört durch das kolossale Wachstum einiger Follikel, die der Reife entgegengehen. Diese Follikel nehmen eine immer stärkere Gelbfärbung bei ihrer Grössenzunahme an, und die nahezu reifen Follikel über 30 bis $\mathrm{zu} 40 \mathrm{~mm}$ Durchmesser haben eine gesättigte kadmiumgelbe Farbe. Ich fand bis zu 6 Follikel über $10 \mathrm{~mm}$ Durchmesser, meist finden sich aber nur 3 bis 4 . Der grösste von mir untersuchte Follikel hatte $37 \mathrm{~mm}$ im Durchmesser. Das darin enthaltene $\mathrm{Ei}$ hatte wohl dieselbe Reife wie die grössten bisher untersuchten Eier (von $\mathrm{Holl}$, welches $40 \mathrm{zu} 35 \mathrm{~mm}$, und von Loyez, welches fast $4 \mathrm{~cm}$ maß). Bei den verschiedenen Hühnerrassen ist die Grösse der reifen Follikel am Ovar sehr verschieden. Holl und Loyez geben nicht an, welche Rasse sie zu ihrer Untersuchung benutzt haben; ich benutzte russische und galizische Hühner, welche verhältnismässig kleine Eier legen. Die grossen Follikel hängen an oft $1 \mathrm{~cm}$ langen Stielen tief herab. An ihrer Obertliache spinnen die Blutgefässe ein feines dichtes Netz. Nur eine 1 bis $2 \mathrm{~cm}$ lange weissliche Linie, an der dem Stiele entgegengesetzten Fläche - die Narbe - bleibt vollständig frei von Blutgefüssen. An dieser Stelle platzt der Follikel und lässt das $\mathrm{Ei}$ in den Trichter des Eileiters gleiten. Schon wenige Stunden nach diesem Vorgange, wenn das Ei sich noch im mittleren Teile des Eileiters befindet, hat sich die hohl gewordene Follikelhülle zusammengezogen, nur ein etwa $1 \mathrm{~cm}$ weiter sog. Kelch zeigt den verlassenen Sitz des Eies an. Solche Kelche findet man an Ovarien von Legehennen vielfach. Die Rückbildung derselben geht aber sehr schnell vor sich, es bleibt zuletzt nur noch ein kleiner Knoten zurück und auch dieser verschwindet, wenn ein $\mathrm{Ei}$, das im Stiel des ersten Follikels lag, der Reife entgegenschreitet; das Gewebe wird in die Theca des neuen Follikels eingezogen.

Bei älteren Hühnern, vor allem bei Bruthühnern, finden sich immer noch grössere Follikel, die ein ganz anderes Bild zeigen. Ihre Oberfläche ist uneben und runzelig, die Gefässe verlaufen in tiefen Furchen. Von der Narbe ist häufig nichts zu sehen, oder Gefüsse verlaufen in ihr. Die Follikelhülle macht einen 
bedeutend verdickten Eindruck. Das reine Gelb, das den reifenden Eiern eigen ist, wird durch die dunklere, dickere Hülle mehr oder weniger verdeckt. Diese Follikel befinden sich in Rückbildung. Es kommen auch Follikel vor, die noch von aussen fast ganz den normalen gleichen, bei denen man auf dem Durchschnitte am fixierten Materiale nur eine geringe Verdickung der Theca findet und keine regelmässig konzentrische Kreise bildende Dotterschichtung, wie sie die normalen Eier zeigen, sondern unregelmässige gewellte Dotterlinien. Diese Follikel befinden sich ohne Frage in Rückbildung. Bei kleineren Follikeln gibt ebenfalls die verdickte Theca und die dadurch verdeckte Farbe meistens schon makroskopisch hinreichenden Anbalt, um sich vor untergehenden Eiern $z u$ hüten. Auch bei nicht brütlustigen Hühnern fanden sich einzelne untergehende Eier. Wenn nicht schon makroskopisch, so ist meistens mikroskopisch der Zerfall leicht $\mathrm{zu}$ erkennen. Ich habe alle Hühner, die in Rückbildung befindliche Eier zeigten, gänzlich von der Untersuchung ausgeschlossen, nur das Huhn 37, welches gerade den Beginn der Rückbildung zeigt, habe ich angeführt, um die Unterschiede gegenüber den normalen Eiern zu zeigen.

Bei allen 93 von mir untersuchten Hühnern fand ich nur das linke Ovar entwickelt. Ein rechtes Ovar scheint demnach sehr selten zu sein, auch in der Literatur finden sich nur vereinzelte Fälle angeführt von Barkow, Wagner, Stannius und His. Eine in der Leipziger Geflügelzeitung 1907, Heft 6, erschienene Arbeit über diesen Gegenstand von $\mathrm{Kl}$ e y t e $\mathrm{u}$ b e (warum verkümmert beim Huhn stets die rechte Hälfte des Eierstocks?) war mir unzugänglich, hat auch für das bearbeitete Thema keine Bedeutung.

Auf Quer- und Längsschnitten zeigt das Ovar eines am 21. Bebrütungstage ausgekrochenen Hühnchens eine scharfe Trennung in zwei Schichten. Die tiefere Grundschicht des Eierstockes wird von sehr zahlreichen, relativ weiten Gefässen angefüllt mit dünner Wandung. Die Dicke dieser Schicht betrăgt in der Mitte des Ovars bis $\mathrm{zu} \mathrm{3/4} \mathrm{mm.} \mathrm{Hier} \mathrm{steht} \mathrm{sie} \mathrm{durch} \mathrm{die} \mathrm{zum}$ Eierstock führenden Gefässe und das umgebende Gewebe mit der Aorta und dem daneben liegenden Parovarium in direkter Verbindung. Das Bindegewebe dieser Gefässschicht ist sehr zellreich mit meist runden oder ovalen bläschenförmigen Kernen, die eine sehr feine chromatische Struktur zeigen aus einigen Körnern und zarten Fäden. Weite zartwandige Lymphräume fallen zwischen 
den mit Blut angefüllten Gefässen auf. In den zarten Bindegewebszügen treten einzelne kleine Nester hervor, in denen zwei bis vier grössere Zellen zusammen liegen. Diese Zellen haben einen grossen. klar begrenzten Zellleib, dessen Protoplasma sehr hell, aber mit feinen scharfen Strukturfäden durchsetzt ist. Das Bild des Zellleibes erimnert sehr an das von Drüsenzellen. Die Zellleiber nehmen etwas Hämatoxylin, dagegen nur sehr schwer Eosin an. Die Kerne dieser Zellen sind grösser als die der benachbarten Bindegewebszellen und fallen besonders durch ihren starken Chromatingehalt auf. Die Grösse dieser Zellen beträgt $10-18 \mu$, die der Kerne $4-5,2 \mu$. Abbildung 1 zeigt ein solches Nest aus dem Ovar von Huhn 90. Ich muss diese Zellen, die ich nirgends in der Literatur beschrieben oder abgebildet fand, als die Zwischenzellen des Ovars auffassen. Diese Zellen fielen mir besonders auf in Ovarien von Hühnern im Alter von einigen Monaten. Hier sind sie oft sehr stark entwickelt. Wïhrend das eben geborene Huhn nur kleine Nester mit wenigen Zellen und ausschliesslich in der Gefässschicht zeigt, finden wir beim 1 Monat alten Hülnnchen die Zwischenzellen schon als anselınliche Stränge mit vielen Zellen an den Gefïssen entlang in das Oocytenlager vordringen. Das Bild der Zellen ist dasselbe wie früher. Die Grösse der Zellen ist bis zu $20 \mu$ angewachsen, die Kerne lraben dieselbe Grösse behalten. Im Alter von 3-6 Monaten ist das Ovar an allen Stellen sehr stark von den Zwischenzellstrüngen und -Nestern durchsetzt. Damit hat sich auch die vorher scharfe Grenze zwischen der Gefässschicht und Oocytenschicht verloren. Bei älteren Hühnern findet man die Zwischenzellen immer noch, und besonders in der Nähe der Gefässe. Sie liegen hier gruppen- und nesterweise zwischen den Follikeln und vor allem auch in den Stielen der grösseren Follikel, immer dort, wo besonders starke Blutzufuhr günstige Ernährungsbedingungen bietet. Im späteren Alter der Hühner verlieren sie sich mehr und mehr und, soweit sie noch vorhanden sind, fallen sie dann weniger auf, da ihr Zelleib seine charakteristischen Merkmale einbüsst. Sie machen dann oft nur den Eindruck besonders gut genährter Bindegewebszellen.

Die Parenchymschicht des Ovars vom eben geborenen Hühnchen stellt ein dichtes Oocytenlager von 120-200 $\mu$ Dicke dar. Am lateralen und kaudalen Rande endet diese Rinden- 
schicht, indem sie die Gefässschicht ein wenig überragt; am medialen und kranialen Rande dagegen schlägt sie sich wulstig nach unten um und überzieht auch ein Stück der dorsalen Fläche der Gefässschicht. Die Oberfläche wird von einer einfachen Lage des Eierstockepithels bekleidet. Die Zellen haben eine Höhe von $6,5-9 \mu$, ihre Gestalt ist kurz zylindrisch. Der Zellleib enthält einen relativ grossen ovalen Kern mit chromatischen Flecken und zarten Fadchen. Mitosen habe ich im Ovarialepithel nicht mehr gefunden. Nach d'Hollander werden sie schon ungefähr nach dem 1̄̄. Entwicklungstage selten und hören gegen die Geburt hin ganz auf. Unmittelbar unter dem Epithel zieht sich eine nicht geschlossene feine Bindegewebsschicht mit kurzen spindelförmigen Kernen hin, in der Blutgefüsse verlaufen; diese Schicht steht durch säulenartige Fortsătze, die von der Gefüssschicht aufsteigen, mit dieser letzteren in Verbindung. In diesen Zügen verlaufen Blutgefüsse, die sich nach allen Seiten baumartig verzweigen. In den weiten Maschen dieses zarten Bindegewebsnetzes finden sich grosse Nester, in denen zwei verschiedene Zellarten ziemlich wirr durcheinander liegen. Die grossen Zellen sind die Oocyten; die kleineren Zellen haben einen unbedeutenden Zellleib mit ovalem Kern, der in seinem Aussehen dem der Epithelzellen sehr ähnlich ist. Sie bilden die aussere Umgrenzung des Zellnestes, reichen auch bis an die Epithelzellen der Eierstocksoberfläche heran und dringen zwischen die Oocyten ein und drängen sie auseinander. Oft sind schon einzelne Gruppen von ihnen umringt. Die Zellen haben aber keine regelmässige Form, sie machen fast den Eindruck von Bindegewebszellen, unterscheiden sich aber von diesen sehr wesentlich durch das Aussehen ihres Kerns. Diese Zellen sind die späteren Follikelepithelien.

Die Abstammung dieser Zellen ist von den Autoren sehr verschieden erklärt. Nach Waldeyer, Balfour, Schulin, Borsenkow, Nassbaum, Janosik stammen sie vom Keimepithel ab. Kölliker und Rouget leiten das Follikelepithel von besonderen Zellsträngen her, die aus dem Urnierenkanälchen in das Markstroma des Eierstockes eindringen. Von Mihalkovicz leitet die Follikelepithelien in derselben Weise ab, lässt aber die "Sexualstränge" aus dem Keimepithel entstehen. Semon und Hof fmann behaupten dagegen ein Einwachsen der Sexualstränge aus der Urniere. Holl, Schrön und Foulis treten für die bindegewebige Herkunft der Follikelepithelien ein. Die jungen Oocyten liegen anfangs nackt im Stroma, durch Anlagerung und Differenzierung der angrenzenden Bindegewebszellen entstehen sdie Follikelepithelien. Cadiat und Harz halten es für wahrscheinlich, dass die 
Primordialeier die Follikelepithelien selbst bilden. Kohlbrugge lässt das Follikelepithel bei einer Eidechsenart aus Zellen entstehen, die dem Ei vollständig gleichwertig sind und sich um dasselbe lagern. Er geht in seiner Egalisierung der Zellen des Ovars so weit, dass er eine Theca folliculi im Sinne einer bindegewebigen Hülle leugnet, die deckende Schicht des Follikels geht vielmehr aus sich modifizierenden Follikelzellen hervor. Eigenartig ist auch der von ihm geschilderte Ersatz der Follikelzellen aus Zelldepots, die in der Wandung der Follikels oder in deren Nähe liegen. Ohne mir ein bindendes Urteil hieriiber erlanben zu wollen, möchte ich diese Zellnester mit den yon mir beim Huhne gefundenen " $Z$ wischenzellnestern" in Parallele stellen. Die neueste Arbeit iiber die Ongenese des Huhnes und auch über die Abstammung der Follikelepithelien ist von d'Hollander 1904 erschienen. Hiernach gestaltet sich der Vorgang in folgender Weise: Die Zellen des Keimepithels - d'Hollander nennt sie oberflichliche indifferente Zellen (cellules indifférentes superficielles) - teilen sich. Ein Teil cler neu entstehenden Zellen bleibt an der Oberflache des Eierstockes und bleibt Keimepithel (cellules de l'assise épithéliale), die anderen wandern in die Tiefe und sind die tiefen indifferenten Zellen (cellules indifferentes prof $)$ ndes). Durch Differenzierung entstehen hieraus einerseits Follikelzellen, andererseits Oogonien.

Die Entstehung der Follikelepithelien aus dem Keimepithel ist jetzt wohl als erwiesen anzunehmen. Jedenfalls zeigen die Follikelzellen beim eben geborenen Huhn ein ganz anderes Aussehen als die Bindegewebszellen; bindegewebiger Abkunft sind sie also sicher nicht. In weiter entwickelten Ovarien nehmen die Follikelzellen an Zahl immer mehr zu. Beim drei Tage alten Huhne sind schon einzelne Oocyten fast ganz durch Follikelzellen von dem Einest getrennt. Beim sechs Tage alten Huhn haben die Oocyten in der Mitte des Ovars fast sämtlich ihre eigene Epithelhülle, es finden sich aber auch Gruppen von mehreren Eiern von einer gemeinsamen Hülle umgeben. Häufig kann man sehen, wie Follikelzellen sich zwischen Eizellen einschieben und sie von den grösseren Gruppen trennen. Am Rande des Ovars tinden sich noch Einester; in denen die Oocyten und Follikelzellen regellos durcheinander liegen. Mit acht Tagen ist die Follikelbildung nahezu ganz zum Abschluss gebracht. Das Ovar zeigt am Rande allerdings auch noch einzelne Gruppen von Eiern mit gemeinsamer Epithelhülle. Auch Follikel mit zwei und drei Eiern finden sich noch mebrfach. Die Einester sind jetzt jedoch vollstündig verschwunden.

Die Oocyten im Ovar des eben geborenen Huhnes fallen durch ihre grossen und scharf strukturierten Kerne besonders 
auf. Kernteilungsfiguren habe ich an Eizellen nicht beobachtet. Keine Eizelle gab durch ihr Aussehen die Berechtigung, sie für eine Oogonie halten zu können. Oogonien finden sich demnach im Ovar des eben geborenen Hühnchens nicht mehr. Mustert man das Oocytenlager genauer durch, so fullt sofort auf, dass die Oocyten an den Enden der Schnitte - also am Rande des Ovars - ganz andere Bilder zeigen, als die in der Mitte. Es lassen sich die verschiedenen Stadien, welche die Oocytenkerne durchlaufen, sehr gut in einem Schnitte verfolgen.

Betrachten wir eine Oocyte am äussersten Ende eines Querschnittes vom Ovar des gleich nach der Geburt getöteten Huhnes 81 (Abbildung 2). Das Ei hat eine unregelmässige, etwa ovoide Form. Seine Grösse betrïgt $0.012 \mathrm{zu} 0,016 \mathrm{~mm}$. Das Keimbläschen ist kreisrund, hat 6 " im Durchmesser. Es wird von einer sehr feinen aber deutlichen scharfen Kernmembran umschlossen. Der Kernsaft ist wasserhell und klar. Im Kerninnern fallen einige grössere chromatische Brocken und Flecken auf; an der Innenfläche der Kernmembran finden sich wenige kleine chromatische Kürnchen. Der Kernsaft wird von feinen grauen, sich nur schwach fürbenden Fäden durchzogen. Diese schlingen sich wirr durcheinander: bei der Feinheit des Objektes will ich es dahingestellt lassen, ob sie nicht vielleicht ein wirkliches Netz bilden. An diesem feinen Fadenwerk kommen auch vereinzelte kleine chromatische Körner vor, besonders an den Krenzungsstellen der Fïden.

Der Eileib besteht aus einem sehr zarten, feinkörnigen Protoplasma Er ist an den Berührungsstellen mit anderen Zellen zum Teil klar begrrenzt, es zeigt sich hier eine feine dunkle Linie; an anderen Stellen ist die Begrenzung verschwommen. Eine Membran hat die junge Eizelle nicht, die sich verschiedentlich zeigende dunkle Linie kann nur als Berïhrungslinie mit anderen Zellen erklärt werden. Ein grosser Teil des Eileibes wird von einem ziemlich scharf begrenzten, dunkel gekörnten, kappenartigen Aufsatz des Keimbläschens eingenommen. Dieses wird noch ungefähr zur Hälfte von Ausläufern dieses dunklen Gebildes umfasst. Inmitten der stärksten Stelle dieses dunkeln Feldes zeigt sich ein grosser heller Fleck. In diesem fällt sofort ein kleines, scharfes, tiefschwarzes Korn von einem dunkelgrauen, schmalen Hofe umgeben, auf. Dieses Gebilde ist ohne Frage der Dotterkern (corps vitellin de Balbiani) der Oocyte.

Die Eikerne in der Nachbarschaft zeigen alle so ziemlich dasselbe Bild. Ihre Grösse beträgt 6 bis $7 \mu$. Sie haben kreisrunde Form; doch kommen auch kurzovale Kerne vor, bei denen ein Durchmesser um etwa 1 bis $1^{1 / 2} \mu$ kleiner ist, als der grösste. Im allgemeinen haben die Kerne Kugelgestalt. Das Fadenwerk ist bei allen diesen Kernen gleich fein und zart. Der Gehalt an chromatischen Körnchen ist dagegen etwas verschieden. Viele Eikerne enthalten nur so wenig Chromatin, als der in $\mathrm{Abbildung} 2$. Beachten wir aber die Kerne, welche mehr nach der Mitte des Ovars hin liegen, so wird der Chromatingehalt immer stärker. Die Chromatinkörner, welche der Kernmembran innen anliegen, werden zahlreicher. Sie bekleiden 
oft, zu Reihen angeordnet, einen mehr oder weniger grossen Abschnitt derselben. Die chromatischen Eallen und Brocken im Innern nehmen an Grösse zu. Sie haben rauhe, zackige, unregelmässige Formen. Diese Sammelstätten des Chromatins stehen mit dem Fadenwerk in Verbindung. Wahrscheinlich finden sich hier Kreuzungs- oder Knotenpunkte der Fäden, an denen sich das Chromatin festsetzt. Sie sind deshalb als Netzknoten aufzufassen. Auch im Verlauf der Fäden finden sich mehrere und grössere chromatische Körner. Abbildung 3 zeigt eimen solchen Kern von $7, u$ Durchmesser von Huhn 81.

Der Eileib zeigt keine Besonderheiten. Die kleinsten Oocyten haben etwa 0,008 bis $0,010 \mathrm{~mm}$ im Durchmesser. Die grössten, welche dasselbe Kernstadium zeigen, etwa $0,016 \mathrm{~mm}$. Die meisten Oocyten zeigen den Dotterkern nicht, sondern es findet sich gewöhnlich nur ein verschieden breiter dunkler Schatten, meist halbmondförmig, an einer Seite des Kerns. Es kommt vor, dass der Kern ringfürmig von einer schmalen dunklen Zone umgeben ist. In einigen Fällen ist die Mantelschicht des Dotterkerns von derselben Grösse, wie in Abbiidung 2, anch ein heller Fleck zeigt sich darin, aber es fehlt das Zentrosom. Alle diese Bilder entstehen dadurch, dass die Oocyten in den verschiedensten Richtungen im Schnitt getroffen sind; nur ein Schnitt kann das sehr kleine Zentrosom und den Kern in der Mitte treffen. Solche von Zufälligkeiten abhängigen Schnitte finden sich natürlich nicht in sehr grosser Zahl.

Folgen wir dem Oocytenlager nur wenig nach der Mitte des Ovars, so zeigen sich uns schon andere Bilder von Eizellen. Der Chromatingehalt dieser Kerne hat bedeutend zugenommen. Oft findet sich eine fast geschlossene ringförmige Lage relativ grosser Chromatinkörner an der Innenfläche der Kernmembran; ebenfalls nehmen die chromatischen Brocken im Innern an Grösse zu. Vor allem fällt an den Kernen auf, dass das Fadenwerk sich wesentlich verändert hat. Statt der feinen, aber ziemlich scharfen Fäden finden wir jetzt stärkere rauhe und dunklere Züge. Sehr feine chromatische Körnchen scheinen sich in grosser Menge an den Fäden niedergeschlagen zu haben. Die Fäden sehen aus wie bereifte feine Zweige eines Baumes.

Diese Veränderungen zeigt ein Eikern von Huhn 81 (Abbild ung 4). Das Ei hat eine Grösse von $0,013 \mathrm{~mm}$, ist ziemlich rund. Im Eileib zeigt sich nichts besonderes; der Kern ist nur einseitig von einer schmalen halbmondförmigen dunklen Zone umgeben. Der Kern misst 7:7,8 u. An der Innenfläche der Kernmembran findet sich eine grosse Menge chromatischer Körner. Im Innern haben sich zahlreiche chromatische Brocken gebildet, die zum Teil lange Spitzen und Zacken besitzen. Das Fadenwerk des Kerns ist leicht bekörnt und rauh, macht einen bereiften Eindruck. Im Zentrum erscheinen diese Fäden ein wenig dicker, nach der Kernmembran zu nehmen sie etwas an Stärke ab. Diese letzte Beobachtung habe ich an vielen Kernen machen können; doch finden sich auch Bilder, die das Gegenteil zeigen; oft findet sich gar kein Unterschied. Die Bereifung der Fäden geht demnach nicht in bestimmter Richtung von der Mitte nach dem Rande zu, oder umgekehrt vor sich, sondern die Ablagerung der chromatischen Körnohen erfolgt ganz willkürlich. 
Die nun folgenden Oocytenkerne zeigen weniger Körner an der Innenflïche der Kernmembran: die chromatischen Brocken nehmen an Zahl und Grösse zu und das Fadenwerk wird dunkler.

Abbildung 5 stellt einen $8 \mu$ grossen Kern von Huhn 81 dar. An der Innenfläche der Kernmembran finden sich gar keine körnigen Anlagerungen. Sehr viele chromatische Brocken und Haufen mit rauher, zackiger Oberfläche liegen im Kern zerstreat an den Kreuzungsstellen des Fadenwerkes. Die Fäden sind stark gekörnt und dunkel, Der Kernsaft ist auch bei diesen Kernen immer noch wasserhell.

An benachbarten Oocytenkernen finden wir schon bedeutende Unterschiede. Vor allem fallen die schärferen dunklen Fadenzüge auf und die Zurückziehung des gesamten Kerninhaltes auf das Zentrum. In Abbildung 6 sehen wir einen $8, \mu$ grossell Oocytenkern von Huhn 81. Im Invern des Kerns finden sich mehrere grosse chromatische Haufen. Sie hängen mit stärkeren, unregelmässigen, rauhen Fäden zusammen, die sich tiefschwarz gefärbt haben. Dazwischen ziehen einige hellere Fadenzüge durch. Der gesamte Kerninhalt hat sich von der Kernmembran zurückgezogen. Beim ersten Anblick glaubt man an eine Schrumpfung. Es zeigen aber sehr viele Kerne dasselbe Bild; auch bei anderen Präparaten findet man dieses Stadium. Auch alle übrigen Kerne in diesen Präparaten zeigen nicht die geringsten Veränderungen, die dazu berechtigten, auf eine Schrumpfung zu schliessen.

Huhn 82 ist etwa 4 Stunden nach der Geburt getötet. Es ist am 22. Bebrütungstage ausgekommen. Das Ovar zeigt dasselbe Stadium wie Huhn 81; die am weitesten in der Entwicklung fortgeschrittenen Oocyten finden sich bei diesem Huhn in etwas grösserer Zahl.

Die Weiterentwicklung zeigt uns in Abbildung 7 ein 8-9 u grosser Eikern dieses Huhnes. Der Kerninhalt nimmt im allgemeinen noch das Zentrum ein. Es ist ein Gewirre, in dem einzelne dicke, tiefschwarze Fäden mit chromatischen Brocken durcheinander liegen. Einige dicke Fäden ragen klar und frei daraus hervor und erreichen zum Teil auch die Kernmembran. Einige hellere Fäden finden sich auch noch, sonderbarer Weise liegen die dicken dunkeln und die hellen Fäden ziemlich getrennt voneinander nach entgegengesetzten Polen des Kernes hin. Dies fand ich in sehr vielen Kernen dieses Stadiums deutlich ausgeprägt.

Die Keimblüschen der Oocyten, die die Mitte des Ovars einnehmen, zeigen in sehr grosser Zahl ungefähr alle dasselbe Stadium sowohl bei Huhn $\mathbf{8 1}$ wie 82. Diese Bilder, wie sie in $\mathrm{Ab}$ bildung 8 und 9 wiedergegeben sind, charakterisieren das Entwicklungsstadium des Ovars des Huhnes am ersten Lebenstage.

Abbildung 8 zeigt einen 9 a grossen Kern von Huhn 82 . Der Kern hat kreisrunde Gestalt; eine einfacbe Kernmembran, die sich als scharfe, dunkle Linie ausprägt, schliesst ihn nach aussen ab. In dem hellen Kernsaft verlaufen dicke tiefschwarze Chromatinfäden, meist ziemlich gerade gestreckt, einige auch leicht geschwungen oder gekrümmt. Die glatten, dicken Fäden sind gegenüber den in den jüngsten Oocyten gefundenen zarten Fädchen schon mehr als Stränge zu bezeichnen. Der Kern bietet 
ein sehr klares Bild. Jeder einzelne Faden lässt sich deutlich in seiner ganzen Länge verfolgen. Sie bilden kein Gewirre oder dichtes, unentwirrbares Netz oder Knäuel, sondern nehmen einen geordneten, regelmässigen Verlauf. Stärkere Krümmungen und Verschlingungen zeigen die Fäden nicht, sie beschreiben nur leichte Bogenlinien. Sie machen mehr den Eindruck dicker, fast plumper, schwer biegsamer Stäbe, die in den Kernraum eingezwängt sind. Die meisten Fäden haben Anschluss an die Kernmembran mit einem oder auch beiden Enden; einige endigen jedoch auch frei im Kerninnern. Die Fäden sind vollständig glatt und scharfrandig und in ihrem ganzen Verlaufe gleichdick. Verzweigungen finden sich an den Fäden nicht. Dass es sicher nicht ein gewundener Faden, sondern mehrere sind, zeigt sich auf den ersten Blick an den vielen Enden und den zahlreichen klar durch den ganzen Kern zu verfolgenden Fäden. Ein Kernkörperchen oder chromatische Brocken und Haufen fehlen.

Abbildung 9 von Hnhn 82 zeigt ungeführ dasselbe Bild. Der Kern hat 9,8 "im grössten Durchmesser. Die chromatischen Fäden sind in diesem Kern noch klarer. Ein schön geschwungener fällt besonders auf.

Die meisten Oocytenkerne in der Mitte der beiden Ovarien von Huhn 81 und 82 zeigen dasselbe Aussehen. Die Grösse der Kerne beträgt 9-11 "“. Immer zeigen sich deutlich zahlreiche dicke, glatte, tiefschwarze Füden in leichter Krümmung, die den Kern ganz ausfüllen. Über die Zahl der Faden lässt sich nichts bestimmtes angeben, da eine einwandfreie Zählung bei der Feinheit des Objektes unmöglich ist. Ein Kernkörperchen habe ich nie gefunden. Ebenso fehlen alle sonstigen chromatischen Körneransammlungen.

Der Eileib zu diesen Kernen zeigt noch immer die zarte Struktur wie bei den jüngsten Oocyten. Ihre Grösse hat etwas zugenommen, sie messen 0,013-0,016 mm. Die Begrenzung des Eileibes ist meist ziemlich scharf, eine Membran fehlt jedoch. Das Dotterkernlager findet sich in vielen Oocyten in den verschiedensten Formen, halbmondförmig oder kappenartig; in einzelnen zeigt sich auch das Centrosom mit seinen umgebenden Schichten wie in Abbildung 2.

Alle bisher beschriebenen Kernstadien, ausser den allerjüngsten, finden sich auch noch im Ovar eines drei Tage alten Huhnes 89, hier aber mehr nach den Enden zugerückt. Die grösste Zahl der Oocyten zeigt dieselben Bilder wie die Abbildungen 8 und 9, also die starken, fast gerade verlaufenden oder leicht geschwungenen Fäden, die den ganzen Kern ausfüllen. Mehrere Oocytenkerne in der Mitte des Ovars unterscheiden sich aber wesentlich von den eben beschriebenen.

Als nächste Veränderung fällt besonders auf, dass in diesen Kernen mit den dicken Fäden ein helles, vollkommen freies Zentrum auftritt. Abbildung 10 von Huhn 89 zeigt einen $10 \mu$ grossen Oocytenkern. Die dicken Fäden haben sich vollständig vom Zentrum nach der Peripherie zurïckgezogen; sie liegen ganz in der Nähe der Kernmembran, laufen zum Teil unter ihr entlang, während das Zentrum vollständig frei davon nur von Kernsaft ausgefüllt ist. Die Fäden sind stärker gekrümmt, bilden kleine Bögen und schlingen sich mehr durcheinander. Einige Fäden sind rauh 
geworden; ihre glatte Oberfläche haben sie verloren, sie zeigen kurze Spitzen und Zacken.

Ein anderer Kern von derselben Grösse in Abbildung 11 zeigt auch alle Fäden aus dem Zentrum nach der Peripherie hingerückt. Die Fäden sind stark gekrümmt und haben eine rauhe, zackige Oberfläche. An einem langen Faden zeigt sich eine Längsspaltung. Zwei freie Enden spreizen sich auseinander. Auch im Verlauf des Fadens zeigt sich deutlich ein feiner Spalt. Der dicke Faden hat sich in der Längsrichtung in zwei feinere geteilt, die aber noch in lockerem Zusammenhange stehen. An einem allerdings nur kurzen Fadenstumpf zeigt sich an einem Ende ebenfalls schon die Spaltung. Einzelne Oocytenkerne zeigen schon die vollendete Längsspaltung aller chromatischen Fäden.

In $\mathrm{Abbildung} 12$ von Huhn 89 sehen wir den $10 \mu$ grossen Kern ganz angefüllt mit sehr zahlreichen feinen chromatischen Fäden. Die Zahl der Fäden hat sich gegenüber der in den letzten Abbildungen bedeutend vermehrt, sie scheint sich verdoppelt zu haben. Die Fäden selbst sind sehr viel feiner als vorher. Sie sind an der Oberfläche aber wieder glatt und scharfrandig. Zwei Fäden sieht man noch miteinander verklebt, sie müssen gerade durch Spaltung eines dicken entstanden sein. Bei einzelnen Fäden zeigt sich noch in ihrer Lage zueinander, dass sie aus einem Faden entstanden sind; sie liegen sich noch gegenüber und sind nur wenig auseinander gerückt. Manche Füden endlich umschlingen sich schwesterlich. Der Kernraum ist von den Fäden vollständig angefüllt, es bleibt kein freies Zentrum. Der Kernsaft ist vollständig hell und klar. Die Kreuzungsstellen der Fäden sind scharf, irgendwelche körnigen Anlagerungen feblen. Ein Nukleolus ist nicht vorhanden. Der Eileib zeigt noch immer dasselbe Bild, an Grösse hat er nicht zugenommen.

In dem Ovar eines sechs Tage alten Huhnes (90) finden wir an den Enden der Schnitte - also am Rande des Ovars - die Keimbläschen der Oocyten mit denselben dicken starren Fäden angefullt, wie sie Abbildungen 12 und 13 zeigen. Weiter nach der Mitte hin lassen sich alle Stadien der weiteren Ausbildung in derselben Weise vertolgen, wie sie uns das dreitägige Huhn 89 zeigte, bis zur vollendeten Längsteilung der Fäden. In der Mitte der Schnitte zeigen die Keimbläschen jedoch schon fast sämtlich ein Kernkörperchen. Verfolgen wir an den Bildern verschiedener Kerne die Bildung des Nukleolus (Keimflecks).

Eine Oocyte desselben Huhnes mit schwach gekörntem und faserigem Protoplasma wird fast ganz von Follikelepithelien umschlossen, an zwei Stellen bleiben nur noch kleine Lücken in dem Epithelkranze. Die Grösse des Eies beträgt $0,017 \mathrm{zu} 0,020 \mathrm{~mm}$. Der Kern (Abbildung 13) hat $10 \mu$ im Durchmesser. Er liegt nicht genau im Zentrum der Eizelle, sondern nach dem einen Pole hingerückt. Verdichtungen im Protoplasma, die als Dotterkern zu erklären wären, finden sich nicht. Der Kern wird von einer zarten, scharfen Kernmembran umhüllt. An der Innenfläche der Kernmembran liegen zahlreiche, rerschieden grosse chromatische Körnchen. Der ganze Kern ist im übrigen von einem dichten Netz von chromatischen Fäden ange- 
füllt. Die Fäden sind ungefähr ebenso fein wie in den zuletzt beschriebenen Kernen, doch finden sich an ihnen einzelne feinkörnige Anlagerungen. Die Fäden schlingen sich wirr durcheinander, sie sind geschwungen und gekrümmt; sie bilden ein dichtes Netz. Man könnte annehmen, dass ein einziger Faden sich im Kerne windet und knäuelt, denn freie Enden treten nicht immer klar hervor. Es ist jedoch sehr unwahrscheinlich, dass die bisher vorhandenen zahlreichen Füden sich zu einem aneinandergeschlossen haben sollten. An den Knotenpunkten des Netzes haben sich chromatische Körner in verschiedener XIenge zu Netzknoten angesammelt.

Eine andere Oocyte misst 0,0156 zu $0,019 \overline{\mathrm{m}} \mathrm{m}$. Der exzentrisch liegende Kern ist kreisrund, hat 9,5 $\mu$ im Durchmesser. Der Kern wird von einem wirren, feinfädigen chromatischen Netz angefüllt. An der Innenfläche der Kernmembran und an den Fäden des Netzes finden sich kleine chromatische Körnchen angelagert. Einzelne Füden ziehen auch dicht an der Kernmembran hin. Unter mehreren kleinen Netzknoten, an denen nur einzelne chromatische Körnchen angesammelt sind, tritt ein Körnerhaufen von $2,6 \mu$ Grösse hervor. Er liegt ziemlich zentral, seine Oberfläche ist ranh, gekörnt und gezackt. Die chromatischen Füden stehen mit ihm in enger Verbindung. Es ist ein Netzknoten, an dem sich eine grosse Menge chromatischer Kürnchen angesammelt hat. Der unregelmüssig geformte Zelleib gehört zu einer Gruppe von fünf Eiern, die von einer gemeinsamen Epithelhülle umschlossen werden. In der vom Kern freigelassenen Hälfte des Eies liegt dem Kern ein hoher spitzhutförmiger auf dem Schnitte fast dreieckiger, dunkel gekörnter Protoplasmahaufen an von etwa $6, \mu$ Höhe. Der Kern wird von Ausläufern des dunkeln, gekörnten Protoplasmas nicht umfasst. Fast an der höchsten Stelle findet sich in diesem Dotterkernlager ein Centrosom mit seinen ringförmigen Höfen.

Beim acht Tage alten Huhn (68), bei dem die Follikelbildung ungefähr zum Abschluss gekommen ist, lässt sich die Bildung des Nukleolus noch weiter verfolgen. Zwei dicht zusammenliegende, von gemeinsamer Hülle umschlossene. Oocyten von Huhn 68 zeigt Abbildung 14. Das kleinere linke $\mathrm{Ei}$ ist 0,017 zu 0,0198 mm gross. Der Eileib ist sehr zartfaserig und sehr schwach gekörnt. Das Keimbläschen hat kurzovale Form und liegt in der Mitte der Eizelle. Seine Grösse beträgt 10,8 zu 12,6 $\mu$. Der Kern wird vollständig von einem chromatischen Netze ausgefüllt. Die leicht geschwungenen Fäden sind nicht ganz glattrandig, sie zeigen an einzelnen Stellen geringe Verdickungen. Die Fäden schmiegen sich zum Teil eng an die Kernmembran an, verlaufen im Kerninnern nach allen Richtungen durcheinander und bilden ein dichtes Netz, in dem einige weitere Maschen vorkommen, die den hellen Kernsaft zeigen. In einer grossen Lücke des Kernnetzes liegt ein kugeliges, an der Oberfläche vollständig glattes Kernkörperchen von 2,7 $\mu$ Grösse. Es liegt vollständig frei im Kernsaft und steht mit keinem Faden des Kernnetzes mehr in Verbindung.

Das rechte, etwas grössere Ei misst $0,018 \mathrm{zu} 0,0206 \mathrm{~mm}$. Auch dessen Eileib zeigt keine Besonderheiten. Der ungefähr zentralliegende Kern ist fast kreisiund, er misst $10,8 \mathrm{zu} 11,5 \mathrm{~mm}$. Der Kernraum wird 
vollständig von einem dichten Netz angefüllt. Die Fäden desselben sind feiner als in dem benachbarten Eikern. Sie zeigen nur ganz geringe Verdickungen an einzelnen Stellen. An der Innenfläche der Kernmembran verlaufen einige Fädchen und hier liegen auch einzelne kleine chromatische Körnchen. Die Fäden schlingen sich stark durcheinander, Verzweigungen scheinen sie nicht zu besitzen. Ziemlich in der Mitte des Kerns liegt ein grosser chromatischer Haufen von 2,6 zu $3,5 \mu$. Er ist nicht vollständig glattrandig, besonders nach einer Seite hin ist er mit kleinen Zacken und Körnchen und mit einem grösseren Höcker besetzt. Die Fäden des Kernnetzes stehen mit ihm in vielfacher Verbindung.

Abbildung 15 zeigt ein Ei mit vollständiger Follikelepithelhülle von Huhn 68. Das Ei hat eine Grösse von $0,0182 \mathrm{zu} 0,0276 \mathrm{~mm}$. Der ungefähr zentralliegende Kern von ovaler Gestalt misst 10, 0 zu $14 \mu$. Das chromatische Netzwerk füllt den Kern vollständig. Einzelne Fäden verlaufen direkt an der Kernmembran. Die Füden sind nicht vollständig glatt und gleichmässig dick. Im Zentrum zeigen die Füden sich bedeutend dicker als an der Peripherie. Sie besitzen Anschwellungen und unregelmässige Verdickungen. Die Fäden, die direkt an der Kernmembran liegen, sind ganz gleichmässig fein und ziemlich glattrandig. In einer Masche des Netzes liegt vollständig frei ein kugeliger Nukleolus von $2,9 \mu$ Grösse. Die Oberflache desselben ist vollständig glatt. Das Protoplasma der Eizelle ist sehr feinfaserig und mit feinen Kürnchen durchsetzt. An einer Längsseite liegt dem Kern ein dunkles, stark gekörntes, protoplasmatisches Gebilde von kegelförmiger Gestalt an. In diesem, wie der Schatten des Kernes aussehenden Anhange zeigen sich zahlreiche, sehr feine schwarze Körnchen. Fast an der Spitze des Dotterkernlagers tritt ein ziemlich grosser heller Fleck hervor und in demselben zeigt sich ein tiefschwarzes rundes Korn mit schmalem grauem Saume.

Nach mehreren Messungen an Eiern, die dasselbe Kernstadium zeigen, beträgt die Grösse der Oocyten jetzt 0,013 bis $0,0299 \mathrm{~mm}$. Die Kerne haben meist runde oder kurzovale Form und messen 9,1 bis $14,7 \mu$. Das jetzt immer vorhandene und meist schon vollständig'abgeglättete Kernkörperchen hat einen Durchmesser von 2,0 bis 3,5 $\mu$, im Mittel etwa 2,6 $\mu$. Die verschiedene Dicke der Kernfäden im Zentrum und in der Peripherie tritt an vielen Kernen deutlich hervor. Besonders klar zeigt sich der Unterschied beim Vergleich eines Abschnittes eines Kernes, in dem nur die feinen Randfäden vorkommen, mit einem Schnitte durch die Mitte eines Kernes, in dem die Fäden schon fast ganz verdickt sind. A b bildung 16 zeigt eine abgeschnittene Calotte eines Kernes. Hieran lässt sich auch der leichtgeschwungene zierliche Verlauf der Fäden, die immer gleichmässig dick erscheinen, verfolgen. Die Fäden verzweigen sich nicht, gehen auch keine Verbindungen untereinander ein. Das Kernnetz setzt sich also aus zahlreichen einzelnen Fädchen zusammen. Ein Vergleich mit den zentralen verdickten Fäden in Abbildung 15 zeigt. den Dickenunterschied deutlich.

Eine Oocyte von einem 12 Tage alten Huhn 72 ist $0,0216 \mathrm{~mm}$ breit. und $0,040 \mathrm{~mm}$ lang. Der Kern liegt ziemlich in der Mitte der Eizelle, er 
misst 12.6 zu $14,4 u$. In dem sehr schwach feingekörnten Kernsaft zeigt sich ein lockeres feinfädiges chromatisches Netz. Die Fäden sind an einzelnen Stellen schwach gekörnt; etwas exzentrisch liegt ein etwa 4 " grosses Kernkörperchen. Die Oberfäche desselben ist mit feinen Körnern besetzt und erscheint infolgedessen rauh. An der einen Seite des Kerns liegt ein Irappenartiges, dunkel gelkörntes Dotterkernlager. Inmitten desselben liegt ein tiefschwarzes Centrosom von einer nur sehr schmalen grauen und der darauf folgenden breiten hellen Zone umgeben. Der übrige Eileib ist leicht schaumig.

Eine Oocyte eines 14 Tage alten Hnhnes 74 misst 0,026 zu $0,0315 \mathrm{~mm}$ (Abbildung 17). Der etwas exzentrisch liegende Kern ist etwa kreisrund, er hat 16.2 zu 18 " im Durchmesser. Die Kernmembran ist eine feine scharfe Linie. Der ganze Kernraum wird von sich durcheinanderwindenden Chromosomen angefüllt. Die Fäden sind nicht ganz glattrandig, sondern zeigen eine leicht gekörnte Oberfläche und ganz geringe Verdickungen. Freie Enden treten an den Fäden lilar hervor. Verzweigungen finden sich nicht. Einzelne Fäden kann man in ihren Verschlingungen deutlich vertolgen. Es winden sich dann immer zwei Fäden umeinander. Im Zentrum und an der Peripherie haben die Fäılen ungeführ gleiche Stärke. Die weiten Maschen des Kernnetzes sind von Kernsaft angefüllt. Dieser ist durch sehr feinkörnige Einlagerungen leicht getriibt. Exzentrisch liegen in geringem Abstande voneinander frei im Kernsaft zwei kugelrunde glatte Kernkörperchen. Das eine hat 24 , das andere 2,7 " in Durchmesser. Der Kern ist von einer starkgekörnten ringförmigen dunklen Zone ungeben. Nach einer Seite verbreitert sich die Zone ant meh* als das Doppelte ihrer Breite. In diesem dunkelkörnigen Protoplasma - einem Dotterkernlager sieht man undeutliche Fäden verlaufen, die sich wirr durcheinander ziehen. Einige grössere dunkle, schwarze Körner fallen noch auf. An der höchsten Stelle des verbreiterten Teiles liegt ein Centrosom. welches von den charakteristischen, bisher nie fehlenden Höfen umgeben ist.

In einer Eizelle desselben Huhnes $7 \pm$ zeigt der Kern, der eine Grösse yon 14,3 zn 18,2 "hat, dieselben körnigen Fäden, die sich mehrfach paarweise durcheinanderschlingen. Der Kernsaft ist fein gekörnt und macht ladurch einen konsistenteren Eindruck. Im Kernsaft liegt vollständig frei ein glänzend schwarzes Kernkörperchen von ovaler Gestalt; es misst 2,6 zu 3,5 u. Durch Schrumpfung hat sich zufallig anf einer Stelle der Kerninhalt ein wenig von der Kernmembran abgehoben. Hier zeigt sich dieselbe als dentliche feine schwarze Linie. Der etwas zurückgezogene Kernsaft hört nach dem entstandenen Spalte mit scharfem Rande anf. An diesem Rande ist der Kernsaft dunkler und dichter gekörnt als in der Mitte des Kernes, man kann die nach dem Rande allmählich zunehmende Verdichtung an der dunkler werdenden Färbung verfolgen. Dies lässt sich auch an Stellen, die sich von der Kernmembran gelöst haben, feststellen, nachdem man erst darauf aufmerksam geworden ist. Das zugehörige Ei hat eine Grösse von 0,0328 zu $0,0455 \mathrm{~mm}$. Das Protoplasma macht einen sehr feinfaserigen, fast schaumigen Eindruck. Nach dem Kern zu verdichtet es sich und nimmt eine dunklere Körnung an. Diese dunkel gekörnte Zone umgibt den Kern 
ringförmig. Darin finden sich einzelne chromatische Brocken. An einer Seite des Kernes zeigen sich darin verschwommene feinkörnige Faserzüge. An der entgegengesetzten Seite treten grosse helle Blasen, dicht aneinanderliegend, hervor. In dem übrigen Protoplasma fallen in der Nähe dieses mit hellen Blasen durchsetzten Teiles des Dotterkernlagers rundliche Haufen und kugelige Gebilde von feinen tiefschwarzen Körnern auf.

Ein anderes Ei von 0,0396:0,045 mm zeigt Abbildung 18. Der ovale Kern liegt exzentrisch und misst 19,8:21,6 $\mu$. Der Kern enthält dunkel gekörnten Kernsaft, der nach der Kernmembran hin einen schmalen verdichteten Randsaum bildet. Das Innere des Kerns durchziehen sich locker durcheinanderschlingende körnige Chromosomen. Einzelne kleine Chromatinbröckelchen liegen frei im Kernraum. Etwas exzentrisch liegt ein glïnzendes glattes Kernkörperchen von 2,7 « Grösse. Der Kern ist rings von einer mehrere " breiten dunkel gekörnten Protoplasmazone umgeben, die gegen den übrigen Eileib ziemlich scharf abgesetzt ist. An einem Pole des Kerns verbreitet sich die Zone auf fast das Doppelte. Hier liegen drei chromatische Brocken in einer Reihe dicht nebeneinander, von einem hellen Hofe umgeben. Ausserdem zeigen sich in dem Dotterkernlager fadenartige Gebilde - Pseudochromosomen - und helle Blasen. Der ibrige Zellleil besitzt ein schaumiges Protoplasma. Darin zeigen sich einige zerstreut angeordnete Ringe, die sich aus einzelnen um ein helles Zentrum liegenden Körnern zusammensetzen. Die im Dotterkernlager der zuletzt beschriebenen Eier liegenden hellen Blasen, die Pseudochromosomen, chromatischen Brocken und Körner treten in zahlreichen Eiern in den verschiedensten Formen auf. Die Pseudochromosomen sind oft stark gewunden und durcheinander geschlungen, oft verlaufen sie auch ziemlich gestreckt oder nur leicht gekrümmt. Die chromatischen Brocken sind nicht immer von einem hellen Hofe umgeben. Im übrigen Eileibe zeigen sich jetzt fast immer, allerdings verschieden deutlich, die ringförmig angeordneten, tiefschwarzen Körner. Manchmal liegen diese Körnerringe in grossen Haufen in der Nühe des Kernes, oder des Dotterkernlagers, oft an peripheren Stellen des Eies dicht am Epithel.

Das grösste Ei von Huhn 74 misst 0,0624:0,0806 mm. Der Kern liegt ungefähr zentral. Er hat eine Grösse von $26: 27,3 \mu$ (Abbildung 19). Der Kernsaft ist stark gekörnt, mit deutlich erkennbaren Körnern und kleinen Nukleolen durchsetzt. Nach der Kernmembran hin verdichtet sich der Kernsaft zu einem schmalen Randsaume. Die Kernmembran ist einfach, zeigt sich als feine Linie. In dem Kernsafte verlaufen sich locker durcheinander schlingende Chromosomen. Die meisten machen den Eindruck körnig bröckliger Fadenzüge. Einige sind ganz zerfallen und bestehen als Reihen von Nukleolen in verschiedener Grösse, die aber noch in irgend einem lockeren Zusammenhange zu stehen scheinen. Sie sehen aus wie Streptococcen oder Perlschnüre. Im Kernsaft liegen ausserdem einzelne Haufen von chromatischen

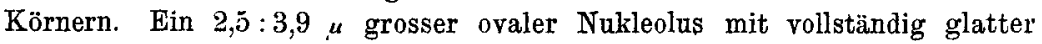
Oberfläche liegt exzentrisch im Kern.

Eine Oocyte im Ovar eines 21 Tage alten Huhnes 91 hat eine Grösse von 0,0221:0,0325 mm. Das kreisrunde Keimbläschen misst 12,6 $\mu$. Das 
chromatische Knäuel besteht aus feinen, nur wenig verdickten Fïden: es fiillt den Kernraum nicht vollständig aus. Ein das Knäuel zu etwa ${ }^{3 /+}$ des Umfanges umfassender halbmondförmiger Spalt bleibt frei, der nur von hellem sehr fein gekörntem Kernsaft ausgefüllt wird. Im Kernnetz liegen ganz frei zwei Nakleoli von $2, \check{\partial}$ und $3 \mu$ Grösse. Thre Gestalt ist unregelmässig, sie zeigen einige Zacken und Fortsätze.

Eine der grössten Oocyten von Huhn 91 ist $0,0918 \mathrm{~mm}$ breit und $0,144 \mathrm{~mm}$ lang. Der kreisrunde Kern (Abbildung 20) hat 45 " im Durchmesser. Der Kernsaft ist stark gekörnt und enthält mukle(lenartige dicke Körner. Die Chromosomen, welche gewunden und miteinander verschlungen fast den ganzen Kernraum ausfüllen, setzen sich aus körnig faserigen Zügen zusammen. Von dem mittleren Achsenfaden laufen nach allen Seiten feine Fortsätze aus, welche aber nur ziemlich kurz sind. Die Gebilde sind mit sehr feinen Körnchen übersät, sodass ein fast verschwommen faseriges und hörniges Bild entsteht. Diese Chromosomgebilde schlingen sich durcheinander, sodass es oft aussieht, als verzweigten sie sich baumartig. In der Nähe der Kernmembran liegen zwei grosse chromatische Brocken mit zackigen Fortsïtzen und rauhiger Oberfläche - Überreste des in Auflösung begriffenen Kernkörperchens - in deren Nachbarschaft findet sich noch eine grössere Nukleole. Der Kern ist ron einer feinen, sich als Linie ausprägenden Kernmembran umhüllt. Dieser liegt innen ein schmaler verdichteter Randsaum des Kernsaftes als körniger Belag an.

Abbildung 21 zeigt einen Follikel mit zwei Eiern (Huhn 91). Die beiden Eier liegen eng aneinander, doch scheint es, als wollten Follikelzellen von einer Seite her zwischen sie eindringen. Das kleinere Ei misst 0,054:0,0684 mm, das grössere 0,0684:0,108 mm. Der Kerm des kleineren ist 21.6:27 " gross. In dem stark gekörnten Kernsaft zeigen sich körnig bröcklige Chromosomen. Das Kerngerüst nimmt fast den ganzen Kernraum ein. Der Kern wird von einer einfachen Kernmembran umhüllt, der innen eine verdichtete Zone des Kernsaftes anliegt. Ein Kernkörperchen oder Reste desselben finden sich in diesem und den zugehörigen Schnitten nicht. Einige grössere chromatische Brocken zeigen sich an verschiedenen Stellen. Dem Kern liegt ein rundliches, dunkel gefärbtes Dotterkernlager an, in dem aber keine besonderen Gebilde sichtbar sind. Der Kern des grösseren Eies ist $30,6: 36 \mu$ gross. Dieser Kern zeigt dieselben querfaserig körnigen Chromosomen, wie Abbildung 20, sie erscheinen aber schmäler und haben nicht so lange Fortsätze. In der Nähe der Kernmembran liegen zwei rauhe, zackige chromatische Brocken von 3 und 4,2 $\mu$ Grösse, Reste des Kernkörperchens.

Eine Oocyte eines 29 Tage alten Huhnes 80 hat eine Grösse von $0,0286: 0,039 \mathrm{~mm}$. Der Kern hat eine Grösse von 1亏,6:18,2 $\mu$. Das chromatische Kerngerüst besteht aus ziemlich glatten Fäden, die nur einzelne Verdickungen zeigen. Der Kernraum wird nicht vollständig ausgefüllt. Es bleibt ein schmaler ringförmigex Spalt frei, in dem sich nur heller Kernsaft befindet. In dem chromatischen Knäuel liegt ein tiefschwarzes, glänzendes, 2,8 u grosses Kernkörperchen. 
Das grösste Ei desselben Huhnes misst 0,0130:0,175 mm. Der Kern hat eine Grösse von 62, $4: 71, \tilde{0}$ ". Das chromatische Gerüst des Kernes besteht aus körnig querfaserigen Zügen. Die Körnchen sind sehr fein. Die Fasern erstrecken sich nach beiden Seiten des stärkeren Achsenzuges weit aus. Der Kernraum wird nicht vollständig ansgefüllt, ein Randsaum wird nur von dem feinkörnigen Kernsafte eingenommen. An der Peripherie des Kernes liegt ein $4,5: 6, \overline{5}$ " grosser dreiteiliger chromatischer Brocken mit rauher, zackiger Oberfläche. Einzelne kleinere chromatische Brocken finden sich im Kern zerstreut vor. Ein Dotterkernlager zeigt sich in der Nähe des Kernes nicht.

Eine Oocyte eines zwei Monate alten Huhnes 66 hat eine Grösse von $0.040 \mathrm{~mm}$. Der Leib des Eies zeigt ein feinfädiges, schwachkörniges Protoplasma. An einer Seite des Kernes verdichtet es sich zu einem schatten:rrtigen, abgerundeten Gebilde, in dem einzelne tiefschwarze Körner herrortreten. Der Kern ist kurz oval, 20 " lang und $16 \mu$ breit. Er liegt exzentrisch an einem Pole des Eies. Eine einfache, scharfe Kernmembran umschliesst ihn. Das Fadenwerk des Kernes füllt den Kernraum nicht aus. Ein schmaler Saum an der Peripherie wird nur von dem hellen Kernsaft :unsgefüllt. Dieser Saum verbreitert sich an einem Pole des Kernes auf das trei- bis vierfache. Das chromatische Knäuel von etwa $10 u$ Durchmesser besteht aus mehreren zierlich verschlungenen Füden. Diese sind nicht ganz glattrandig, sondern rauh and mit feinen Körnchen besetzt. Im Verlauf ter Füden treten einzelne Verdickungen und kreisrunde dicke Körner auf. Nach dem Rande des Knäuls hin, nur $2 u$ von der Kernmembran entfernt, liegt ein 2,6 $\mu$ grosser, kreisrunder, scharf begrenzter Nukleolus.

In einem anderen $\mathrm{Ei}$ desselben Huhnes von $0,027 \mathrm{~mm}$ Grïsse. dessen Kern $18 \mu$ im Durchmesser hat, liegt dem Kern ein halbmondfürmiges Dotterkernlager an, in dem zwei sehr dunkle, grosse, körnige Flecken erscheinen und dichte, wirr durcheinandergeschlungene feine Fïden (Pseudochromosomen).

Eine der grössten Oocyten des drei Monate alten Huhnes 93 misst 0.25̄5: $0,391 \mathrm{~mm}$. Ihr Kern hat eine Grösse von 85:98,6 u (Abbildung 22). Eine einfache, leicht wellig verlaufende Kernmembran umhüllt ihn. Die Innenfäche derselben ist mit einer dichten Körnerschicht belegt. Der stark gekörnte, wie mit kleinen chromatischen Nukleolen durchsetzte Kernsaft füllt den Kernraum ganz aus. Er zeigt keine verdichtete Randzone: im Gegenteil, die Körner des Kernsaftes werden nach dem Rande zu kleiner und nehmen an Menge ab. Das Innere des Kernes nehmen geschwungene, mit langen, feinen Querfasern versehene Züge ein, die nach allen Richtungen durcheinander laufen. Ein peripherer Raum bleibt von ihnen frei. Diese sehr feinfasrigen Chromatinfadenstränge ( $\mathrm{B}$ orn) sind mit feinen Körnchen bedeckt, weIche in diejenigen des Kernsaftes übergehen. Dadurch werden die Enden der Fäserchen mehr oder weniger verdeckt. Als strahlige, feinkörnige Flecken zeigen sich die Chromatinfadenstränge im Querschnitt. Nahe der Peripherie des chromatischen Gerüstes findet sich ein ovaler 3,5:6" " grosser, rauher, chromatischer Brocken als Rest des Kernkörperchens. In 
der Nihe des Kerns findet sich nichts von einem Dotterkernlager. Bei Durchmusterung der vollständigen Serie dieses Eies findet man ungeführ in der Mitte des Eileibes einen dunkleren, stärker gekörnten, etwas faserigen Fleck von fast derselben Grösse, wie der Kern, sich nur wenig allhebend. Dieses jetzt frei im Zentrum liegende Gebilde dürfte der Dotterkern des Eies sein. Ein Centrosom oder pseudochromatische Gebilde sind nicht darin zu finden.

Abbildung 23 ist nach einer Oocyte des Huhnes 58 gezeichnet. Das Ei misst 0,039:0,0442 mm. Es enthält zwei Kerne; der kleinere Kern hat 13 " im Durchmesser. In seiner Mitte liegt ein 10,4 u grosses chromatisches Knäuel aus ziemlich glatten, mit Körnern und geringen Verdickungen rersehenen Chromosomen. Ein zirka 1-2 “ breiter peripherer Saum wird nur von hellem Kernsaft angefüllt. Die Kernmembran ist einfach. Der grössere Kern lat $16,9: 18,2 \mu$ Grösse. Das in derselben Weise eingerichtete chromatische Knänel hat 11,7 $\mu$ Durchmesser. An einer Stelle seines Randes liegt ein glänzendes, 2,6 $\mu$ grosses Kernkörperchen. Zwischen beiden Kernen und sich beiderseits noch weit vorwölbend liegt ein dunkles, stark gekörntes Dotterkernlager, das in den ubrigen Eileib fascrige Ausläuter entsendet.

Dieses Huhn enthült relativ viele Follikel mit 2 auch mit 3 Eiern. Eier mit mehreren Kernen habe ich jedoch weiter nicht gefunden.

Das grüsste Ei desselben Huhnes 58 misst 0,615:0,70) mm. Der Kern hat $125 \mu \mathrm{im}$ Durchmesser. Er ist von stark gekörntem Kernsaft vollstïndig ausgefillt. Die einfache aber starke Kernmembran besitzt an ihrer Innenflïche einen körnigen Belag. In dem Kernsaft zeigen sich schattenhaft undeutliche, körnige Chromatinfadenstränge. Die Faserung ist nahezu ganz verschwunden. Die Gebilde scheinen sich nur aus feinen Körnchen zusammenzusetzen. In einem anderen Schnitte desselben Kernes findet sich ziemlich zentral ein körniger Fleck von 3,9 "Grüsse, wahrscheinlich das Kernkörperchenrudiment.

Ein zirka 6 Monate altes, im Januar getötetes Huhn 1 zeigt an der Obertläche des Ovars noch eine ziemlich geschlossene Schicht kleinerer Oocyten, während die grösseren in den tieferen Schichten liegen. Eine Oocyte dieses Huhnes hat eine Grösse von 0,054:0,061 mm. Der Eileib zeigt ein sehr feinkörniges, schaumiges Protoplasma. Der Eikern (Abbildung 24) misst 27:37,8 $\mu$. In der Mitte desselben liegt ein $16 \mu$ grosses chromatisches Knäuel, um das ein breiter, von dem hellen Kernsaft erfüllter Raum bleibt. Die Chromosomen sind körnig bröcklig und varikös. In einer grossen Lücke des Knäuels liegt ein 2,7 "grosser, rauher, mit Körnern besetzter Nukleolus, neben dem sich ein kleiner chromatischer Brocken befindet. Die Kernmembran zeigt sich als feine scharfe Linie.

Eine andere Oocyte desselben Huhnes ist 0,05̃:0,071 mm gross. Der Kern misst 27:35 $\mu$. Das an einem Pol liegende chromatische Knäuel von $12 \mu$ Durchmesser setzt sich aus stark bröckligen und varikösen Fäden zusammen. Ein Faden tritt vollständig daraus hervor und zieht nach der Kernmembran hin. Dicht unter derselben teilt er sich. Ein Kernkörperchen fehlt, der Kernsaft ist sehr fein gekörnt. Die Kernmembran ist innen mit einer 
dünnen Körnerschicht bedeckt, die sich an einzelnen Stellen verdickt. Der Eileib zeigt ein feinkörniges, schanmiges Protoplasma. In demselben treten an verschiedenen Stellen Körnerringe hervor. Diese finden sich zu einem besonders grossen Haufen dicht am Kern, an einer Stelle, an der die Kernmembran einen stärkeren körnigen Belag trägt. Ausserdem zeigen sie sich in der Nähe der Epithels, besonders bei dicht am Ei liegenden Epithelkernen. In der Nachbarschaft des zur Kernmembran strebenden Chromatinfadens finden sich ähnliche chromatische Gebilde und einige Brocken. Derartige Bilder finden sich in vielen Eiern. Die ursprüngliche Absicht, diesen sehr wahrscheinlichen Austritt chromatischer Substanz aus dem Kern weiter zu verfolgen, musste ich aus Langel an Zeit aufgeben. Die Körnerringe finden sich in fast allen Eiern, auch in solchen von etwa $0,300 \mathrm{~mm}$ Grösse. Sie sind schon von mehreren tutoren gesehen, aber in der verschiedensten Weise erklärt worden. Leguge beschreibt sie als diffusen Dotterkern. Stuhlmann nennt sie Reifungsballen. Mertens gibt sie in seiner Abbildung 25 wieder. Ähnliche Gebilde fanden Carnoy und Lebrun bei Salamandra maculosa. Sie bringen sie zur Dotterbildung in Beziehung Dieser Erklärung muss ich mich anschliessen.

Ungeführ das grösste $\mathrm{Ei}$ desselben Huhnes hat eine Grösse von $0,286: 0,400 \mathrm{~mm}$. Sein Kern misst $72: 94 \mu$ : er wird, bis auf einen nur von gekörntem Kernsaft erfüllten schmalen Saum am Rande von breiten, sich verschlingenden, körnig faserigen Zügen angefüllt. Einige haben ihre Faserung schon fast ganz verloren und scheinen mehr aus feinsten Körnchen zu bestehen. Die scharfe Kernmembran bildet an der Innenfläche einen dicken körnigen Belag.

Eines der grössten Eier von Huhn 3 (von ungefähr demselben Alter wie Huhn 1) hat eine Grösse von 0,750 zu $0,960 \mathrm{~mm}$. Der Kern (A b bildung 25) hat eine Grösse von 165:169 $\mu$. Er liegt etwas exzentrisch mitten im Eileib. Der Kernsaft ist sehr stark aber fein gekörnt. In demselben verlaufen dichte, kïrnige Züge, die sich im Kernsaft verlieren. Faserige Bildungen treten darin nicht hervor. Ein peripherer Saum bleibt von diesen Körnerzügen oder Körnerstrassen frei. Die einfache Kernmembran verläuft leicht gewellt, sie zeigt innen einen körnigen Belag.

Der Eierstock eines wenig älteren Huhnes 4 enthält schon kleine gestielte Follikel. Einer derselben enthält ein Ei von 3,054:4,644 mm. Der Kern hat sich der Oberfläche des Eies genähert. Die grössten Maße des Kernes betragen 285 " Breite und 240 "Dicke. Die Kernmembran zeigt sich als scharfe, wellige Linie. Der Kern ist vollständig von stark gekörntem Kernsaft angefüllt. Besonders im Zentrum findet sich eine stärkere Körneransammlung, in der sich einige Bruchstücke scharfer, paarweise verschlungener, sehr feinfädiger Chromosomen zeigen. In den Nebenpräparaten finden sich nur kleine Stückchen und Bröckeln.

Die grösste Oocyte eines Huhnes 5 von demselben Alter, aus einem noch nicht gestielten Follikel misst $0,705: 1,320 \mathrm{~mm}$. Der 142,8:170 $\mu$ grosse Kern ist von der Oberfläche des Eies noch weit entfernt. In dem feinkörnigen Kernsaft verlaufen undeutlich schattenhaft einige körnige 
breite Züge, welche an die Chromatinfadenstränge erinnern, aber keine Faserung zeigen. Die Kernmembran ist leicht gewellt und innen mit Körnchen belegt.

Das Ovar eines etwa acht Monate alten Huhnes 6 bildet schon eine kleine Weintraube. Ein kleinerer gestielter Follikel von ca. $2 \mathrm{~mm}$ Grösse enthält ein Ei von 1,782:1,944 $\mathrm{mm}$. Der Kern misst an der grössten Stelle $250 "$ Breite und $190 \mu$ Höhe. Er ist ca. 50 $\mu$ von der Oberfläche des Eies entfernt. Der starkgekörnte Kernsaft zeigt in den Präparaten, welche das Zentrum des Kernes enthalten, einen den grössten Teil des Kernraumes einnehmenden Haufen von grossen nukleolenartigen dicken chromatischen Körnerm. In einigen Schnitten tritt in diesem Nukleolenhaufen nach dem Grunde des Keimbläschens hin ein hellerer, weniger stark gekörnter nukleolenfreier, grosser Fleck auf. Sonst zeigt sich in sämtlichen Schnitten des Kernes nichts, anch nicht nach mehrmaliger Färbung und vorsichtigster Differenzierung. Die Kernmembran verlüuft faltig und zeigt pseudopodienartige Fortsütze.

Der grösste Follikel dieses Huhnes von knapp $3 \mathrm{~mm}$ enthält ein Ei von 1,890:2,700 mm Der Kern misst in der Breite 234,6 " und in der Höhe 272 u. Er ist etwa 34 " von der Eioberfläche entfernt. Im Zentrum zeigt der Kern wieder einen grossen Nukleolenhanfen. Nach dem Grunde des Kernes zu hebt sich darin in einigen Schnitten ein heller Hof ab. In drei Schnitten zeigen sich in diesem hellen Hofe sehr feinfuidige, zarte, paarweise verschlungene Chromosomen.

Alle übrigen $\mathrm{zu}$ den Untersuchungen benutzten älteren Hülner enthielten sümtlich Oocyten, welche diese bei den Hühnern $1,3,4$ und 6 beschriebenen Stadien zeigten. In den kleineren Oocyten ist jetzt aber meistens das Kernkörperchen schon verloren gegangen. Es finden sich aber noch vereinzelte Eizellen, in denen es sich noch ziemlich vollständig erhalten hat; ganz glatte Oberfläche habe ich aber bei keinem mehr gefunden. Als Beispiele für die Entwicklung der Oocyten bei älteren Hühnern mögen die folgenden von einem mindestens 2 jährigen Huhne 22 dienen, welches Anfangs Februar vor seinem Eintritt in eine neue Legeperiode getötet ist, also noch keine grösseren Follikel besass.

Eine kleine Oocyte dieses Huhnes misst im grössten Durchmesser $0,028 \mathrm{~mm}$. Der ungefähr zentral liegende Kern misst 14 "(Abbildung 26). Inmitten des Kernes liegt ein dichtes chromatisches Knäuel von $10 \mu$, welches aus körnigen, aber in ihrem ganzen Verlaufe gleichmässig dicken Fäden besteht. In einer Lïcke des Fadenwerkes liegt ein etwa $3 \mu$ grosser Nukleolus. Dieser hat eine rauhe, gekörnte Oberfläche und steht in Berührung mit einem kleinen chromatischen Brocken. Der Kernsaft, welcher auch den um das chromatische Knäuel liegenden peripheren Raum ausfüllt, ist wasserhell. Die Kernmenbran stellt eine einfache, etwas körnige Linie dar.

Eine andere Oocyte misst 0,1008:0,1278 mm. Ihr exzentrisch liegender kreisrunder Kern hat einen Durchmesser von 57,6 $\mu$. Das Innere des Kernes füllt ein 48 " grosses chromatisches Gerüst, welches durch einen mit feinlörnigem Kernsaft erfüllten Randsanm von der Kernmembran getrennt 
wird. Diese ist einfach und innen mit Körnchen belegt. Die chromatischen Fäden bestehen aus sehr lockeren Körnerreihen und körnig querfaserigen Zügen, die aber nur schmal erscheinen. Dem Kern liegt ein grosses, kugeliges, dunkel gekörntes Dotterkernlager eben noch an, in dem keine Besonderheiten hervortreten. Im übrigen Eileibe finden sich zerstreute Körnerringe mit hellem Zentrum. Einzelne von diesen liegen auch im Epithel.

Eine grössere Oocyte desselben Huhnes misst (0,318:0,401) $\mathrm{mm}$. Ihr Kern hat eine Grösse von 109,8:135 , . Die starke, einfache, innen mit dichter Körnerlage bedeckte Kernmembran verläuft leicht geschwungen. Der Kernsaft ist stark gekörnt. In demselben ziehen sich zerstreut zahlreiche Chromatinfadenstränge hin. Diese haben gerade in diesem Kerne einen äusserst scharfen Achsenfaden, von dem nach allen Seiten hin feine Fasern weit abstehen. Diese Gebilde sehen hier tatsächlich wie Flaschenbürsten aus. Sie sind mit feinen Körnchen stark besetzt. Mehrere Chromatinfadenstränge zeigen sich im Querschnitt als strahlige Flecken. An den länger getroffenen Gebilden erscheint der Achsenfaden wie aus mehreren gleichlangen kurzen Stücken zusammengesetzt.

Den Kern einer Oocyte von $0,960: 1,275 \mathrm{~mm}$ Grösse zeigt $\mathrm{Ab}$ bildung 27, er hat sich schon auf $40 \mu$ der Eioberflïche genïhert. Er hat eine Breite von 272 " und eine Dicke von 122.4 u. Den Kern umhüllt eine in Wellenlinie verlaufende und gefaltete einfache Kernmembran. Der Kernsaft ist mit feinen Körnchen durchsetzt, die sich in seinem grössten Teile zu einem eigenartigen verschwommenen Netzwerke angeordnet haben; nur an der unteren Fläche des Kernes bleibt ein halbmondförmiger Saum frei. Irgendwelche chromatischen Bestandteile zeigt der Kern auch trotz mehrfacher Färbung in keinem Schnitte. Ungefähr in der Mitte des Eileibes findet sich ein rundlicher, dunkel gefärbter Fleck von etwa $300 \mu$ Durchmesser. Bei starker Vergrösseruug zeigt er sich als in sich abgeschlossenes, aus dicht verflochtenen Fasern zusammengesetztes, kugeliges Gebilde. Die Fasern sind mit sehr feinen Körnchen übersät, welche sich stark mit Hämatoxylin gefärbt haben. Die Maschen des Netzwerkes sind von einer hellen Füssigkeit ausgefüllt. Von einer Membran oder ähnlichen Hülle ist nichts zu bemerken. Mit dem übrigen Eileibe verbindet sich dieses Gebilde durch zarte Fasern. Dies Gebilde ist das Dotterkernlager des Eies. In kleineren Eiern hatte es sich schon mehr oder weniger ganz von dem Kerne gelöst und bildete eine frei im Eileibe liegende Kugel. Jetzt finden wir das Dotterkernlager in derselben Form wieder, es hat aber eine stärkere Färbung angenommen. $\mathrm{Da}$ die Bezeichnung Dotterkernlager nicht mehr zutrifft, werde ich es jetzt Dotterzentrum nennen.

Eine grössere Oocyte von $1,860: 2,025 \mathrm{~mm}$ eines $2^{1 / 4} \mathrm{~mm}$ grossen Follikels enthält einen Kern von $153, \mu$ Breite und 125,8 $\mu$ Höhe. Er hat sich der Oberfläche des Eies auf $120, \mu$ genähert. Die Kernmembran bildet eine einfache scharfe Linie. An der Oberfläche des Kernes verläuft sie ziemlich gradlinig, an den übrigen Rändern stark gewellt und gefaltet. Der Kern ist von dem feinkörnigen, sich aus breiten verzweigenden Zügen zusammensetzenden Netzwerke (wie in Abbildung 27) angefüllt. Die Mitte des Kernes 
ist bis anf einen etwa 30 "breiten Randsaum mit zum Teil grossen, runden chromatischen Nukleolen durchsetzt. Im linken unteren Quadranten dieses Nuklenlenfeldes finden sich in einem nukleolfreien helleren Flecke zwei chromatische Fadengebilde. Jedes besteht aus zwei sich einige Male locker umschlingenden, äusserst feinen, nur sehr schwach färbbaren Füden, die wie aus einzelnen Kömchen zusammengesetzt erscheinen. Weitere chromatische Bestandteile habe ich in keinem Schnitte finden können. Ziemlich in der Mitte des Eileibes findet sich ein Dotterzentrum, von derselben Einrichtung: wie bei dem oben auf pay. 438 beschriebenen Ei.

Etwa der grösste Follikel von etwa $3 \mathrm{~mm}$ dessellyen Huhnes enthielt ein $\mathrm{Ei}$ von $2.325: 2,805 \mathrm{~mm}$. Der Kern ist 221 " breit und 180 a dick. Er ist von der Eioberfläche $48, u$ entfernt. Die einfache Linie der Kernmembran verläuft an allen Seiten unregelmässig. Die Mitte des mit dem feinkörnigen Netzwerke durchsetzten Kernes nimmt ein grosser chromatischer Nukleolenhaufen ein. um welchen ein etwa 30 "breiter Randsaum freibleibt. In der unteren Hälfte des Nukleolenfeldes zeigen sich in einem helleren Hote mehrere verschlungene chromatische Fadengebilde. Jedes besteht wieder aus zwei sehr zarten, verschlungenen Chromosomen. Dic einzelnen Fïlen haben sich schon etwas kräftiger gefüht.

Von den zu der Untersuchung benutzten Legrehiilınern will ich nur diejeniyen hier anführen. welche die grosste Anzahl grosser Follikel besassen. und bei denen alle Präparate gut ausgefallen sind.

Von einem jungen Legehuhn 322 untersuchte ich einen kleineren und sämtliche fünf grossen Follikel. Die Hafe der Follikel betragen: 2.18: 2.60. $6^{1}: 2,13.16,22$ und $32 \mathrm{~mm}$. Das Ei des kleinsten Follikels von $2.18: 2.60 \mathrm{~mm}$ hat eine Grösse von $1.928: 2.254 \mathrm{~mm}$. Der Kern hat eine Dicke ron 173.4 u und eine Breite ron $231.2, \ldots$. El hat sich der Eiobertiache genähert und liegt ungefähr am Übergange der Seitenfläche in die Unterfläche des Eies. Die Kernmembran verläuft gebogen und gekrïmmt. Sie zeigrt an der ganzen Kernoberflüche Vor'sprünge und kleinere Einbuchtungen. Die Mitte des Kernes wirl von einem grossen Haufen chromatischer Nukleolen eingenommen. In mehreren Schnitten zeigen sich verstreute, deutliche, verschlungene Chromosomenpaare. Diese finden sich sämtlich in der linken Hälfte des Nukleolenfeldes. Die chromatischen Fäden bestehen aus zusammenhängenden feinen Kürnchen. Je zwei Fäden umschlingen sich mehrere Male und bilden dabei Schleifen und Ösen. Jedes Chromosomenpar ist von einem hellen nukleolenfreien Hofe nmgeben. Im ganzen fand ich zehn grössere Chromosomenpaare und einige kleine Bruchstücke.

Das Ei des Follikels von $6^{1 / 2} \mathrm{~mm}$ Durchmesser misst $5,8 \pm 0 \mathrm{zu} 6.160 \mathrm{~mm}$. Sein Kern (Abbildung 28) liegt schon ganz nahe der Eioberfläche. Er hat eine Höhe von $238, u$ und eine Breite von 214 $u$. Die Kernmembran verläuft rings um den ganzen Kern mit zackigen Vorsprüngen und Einbuchtungen. Der Kernsaft ist wieder von dem feinkörnigen Netzwerke durchzogen. In der Mitte des Kerns liegt ein chromatischer Nukleolenhaufen mit etwa 100 « Durchmesser von derselben kurz ovalen, aber hochgestellten Form. wie sie der ganze Kern zeigt. Im Zentrum des Nukleolenfeldes liegen 
in zwei Schnitten mehrere verschlungene Chromosomenpaare. Die einzelnen Chromosomen sind sehr scharfe, tiefschwarz gefärbte und vollständig glattrandige feine Füden. Die Chromosomenpaare liegen zu einem dichten Haufen zusammengedrängt. In jedem Schnitte kreuzen sich mehrere, in ganzer Länge getroffene und Bruchstücke von anderen nicht vollständig in einem Schnitte liegenden Paaren. Die Zahl derselben lässt sich hiernach nur ungenau bestimmen, aber acht Paare sind es bestimmt.

Der nächst grössere Follikel hat $13 \mathrm{~mm}$ im grössten Durchmesser. Der zugehörige Kern ( $\mathrm{b} b \mathrm{bil}$ d ung 29) hat eine Breite von $216 \mu$ und eine Höhe von 150 ". Die Oberfliche des Kernes ist fast eben, wie der gerade Verlauf der Kernmembran zeigt. Sie ist nur $7 \mu$ von der Eioberfliche entfernt. An den Seitemrändern verläuft die Kernmembran stark gefaltet. Von unten her springt eine grosse weite Bucht tief in den Kern ein. Die Kernmembran veriäuft hier leicht gehellt. Eine Schrumpfung an dieser Stelle ist jedoch ausgeschlossen, da im Innern der Bucht dem Kern direkt Dotter anliegt and sich keine Lücke darin zeigt. In den drei zentralen Schnitten des Kernes zeigen sich chromatische Fadengebilde, ca. $20 \mu$ unter der Kernoberfläche. Einzelne Chromosomenpaare kann man in ganzer Länge bis zu ihrem freiliegenden Ende verfolgen. In $\mathrm{Abbildung} 29 \mathrm{n}$ zeigt das Bruchstiick des am weitesten rechts liegenden Paares, wie die beiden Füden mit ihren Enden aneinanderstossen. Ob dies die wirklichen Enden der Fïden sind, oder das Chromosomenpaar gerade an der Kreluzungsstelle durchschnitten ist, lasse ich dahingestellt. Über die Zahl der Chromosomenpaare lässt sich nach diesem Kern keine genaue Angabe machen, da nur wenige vollständig vorhanden sind.

Der Folikel von $16 \mathrm{~mm}$ enthält den Kern, wie es bei grösseren Follikeln meistens der Fall ist, ganz in der Nähe des Follikelstieles. Der Kern hat plankonvexe Linsenform. Seine Grösse beträgt $309_{\mu}$ in der Breite und $137 u$ in der Dicke. Die fast ebene Oberfläche des Kernes steht zum Teil mit dem Follikelepithel in direkter Berührung. Der Kernsaft wird von dem schon nehrfach beschriebenen Netzwerk durchzogen. Die Kernmembran zeigt sich an der Oberfläche als fast gerade Linie, die an den Seiten und an der Unterfläche einen unregelmässigen Verlauf nimmt. In den beiden zentralen Kermschnitten finden sich ca. 11 verschlungene Chromosomenpaare und Bruchstücke von solchen. Ein Paar bildet kurz vor seinem rechten Ende eine grosse Öse und steigt dann, sich nochmals umschlingend, im Präparate senkrecht auf. Die ïbrigen Chromosomenpaare zeigen keine Besonderheiten, sie bilden ganz verschieden grosse und verschieden geformte Schleifen und Ösen.

Der nächst grössere Follikel hat einen Durchmesser von $22 \mathrm{~mm}$. Der Kern liegt mehrere Millmeter vom Stielpole entfernt. Er hat plankonvexe Linsenform. Der grösste Teil seiner Oberfläche befindet sich mit dem Follikelepithel in direkter Verbindung. Seine Breite beträgt 32う $\mu$, seine Dicke $104 \mu$. Die Kernmembran verläuft an der Oberfläche ziemlich geradlinig, an den Seiten und an der Oberfläche bildet sie kleine zackige Vorsprünge. Der Kernsaft wird von dem feinkörnigen Netzwerk durchzogen. In den beiden ungefähr durch die Mitte des Kerns gehenden Schnitten finden sich chroma- 
tische Bestandteile, die $16 \mu$ von seiner Oberfläche entfernt liegen. Die Chromosomen zeigen sich nicht mehr in so grosser Länge wie in den letzten Schnitten paarweise verschlungen; Ösen und älnliche Bildungen finden sich noch, aber es zeigen sich nicht immer die freien Enden der Chromosomen. Vieimehr scheint es an mehreren Gebilden in beiden Schnitten, als vereinigten sich die Enden zu je einern dickeren Faden an den Polen der Ösen. An den Polfäden einer Chromatinöse zeigen sich Verdickungen, welche durch Vereinigung der beiden Faden entstanden zu sein scheinen. Es finden sich auch Ösen, welche an den Endlen noch zwci Polfärlen zeigen.

Der grösste Follikel dieses Huhnes hat einen Durchmesser von $32 \mathrm{~mm}$. Der zugehörige Kern hat eine etwas schiefe plankonvexe Linsenform. Seine Breite beträgt $350 \mu$, seine Dicke $119, u$. Seine fast ebene Oberfläche steht fast ganz mit dem Follikelepithel in Berührung. Die Kernmembran bildet nur am Seitenrande zackige Vorsprünge. An der Unterfläche veriäuft sie nur stark wellig. Der Kernsaft wird von dem feinkörnigen Netzwerke durchzogen. In einem der mittleren Schnitte zeigen sich 15, $u$ unter der Oberfläche zwei teilweise übereinanderliegende Chromatinösen, an deren Polen sich zum Teil doppelte, zum Teil schon vereinigte dickere Fülen ansetzen. In der Nähe liegen noch ein paar Bruchstüclie solcher Gebilde, die in lieinem Schnitte in genügender Grösse enthalten sind.

In sämtlichen noch angeführten Kernen finden sich immer wieder die wellig oder im Zickzack verlaufende Linie der Kernmembran und das feinkörnige verschwommene Netzwerk. welches scheinbar die Grundlage des Kernes bildet und ihm den nötigen Halt gibt. Diese immer in fast derselben Art und Weise hervortretenden Kernbestandteile werde ich bei den weiteren Beschreibungen nur noch erwiilnen, wenn sie etwas besonderes bieten.

Von Huhn $\lesssim 0$ habe ich 9 Eier untersucht; deren Follikel hatten einen grössten Durchmesser von 2,15:2.40, 2.97:3.24, 5, 12, 15. 21. 27, 30 und $37 \mathrm{~mm}$. Das Ei des kleinsten Follikels von $2,15: 2,40 \mathrm{~mm}$ hat eine Grösse von $1,814: 2,160 \mathrm{~mm}$. Sein schon auf $18 \mu$ der Oberflïche naheliegender rundlicher Kern ist 292.4 $\mu$ breit und 255 $\mu$ dick. Chromatische Gebilde treten in keinem Schnitte des Kerns hervor. Die mittleren Schnitte enthalten nur eine zentralliegende Ansammlung von chromatischen Nukleolen, welche den grössten Teil des Kernes einnehmen.

Das Ei des zweiten Follikels von 2,97: 3,24 mm misst 2,700: 2,916 mm. Sein Kern von $272 \mu$ Breite und $146 \mu$ Dicke liegt an der Unterfläche des Eies und ist $2 t u$ von der Eioberfläche entfernt. Den grössten Teil des Kernes fuillt des: zentral liegende Nukleolenhaufen aus. Die chromatischen Nukleolen haben aber nur eine blasse Färbung angenommen und liegen zerstreut. Nach der Mitte des Kernes zu zeigen sich in vier Schnitten verschlungene Chromosomenpaare. Die Chromosomen setzen sich aus einzelnen Körnchen zusammen, haben sich aber schon kräftig gefärbt. Die Verschlingungen sind lose und bilden weite Ösen. Ich fand in diesem Kern fünf Chromosomenpaare. Es ist aber kaum anzunehmen, dass dies alle Gebilde sind. Dieselben Schnitte zeigen ein über $300 \mu$ grosses rundes in sich abgeschlossenes faseriges Dotterzentrum. In den Maschen des dunkel gefärbten Fadenwerkes finden sich helle kugolige Blasen. 
Der Follikel von 5 mm Grösse enthïlt ein Ei ron 4,050:4,590 mm. Der Kern liegt fast an der tiefsten Stelle des Eies nahe der Obertläche. Er hat $323 \mu$ Breite und 238 " Dicke. In der Mitte des Kerns enthalten vier Schnitte an verschiedenen Stellen verschlungrene Chromosomenpaare. Die Chromosomen sind sehr feinfïdig und zeigen sich als zarte Linien. Sie werden von einem nur schwach gefärbten, kleinen Nukleolenfelde umgeben.

Der kurz ovale Kern des $12 \mathrm{~mm}$ grossen Follikels liegt 3 " rom Follikelepithel entfernt im unteren Abschnitte der Seitenfläche des Eies. Er ist $293 \mu$ breit und $202, "$ dick. In drei Schnitten finden sich verschlungene Chromosomenpaare in Zentrum des Kerns, $70 \mu$ unter seiner Oberfliche. Der erste Schnitt enthält nur kleine abgeschnittene Bruchstückchen, der 2. und 3. zeigen zahlreiche Chromosomenpaare in fast vollständiger Länge. Die Schleifen und ösen sind ganz verschieden; ebenso die Lage und der Verlauf der Chromosomenpaare. Die Zahl der besonders langen Gebilde beträgt 16. Es ist hierbei aber nicht ganz ausgeschlossen, dass einzelne doppelt gezählt sind.

Der Kern des $15 \mathrm{~mm}$ grossen Follikels hat eine Breite von 270) " und eine Höhe ron $133, \mu$. Er liegt am stielpole. Die fast ganz ebene Kernoberfliche ist 6 " vom Follikelepithel entfernt. Von unten her springt eine grosse Bucht tief in den Kern ein. In den vier mittleren schnitten finden sich 18 " unter der Oberfliche des Kerns verschiedene chromatische Fadengebilde. Im ersten Schnitt fällt unter einigen Bruchstücken ein langer peitschenförmig geschlungener Faden mit knotigen Verdickungen auf. Der zweite zu dem Paar gehörige Faden könnte sich entweder aus der oft nur lockeren Verschlingung ganz losgelöst, oder auf die linotigen Verdickungen zusammengezogen haben. Ich glaube eher, wegen der ausserordentlichen Lünge des Gebildes, dass sich dieses aus zwei Fäden zusammensetzt, die in dem dicken mittleren Knoten fest verschlungen sind. In dem vierten Schnitte findet sich ein ähnliches Gebilde, aber noch mit einer grossen Öse. Dic anderen Schnitte zeigen Chromosomenpaare und Bruchstücke derselben in rerschiedener Länge und dichterer oder Ioserer Verschlingung. Da in diesen Schnitten sehr viele Bruchstücke - wahrscheinlich quer zur Schnittebene verlaufender Chromosomenpaare - vorkommen, eignen sie sich zur Bestimmung der Zahl derselben nicht.

Der Follikel von $21 \mathrm{~mm}$ Durchmesser besitzt einen Kern von 345," Breite und 111 « Dicke. Derselbe hat plankonvexe Linsenform mit fast ebener Oberfläche, welche mit einem grossen zentralen Teile das Follikelepithel direkt berührt. In vier aufeinander folgenden zentralen Schnitten (Abbildung 30) finden sich rerschlungene Chromosomenpaare ron teilweise bedeutender Lünge. Von der Kernoberfläche sind sie etwa 20 " entfernt. Auch einzelne kleinere oder Bruchstücke von solchen liegen dazwischen. Das im dritten Schnitte am weitesten rechts unten liegende Gebilde biegt an seinem rechten Ende rechtwinklig um und steigt senkrecht zur Schnittebene auf: in dem 10 "dicken Schnitte lässt sich deutlich noch eine aufrecht stehende Öse verfolgen und nach der Kreuzung treten die freien Enden der beiden Fäden scharf punktförmig hervor. Der 4 . Schnitt ist nicht gezeichnet, 
da er nur Abschnitte von einigen Chromosomenpaaren enthält. Gerade die Chromosomen in diesem Eikerne zeigen so deutliche klare Enden, dass zweifellos jedes Gebilde sich aus zwei verschlungenen Fïden zusammensetzt, und nicht einen in Achtertouren um sich selbst geschlungenen Faden darstellt, wie sie Loyez beschreibt. Die Zahl der Chromosomenpaare scheint diesem Kerne nach 11 zu betragen.

Der $27 \mathrm{~mm}$ grosse Follikel enthält einen Kern von $35 \overline{7}, u$ Breite und $104 \mu$ Dicke. Die nur leicht gewölbte Oberfläche steht zum grössten Teile mit dem Follikelepithel in direkter Berihrung. In den drei zentralen Schnitten finden sich Chromatingebilde, in einem derselben allerdings nur Bruchstücke. etwa to $_{\mu} \mu$ unter der Kernoberfläche. In einem Schnitte zeigen sich noch zwei lange, stark gekrümmte, verschlungene Chromosomenpaare, im übrigen finden sich elliptische $\ddot{O}$ sen oder Teile derselben mit einfachen dickeren oder feinen doppelten Polfälen.

Der $30 \mathrm{~mm}$ grosse Follikel enthält einen plankonvexen, linsenförmigen Kerm von 388 " Breite und 88 "Dicke. Seine Oberfläche steht mit dem Follikelepithel in direkter Beriihrung. Ex zeigt in zwei Schnitten chromatische Ösengebilde und kleine Brnchstïcke. In dem vorhergehenden und dem folgenden Schnitte fanden sich auch noch einige kleinere Stückchen. Die Üsen werden von ziemlich dicken Fïlen gebildet. An den Polen setzt sich nur je ein dicker Polfaden an. Die Gebilde liegen 30 ." unter der Kernsberfläche.

Der grösste Follikel dieses Huhnes von $37 \mathrm{~mm}$ ist überhaupt de1 urrösste aller untersuchten. Trotz der zahlreichen zur Untersuchung benutzten Hiilnner ist es mir nicht gelungen, einen Follikel zu finden. der über dieses Waf: noch hinansging. Ich führe dies daranf zurïck, dass die von mir verwentete Rasse nur sehr kifeine Eier produziert. Der Ausbildung des Kernes nach ist dieser Follikel dem von $\mathrm{H}_{0} 11$ untersuchten $40 \mathrm{~mm}$ langen nnd $: 35 \mathrm{~mm}$ breiten vollständig gleichzustellen. Der Kern liegt ganz in der Nihte des Stielpoles. Er hat Linsenform mit nur schwach gewöllbter Oberflïche. Seine Breite beträgt tōo , $u$ : seine Dicke $72 u$. Der grösste Teil der Oherfläche steht mit dem Follikelepithel in direkter Berührung. Der Rand lïuft ziemlich scharf $z \mathfrak{n}$. Die vollständig erhaltene Kernmembran verläuft an der Oberfläche ziemlich geradlinig, an der Unterfläche dagegen in Bogennnd Zickzacklinie.

Alle Prïparate, welche den Kern in der Witte getroffen haben, zeigen an beiden Enden jedes Schnittes die von Holl beschriebenen Stäbchen (Abbild ung 31). Ich will gleich vorausbemerken: diese von $\mathrm{H} 011$ beschriebenen Gebilde sind keine Stäbchen, überhaupt keine chromatischen Gebilde. In dem Winkel der beiden zusammenstossenden Flächen der Kernmembran liegen jeclerseits etwa sieben stïbchenähnliche Gebilde von verschiedener Länge von $3-\tau \mu$. Die kürzeren sind gerade, die längeren schwach gebogen. Wit ihrem spitzen Ende stossen sie an die 
Oberfläche der Kernmembran. „Daselbst macht es den Eindruck, als werde dieselbe an der Berührungsstelle der Stäbchen von ilnen etwas einwarts gezogen" (Holl). Das andere in den Kernsaft frei hineinragende Ende nimmt etwas an Dicke zu und zeigt besonders bei den grösseren Gebilden eine knopfförmige Verdickung. Bei einzelnen fällt bei bestimmter Einstellung des Mikroskopes in der Endverdickung ein helles Zentrum auf. Ausserhalb des Kernes ist von den Gebilden nichts zu sehen. Sie hören also an der Kernmembran auf. Verfolgt. man diese Gebilde durch Senken des Tubus durch die ganze Dicke der schnitte, so ist man erstaunt, sie nicht als stïbchenförmige Gebilde verschwinden $\mathrm{zu}$ sehen - nach Holl sind sie ja höchstens 0,1 " breit und als Stïbchen natürlich auch ebenso dick sondern man kann sie durch die ganze Schnittdicke von $10 \mu$ verfolgen und sogar in den sämtlichen Nachbarschnitten finden sie sich wieder und lassen sich auch hier in der ganzen Schnittdicke weiter verfolgen. Wir können demnach keine Stäbchen vor uns haben, sondern platte membranartige Gebilde. Beachtet man die Einziehung der Kernmembran an der Spitze der Gebilde und den hellen Fleck in der knopfförmigen Verdickung, die sich beide ebenfalls durch die Schnitte verfolgen lassen, so erkennt man, dass es Falten der Kernmembran sind. Die Falten sind vollstandig zusammengedrückt und so erscheinen die beiden zusammenliegenden Blätter der feinen Kernmembran als eine Linie. An der Umschlagstelle der Falten im Innern des Kernes hat sich die Nembran in einigen Fällen geknickt; dann zeigen die freien Enden der Gebilde keine bedeutende Verdickung. An anderen, besonders den längeren Falten, ist die Membran nicht geknickt, sondern umgebogen. Infolgedessen entsteht hier eine knopfförmige Verdickung und in derselben bleibt, an der tiefsten Stelle der Falte liegend, ein heller Fleck.

In den drei zentralen Schnitten des Kernes finden sich chromatische Ösen und Brocken $25 \mu$ unter der Oberfläche (Abbildung 31). Die drei in den Schnitten vollständig enthaltenen Ösen sind etwas in die Länge gezogen. An den Enden setzt sich je ein starker Polfaden an. Zwei von den Ö̈sen sind stark gekrümmt. Die ausserdem vorkommenden Brocken sind abgeschnittene Bruchstücke von Ösen, welche in einer anderen als der Schnittrichtung liegen.

Von Huhn 64 wuràen folgende 9 Follikel untersucht: 2.05 : 2,25, $3,13: 3,40,4,32: 5,13,9,11,19,26,29$ und $32 \mathrm{~mm}$. Der kleinste Follikel 
enthält ein Ei von 1,7う̄0:1,975 mm. Der Kern liegt noch etwas exzentrisch mitten im Eileibe. Er hat ungefähr runde Form und ist $323 ; 3 \pm 0, \mu$ gross. Die Kernmembran ist einfach aber stark. Das Kerninnere wird von dem stark gekörnten Kernsaft ausgefüllt. Nach der Mitte des Kernes hin treten dunkel gefärbte, chromatische Nukleolen auf. Andere Gebilde finden sich in keinem Schnitte.

Der nächst grössere Follikel von $3,13: 3,40 \mathrm{~mm}$ enthält ein Ei von $2,592: 2,916 \mathrm{~mm}$. Der schon nach der Oberfläche gerïckte Kern ist $340 \mu$ breit und $204 a$ dick. Der grösste Teil des Kerninnerns wird von chromatischen Nukleolen durchsetzt, ein nur etwa 40 , breiter peripherer Saum bleibt frei von Nukleolen. In der unteren Kernhälfte finden sich in neun Schnitten (Abbildung 32) verschlungene Chromosomenpaare, von einem helleren nukleolenfreien $\mathrm{H}$ ofe umgeben. Die einzelnen Fäden setzen sich aus feinen Körnchen zusammen und haben sich nur schwach gefärbt. Die Verschlingungen sind lose und weit. In sämtlichen Schnitten fand ich 14 Chromosomenpare oder Stücke von solchen.

Der Follikel von 4,32: $5,13 \mathrm{~mm}$ Grösse enthält ein Ei von 4,050 :4,752 mm. Der 289 " breite und 238 u dicke Kern hat sich der Oberfläche des Eies genähert. Im Innern des Kernes finden sich noch chromatische Nukleolen In mehreren Schnitten zeigren sich einzelne Chromosomenpaare an verschiedenen Stellen der unteren Kernhälfte. Im ganzen habe ich fünf vollständige lange Chromosomenpare gefunden. Die einzelnen Fiden sind sehr fein aber scharf und tiefschwarz gefürbt.

Der Kern des $9 \mathrm{~mm}$ grossen Follikels hat sich auf 7 "der Oberfläche genähert. Er liegt an der Seitenfläche des Eies. Er ist 202 " breit und $166 \mu$ dick. Seine Kernmembran verläuft als stark geschlängelte Zickzacklinie. In den beiden mittleren Schnitten des Kernes zeigt sich ein dichtes Knäuel verschlungener Chromosomenpaare, ziemlich im Zentrum des Kerns, 60 u unter seiner Oberfläche. Die Chromosomen sind scharfe, tiefschwarze Fäden und schlängeln sich paarweise stark umeinander. Die einzelnen Paare liegen dicht zusammengeknäuelt und verdecken sich zum Teil. Ausser 12 sehr lang zu verfolgenden Paaren finden sich noch einige kleinere Abschnitte.

Der $11 \mathrm{~mm}$ grosse Follikel enthält einen Kern von $250 \mu$ Breite und 170 "Höhe. Die schwach gewölbte Oberfläche ist $3 \mu$ vom Follikelepithel entfernt. An den Seiten und an der Unterfläche verläuft die Kernmembran scharf geschlängelt. An der Unterfläche beult eine grosse Bucht den Kern $70 u$ tief ein. In der Bucht befindet sich Dotter. In drei Schnitten durch die Mitte des Kernes zeigen sich nur 10 u unter der Oberfläche mindestens 12 in einem Haufen vereinigte Chromosomenpaare. Abbildung 33 zeigt das Dotterzentrum des Eies. Es stellt ein ovoides 350 " langes und $250 \mu$ breites faseriges Gebildes dar, welches sich mit Hämatoxylin stark gefärbt hat. In den Maschen des Faserwerkes liegen helle Bläschen. In der Mitte zeigt sich jetzt ein kugelförmiges Zentrum von 60 a Durchmesser, welches eine körnige Beschaffenheit besitzt. Dieses Zentrum hat stärker Eosin angenommen, zeigt aber sonst keine Besonderheiten. 
Der Kern des $19 \mathrm{~mm}$ grossen Follikels hat eine Breite ron $3: 00$ " und eine Dicke von $110 u$. Seine Oberfläche ist fast vollstündig eben. An den Rändern und an der Unterfliche hat er Falten und zum Teil sehr grosse zackige Fortsätze. In den vier mittleren aufeinanderfolgenden Schnitten finden sich $16 u$ unter der Oberfläche 12 verschlungene Chromosomenpaare und einige Bruchstücke. In dem ersten Schnitte scheinen sie sich schon in Ösen nmzubilden. In den übrigen Schnitten zeigen sich chenfalls solche Gebilde, daneben aber sehr lange, zum Teil stark gekriimmt rerlaufende Chromosumenpaare. Zufällig finden sich in diesem Kern drei Chromosomenpaare, welche auf den ersten Blick für die Ansicht Loyezs zin sprechen scheinen, dass jedes Gebilde nur aus einem Faden hestehe. Ein im zweiten Schnitt liegendes, stark gekrümmtes Paar durchzieht die ganze Dicke des Pr:iparates. Die beiden Schenkel der Krïmmung liegen ganz. nahe übereinander. Das obere Ende dieses Pares endet in rollstandigem Bogen, an dem sich aber ein Knotenpunkt zeigt. Öber diesen hinluls lassen sich die Chromusomen im Präparat noch weiter senkrecht anfsteigend verfolgen; gleich danach hören sie nach beiden Seiten etwas von eimander gespreizt, mit freiem Ende auf. Die beiden anderen in Frage kommenden Paare, besonders das im vierten Schnitte, zeigen nach ihrem rechten Ende hin keinen runden Bogen - wie es der Fall sein miisste, wenn es ein hier umbiegender Faden wirre - sondern eine mehr oder weniger sturk ausgeprigte Ecke, in ter die Chromosomen zusammenstossen oder sich kireuz'n.

Der Kern des $26 \mathrm{~mm}$ grossen Follikels hat eine Breite von 318 " und eine Dicke von 81 ". Seine fast ebene Oberfläche steht zum grossen Teil mit dem Epithel in direkter Beriihrung. An der Unterfliiche besitzt der Kern ebenfalls unregelmässige lange Fortsätze. Abbildung 34 zeigt drei mittlere Schnitte. Die darin 16 " unter der Oberfliiche zentral liegenden Chromatingebilde haben Ösenform mit zum T'eil doppelten. zum Teil schon einfachen Polf̈iden. Ausserdem finden sich einige Bruchstücke.

Der $29 \mathrm{~mm}$ grosse Follikel enthält einen Kern von 341 "Breite und und $68, \mu$ Dicke. An den Seiten und an der Unterfläche verläuft die Kernmembran im Zickzack. In zwei mittleren Schnitten zeigen sich 28 " unter der Oberfläche chromatische Ösen und Bruchstïcke. Die Ösen sind sehr dick, ihre Polfüden einfach.

Der grösste Follikel von $32 \mathrm{~mm}$ Durchmesser besitzt einen Kern ron $388 \mu$ Breite und 94 u Dicke. Am Rande ist die Kernmembran stark gefaltet, die Falten sind jedoch nicht zusammengedrïckt. 25j " unter der Oberfläche finden sich in drei Schnitten ganz eigenartige chromatische Gebilde. Nur einige hiervon sind plumpe chromatische Ösen mit dicken knopfförmigen Polen. Die übrigen chromatischen Gebilde sind dicke, gebogene Stäbe oder Bruchstiicke von in den einzelnen Schnitten nur teilweise enthaltenen Gebilden.

Von Huln 65 habe ich einen kleineren und die fünf grossen Follikel untersucht. Ihr Durchmesser betrug: $2,02: 3,36,7,14,18,22$ und $26 \mathrm{~mm}$. Der kleinste Follikel von 2,52:3,36 mm enthält ein Ei von $2,380: 3,081) \mathrm{mm}$. Der dicht unter der Oberfläche liegende linsenförmige Kern mit stark 
gekrümmter, konvexer Unterfläche ist 218 "breit und 221 " dick. Inmitten des Kernes zeigen sich verstrente chromatische Nukleolen, um welche eine freie Randzone bleibt. In mehreren Schnitten finden sich an verschiedenen Stellen des Nukleolenhaufens nur schwach färbbare verschlungene Chromosomenpaare.

Der Kern des $7 \mathrm{~mm}$ grossen Follikels liegt am Übergang einer Seitenin die Oberfläche. Er hat eine Breite von $224 \mu$ und eine Dicke von $164 \mu$. Die Kernmembran besitzt an der ganzen Kernoberfläche grosse zackige Vorsprünge. Das Zentrum des Kernes nimmt ein Nukleolenhaufen von ungefähr $80 \mu$ Durchmesser ein. Zentral in diesem finden sich in zwei Schnitten zwölf verschlungene Chromosomenpaare und einige Bruchstïcke. Die Fäden sind sehr fein und scharf.

Der Follikel von $14 \mathrm{~mm}$ Durchmesser enthält einen Kern von 282 « Breite und $221, \mu$ Dicke. Die Kernmembran verläuft leicht gewellt. In zwei mittleren Schnitten findet sich etwa im Zentrum des Kernes 70 „unter seiner Oberfläche ein Komplex verschlungener Chromosomenpaare. Die einzelnen Fäden sind sehr scharf und lange zu verfolgen. In beiden Schnitten sind elf ganz erhaltene Chromosomenpaare und einige Bruchstücke vorhanden.

Der Kern des $18 \mathrm{~mm}$ grossen Frollikels ist $333 \mu$ breit nnd 100 " dick. Die Oberfläche ist fast eben und berührt mit ihrer Mitte das Epithel. An den Seiten und an der Unterfläche verläuft die Linie der Kernmembran leicht gezackt. Drei Schnitte durch die Mitte des Kernes zeigen besonders lange und schöne Chromosomenpaare. Fast alle haben sehr deutliche freie Enden, woraus bestimmt hervorgeht, dass zwei Fäden sich immer umschlingen. Im ersten und dritten Schnitte zeigen sich schon ein paar Ösen mit doppelten Polfäden.

Der Kern des $22 \mathrm{~mm}$ grossen Follikels hat ganz flache Kegelform. Seine fast ebene Oberfäche berithrt direckt das Epithel. Die Breite des Kernes beträgt $338 \mu$, die Höhe $101 \mu$ (Abbildung 35). Der Kern zeigt gregenüber dem letzten aus dem $18 \mathrm{~mm}$ grossen Follikel keinen bedeutenden Fortschritt in der Ausbildung der chromatischen Bestandteile. In zwei Schnitten finden sich sehr lange Chromosomenpaare. Besonders eins im ersten Schnitt zeigt stark gekrümmte und weite Verschlingungen. Die freien Enden treten klar hervor. Einzelne Gebilde scheinen sich zn Ösen umbilden zu wollen, sie sind aber noch doppelfädig. Es sind zehn grössere Chromatingebilde und einige Bruchstücke vorhanden.

Der grösste Follikel dieses Huhnes von $26 \mathrm{~mm}$ enthält einen Kern von $439 \mu$ Breite und 85 , $\mu$ Dicke. Der Kern ist ganz flach, hat plakonvexe Linsenforn. Der Rand läuft spitz zu, die Unterfläche zeigt einige zackige Vorspriinge. In drei mittleren Schnitten findet sich ein Komplex verschlungener Chromosomenpaare und einiger chromatischer Ösen; im ganzen sind es neun Gebilde. Die Chromosomenpare zeigen meist enge Verschlingungen. Die Ösen besitzen an jedem Ende zweí Polfäden.

Von dem Huhne 37 will ich noch vier untersuchte Follikel anführen. Ich schicke gleich voraus, dass die Ergebnisse der Oocyten dieses Huhnes für die Untersuchung positiv nicht zu rerwenden sind, da sich drei von Archiv f. mikrosk. Anat. Bd. 72. 
ihnen meiner Ansicht nach in Rückbildung befinden. Es lässt sich abel hierdurch beweisen, dass sich Loye z durch eins der von ihr untersuchten Eier zu einem Irrtum hat verleiten lassen und daraus eine Periode konstruiert hat. die nicht existiert. Die vier untersuchten Follikel dieses Huhnes messen: $2,43: 3,25,3,35: 4,20,17$ und $23 \mathrm{~mm}$.

Der kleinste Follikel von $2,43: 3,25 \mathrm{~mm}$ enthält ein vollkommen normales Ei von 2,214: 3,024 mm. Der Kern hat rom Epithel eine Entfernung von $27 \mu$. Seine Form ist die einer bikonvexen Linse. Seine Breite betrïgt $279 \mu$, seine Dicke $136 \mu$. Im Innern des Kerns zeigt sich der chromatische Nukleolenhaufen, den alle Kerne dieses Stadiums besitzen. An verschiedenten Stellen finden sich in sechs Schnitten feine, körnige Chromosomenpaare, im ganzen zwölf, von einem hellen nukleolenfreien Hofe umgeben.

Das Ei des zweiten Follikels von $3,35: 4,20 \mathrm{~mm}$ Grörsse misst $3,186: 4,050 \mathrm{~mm}$. Der Kern hat eine Breite von $333 \boldsymbol{u}$ und eine Dicke von $197, \ldots$. Er hat sich der Eioberfläche auf $17 u$ genähert. Die Kernmembran verlïuft leicht gewellt. Der Kernsaft ist dunkel gekörnt nnd enthält Nukleolen. In mehreren Präparaten finden sich an verschiedenen Stellen des Kerns chromatische Haufen und Bröckeln, dazwischen einzelne grösssere und kleinere Gebilde. die wie verschlungene Chromosomenpaare ausschen. Die Fäden derselben sind aber dick, wie gequollen und ganz rauh: dic Verschlingungen sind häufig unklar.

Der $17 \mathrm{~mm}$ grosse Follikel enthält einen Kern von 283 "Breite und 114 " Dicke. Er hat plankonvexe Linsenform; die fast ebene Obertliche berürt das Epithel nahezu ganz. In allen mittleren Schnitten finden sich im zentralen Teil des Kerns Nukleolen. Diese bilden keinen in sich ahgeschlossenen Haufen. wie es in kleineren Eikernen der Fall ist, sondern sie breiten sich von der Mitte nach allen Seiten hin ganz unregelmässig aus und verlieren sich nach und nach in den äusseren Teilen des Kernes. Ininitten dieser Nukleolen zeigen sich in drei Schnitten, 15 $\mu$ von der Kernoberfläche entfernt, chromatische Gebilde, einzelne verschlungene Chromosomenpaare und in der Entstehung begriffene Ösen und Bruchstücke solcher Bildungen. In dem vorhergehenden und folgenden Schnitte finden sich auch noch einige Bruchstücke.

Den Kern des grössten Follikels von $23 \mathrm{~mm}$ zeigt Abbild ung 36. Er hat eine Breite von 351 " und eine Höhe von 130 u. Die Unterfläche des Kerns besitzt einige unregelmässige Fortsätze. In allen durch die Mitte des Kerns gehenden Schnitten finden sich wieder die unregelmässig zerstreuten Nukleolen, wie in dem letzten Kerne. In vier zentralen Schnitten liegen darin ca. $30 \mu$ unter der Kernoberfläche chromatische Gebilde. Diese stellen zum grössten Teil Ösen dar und einige andere verschlungene und gekreuzte Fadenstücke von eigenartiger Gestalt. Die meisten Gebilde machen einen rauhen Eindruck.

Der Kern des kleinsten Follikels dieses Huhnes zeigt ganz normale Beschaffenheit. Dagegen unterscheiden sich die drei anderen ganz wesentlich von allen bisher geschilderten Kernen. Die chromatischen Brocken und Haufen, die rauhen, gequollenen 
Chromosomenstïcke, wie sie der Kern des zweiten Follikels von 3,35:4,20 mm zeigt, habe ich in keinem anderen Kerne gefunden. Sie sind nur als Erscheinungen des Zerfalls zu erklären. Die beiden grossen Follikel von 17 und $23 \mathrm{~mm}$ enthalten in ihren Kernen zum Teil ganz normale chromatische Gebilde, einige haben allerdings auch rauhe, unregelmässige Beschaffenheit angenommen. Aber diese Kerne enthalten sonderbarer Weise einen diffusen, sich in die Umgebung verlierenden Nukleolenhaufen. Nukleolen hat kein einziger Kern von sämtlichen Eiern in dieser Grösse gezeigt. Daher ist wohl der Schluss berechtigt, dass Nukleolen in Kernen von Eiern dieser Grösse nicht normal sind. Sie können dann nur Rückbildungserscheinungen sein. Loyez beschreibt in ibrer fünften Periode die Umbildung der chromatischen Faden in elliptische chromatische Gebilde (Ö́sen), deren Umgebung mit kleinen Nukleolen übersăt ist. Diese Beschreibung und vor allem ihre dazu gegebene Abbildung 54 a stimmen vollständig mit den Resultaten meiner Untersuchungen an den Keruen des 17 und $23 \mathrm{~mm}$ grossen Follikels von Huhn 37 überein. Leider gibt Loyez gar keine Angaben über die Grösse der Follikel und Kerne. Der in Frage stehende von ibr in Abbildung 54 a wiedergegebene muss aus einem grossen Follikel stammen; das geht aus den chromatischen Gebilden des Kernes und aus ihrer Beschreibung hervor. In der 6. Periode lässt Loyez aus den elliptischen Gebilden von neuem Fäden hervorgehen. Dieses Verschwinden und Wiederauftreten der Falden hat sich aus meinem genügend umfangreichen Materiale nicht ergeben. Ich folgere hieraus, dass Loyez in der fünten Periode einen in Rückbildung befindlichen Kern geschildert hat, wie ich sie von Huhn 37 beschrieben habe. Demnach kommt die ganze von Loye $z$ beschriebene fünfte Periode in der Wachstumsperiode der Hühneroocyte nicht vor.

\section{Ergebnisse.}

Verfolgen wir num an den vorstehend beschriebenen Eikernen das Wachstum der Oocyten unter besonderer Berücksichtigung der ausserordentlich grossen Zahl der verschiedenen dabei durchlaufenen Kernstadien. In dieser ganzen Periode wächst die Oocyte des Huhnes von $0,012: 0,016 \mathrm{~mm}$ mit einem Keimbläschen von $6 \mu$ Durchmesser zu einer Grösse von $3 r \mathrm{~mm}$ mit einem 
Keimbläschen von $455 \mu$ Durchmesser und $72 \mu$ Dicke aus. Die Bezeichnung dieser Zeit als "Wachstumsperiode" (Waldeyer) ist demnach richtig gewählt.

I. Der Chromatingehalt der jüngsten Oocyten (Abb. 2) ist gering; nur einzelne Körnchen und Brocken zeigen sich an dem feinen Kierngerüst. Bei der Weiterentwicklung sehen wir die Chromatinkörnchen an Zahl bedentend zunehmen. Sie liegen zunächst an der Innenflïche der Kernmembran, dann selen wir grössere Körner und Haufen zahlreicher kleinerer Körnchen im Verlauf der Füden sich in grösserer Menge ansammeln und inmitten des Kerns zu grossen Brocken vereinigen (Abb. 3). Das neugebildete Chromatin tritt in immer grösserer Menge auf. Das Fadenwerk des Kernes beginnt sich stïrker damit zu bedecken. Die anfangs sehr zarten, schwach färbbaren Fidchen werden dicker und dunkler gefärbt (Abb. *). Die Dickenzunahme geht in der Weise vor sich, dass sich die feinen Chromatinkörnchen daran niederschlagen; die Füden erhalten durch die sehr feinen Körnchen eine rauhe Oberfläche, sie bieten ganz das Bild dünner, vom Rauhreif befallener Zweige und Ästchen. Die Chromatinaufnahme geht allmählich ihrem Ende zu. An der Innenfäche der Kernmembran zeigen sich keine Kïrner mehr. Das gesamte Chromatin liegt im Kerninnern, zu Haufen und grossen Brocken angesammelt, oder an den Fäden niedergeschlagen. Die erste Periode. welche das junge Keimblïschen durchzumachen hat, ist beendet. Sie besteht in der Hauptsache in der Chromatinaufnahme oder richtiger Chromatinbildung. Wir sehen nämlich plötzlich Chromatinkörnchen im Kern auftreten. Diese können nur von aussen - also aus dem Eiprotoplasma - hineingelangt sein. Im Eileibe zeigt sich jedoch nicht die geringste Menge chromatischer Substanz. Auch irgendwelche dem Chromatin (z. B. in der Färbung) ähnliche Substanz findet sich im Eileibe nicht. Trotzdem muss der Eileib die Grundstoffe enthalten, die der Kern aufnimmt und sofort als Chromatin ablagert. Die Chromatinurstoffe sind nur durch unsere gewöhnlichen histologischen Methoden nicht darstellbar. Es ist auch denkbar, dass sie im Protoplasma des Eies in gelöster Form vorkommen. Das vom Ei gebildete Chromatin lagert sich zunächst an der Innentläche der Kernmembran ab. Sobald hier neue Körnchen gebildet werden, wird es nach dem Innern des Kernes weitergeschoben. Hier liegt es zu Haufen oder Brocken 
angesammelt und als feiner, dichter Niederschlag auf dem zarten Fadenwerk des Kernes. Diese Periode der Chromatinbildung im Kern erreicht ihr Ende, sobald sich kein neugebildetes Chromatin mehr an der Innentläche der Kernmembran zeigt.

II. Das gebildete Chromatin bleibt nicht regellos im Kern liegen. Es tritt sogleich eine Umlagerung des vorlaufig in Haufen und Brocken oder als Niederschlag angesammelten Chromatins ein. Das Fadenwerk des Kernes nimmt das Chromatin allmăhlich auf. Das gesamte Kerngerüst, einschliesslich der chromatiscben Substanz, zieht sich hierbei von der Kernmembran nach der Mitte des Kernes zusammen (Abb. 5 und 6). Hier bildet sich ein wirrer Haufen von chromatischen Brocken und von hellen, nur wenig mit Chromatin besetzten Faden und solchen, die schon durch die Chromatinaufnalme tiefschwarz geworden sind. Diese letzteren lösen sich allmăhlich aus dem Gewirr wieder los, sie recken ihre mit Chromatin beladenen und nun glatt werdenden Enden vor und suchen die Kernmembran wieder zu erreichen (Abb. 7). Diese Beladung der Fảden mit chromatischer Substanz geht nicht im ganzen Kerne an allen Fäden gleichzeitig vor sich, sondern sie scheint sich von einem Pole des Kernes nach dem entgegengesetzten fortzupflanzen. Sonst sind die eigenartigen Bilder (Abb. 7), dass eine Seite des Kernes fertige, tiefschwarze, glatte Chromosomen, die andere dagegen noch helle zeigt, nicht zu erklären. Ob hierbei das Centrosom einen Einfluss ausübt, lasse ich dahingestellt. $D^{\prime} \mathrm{Hollander}$ hat die Beobachtung gemacht, dass sich das chromatische Fadenknäuel nach demjenigen Pole des Kernes zusammenzieht, an dem der Dotterkern liegt. Nach meinen Beobachtungen kann ich hierüber nichts bestimmtes behaupten. Mit der fortschreitenden Verarbeitung des Chromatins nehmen die chromatischen Brocken und Haufen ab. Sie verschwinden vollständig, sobald die Fäden alles Chromatin aufgenommen haben. Die ursprünglich zarten, feinen, nur schwach färbbaren Fädchen sind dick und plump geworden. Dies Stadium, in welches die Kerne jetzt eingetreten sind, ist äusserst charakteristisch (Abb. 8 und 9). Die glatten, tiefschwarzen, leicht gekrümmten, mehr Stäben ăhnlichen Chromosomen geben dem Keimbläschen ein ganz eigenartiges Gepräge. D'Hollander scheint in diesem Stadium noch einen einzigen geknăulten Kernfaden anzunehmen. Die zahlreichen freien Enden, die sich oft 
in der Mitte des Kernes zeigen, und die noch hïutigeren Enden del Fäden an der Kernmembran beweisen zur Genüge, dass das Fadenwerk aus mehreren Fiden besteht. Ob auch in der ersten Periode mehrere Fäden oder nur einer vorhanden ist, kann ich nicht entscheiden. Als Resultat der vollendeten zweiten Periode finden wir einen Kern, wie er auf pag. 426 f. (Abb. 8 und 9) beschrieben ist.

III. Die vollstïndig ausgebildeten dicken Chromosomen sehen wir in dem nächsten Stadum (Abb. 10) sich nach der Peripherie des Keimbläschens zurückziehen. Die einzelnen Fäden sind nicht mehr ganz glattrandig, sie zeigen auch stärkere Krümmungen. Das Zentrum des Eikerns wird aber vollständig frei, es zeigt sich als heller, nur von Kernsaft erfüllter Raum. Jetzt spalten sich die Chromosomen in ihrer ganzen Länge. Die 'Teilung lässt sich wegen der Dicke und Deutlichkeit der einzelnen Fidden sehr gut beobachten. Am häufigsten erkennt man die Spaltung an den Enden der Füden, aber auch in der Hitte zeigt sich einigemale ein feiner spalt (Abb. 11). Durch diese Längsteilung entsteht die doppelte Anzahl Chromosomen (Abb. 12). Diese entsprechend feineren Fäden füllen wieder den ganzen liernraum ans. Das Charakteristikum dieser Periode bildet die Lüngsteilung und Verdoppelung der Chromosomen. Der ganze Vorgang erimert stark an die Kernteilung. Zu Beginn der Kernteilung seben wir das Fadenwerk ein dichtes Knäuel bilden, aus dem sich die dicken Chromosomen loslösen und zur Teilung schreiten. Ganz ähnlich verläuft der Prozess in der Entwicklung der jungen Oocytenkerne des Huhnes. Das ursprünglich feine, im ganzen Kerne verstreute Fadengerüst zieht sich zu einem dichten Knäuel nach der Mitte der Kernes zusammen (Abb. 6 und 7). Daraus lösen sich neue dicke Chromosomen los (Abb. 8 und 9) und diese spalten sich ebenso in ihrer ganzen Länge (Abb. 11 und 12), wie es die Chromosomenschleifen bei der Kernteilung tun. Hiermit hört aber auch die Ähnlichkeit in den beiden Vorgängeı auf. Während wir bei der Karyomitose die Teilung veiter auf den ganzen Kern und den Zellleib fortschreiten sehen, berührt das Keimbläschen und den Eileib der Oocyte die Teilung der Chromosomen nicht; die Oocyte behält ihre Form und Grösse. Diese Längsteilung hat auch d'Hollander beobachtet, hält aber noch immer an einem Kernfaden fest; er schreibt (35, pag. 144): 
le péloton subit alors au niveau de plusieurs de ses segments une division longitudinale, qui n'intéresse jamais la totalité de sa longeur. Als Resultat der Teilung lässt er eine „chromatische Kette" entstehen. Nach den zahlreichen, gut sichtbaren freien Enden der Fäden in meinen Präparaten muss ich unbedingt daran festhalten, dass nicht ein Faden - auch nicht eine Fadenkette, - sondern dass mehrere Fäden das Kerngerüst bilden.

IV. Das entstandene feine Fadenwerk des Kernes erhält sich in seiner Form. An der Innentläche der Kernmembran sehen wir jetzt wieder chromatische Körner auftreten. Gleichzeitig sammeln sich dieselben auch an einzelnen Knotenpunkten des chromatischen Netzwerkes an (Abb. 13). Lie Grösse des entstehenden Netzknotens ist ganz verschieden, meist treten ein oder zwei, ausnahmsweise auch drei Netzknoten durch stärkere Ansammlung von chromatischen Körnern in Grösse von $1-3 \mu$ hervor. Die feinen Fäden sind nur wenig dicker geworden, sie sind aber nicht mehr so glattrandig, wie unmittelbar nach der Teilung. Obne Frage finden sich auch feine Körnerniederschläge an den Fïden selbst (cf. Oocyte 0,0156:0,0195 mm auf pag. 429) nnd Abb. 14).

Die sich so bildenden chromatischen Brocken und Haufen stehen also mit den Fäden zunächst in Verbindung. Sie Laben Vorsprünge und Höcker, eine rauhe Obertläche und unregelmissige Gestalt, bald fast kugelig, bald mehr in die Lünge gezogen. Die Obertläche des chromatischen Körpers glättet sich immer mehr, gleichzeitig lassen die Fäden von ihm los. Wir sehen dann ein noch angerauhtes, meist rundes oder ovales chromatisches Körperchen zwischen den Fäden liegen, das wir jetzt Nukleolus nennen können. Die Oberfläche des Nukleolus wird bald vollständig glatt (Abb. 14). Seine Grösse beträgt meist 2,6 $u$, es finden sich jedoch Schwankungen zwischen 2 und $3 \mu$. Einige Nale finden sich auch zwei Nukleoli, dann meist etwas kleiner, jeder etwa $2 \mu$ gross, häufig eng aneinanderliegend oder doch benachbart, manchmal aber auch weiter voneinander entfernt. In ahnlicher Weise, durch Zusammenschluss der Chromosomen und Bildung eines Netzknotens, der dann frei wird, schildert Mertens die Entstehung des Nukleolus. Hiernach werden scheinbar die Chromosomen selbst zur Bildung des Kernkörperchens mit verbraucht. Das scheint mir nicht der Fall zu sein, höchstens 
geben die Chromosomen einen Teil ihrer chromatischen Substanz an den Nukleolus ab. Ich halte es aber für wahrscheinlicher, dass vollständig neugebildete chromatische Substanz an den Netzknoten abgelagert wird und den Nukleolus bildet. Diese Periode ist durch die Bildung des Nukleolus sehr interessant. Der Nukleolus ist nämlich bei den Oocyten des Huhnes nur eine vorübergehende Erscheinung, wir sehen ihn bald wieder verschwinden. Die Bildung des Nukleolus ist von d'Hollander' nicht näher beschrieben. Er erwähnt ihn plötzlich bei der Beschreibung seines Kerntypus j, ohne seine Entstehung verfolgt zu haben.

V. Das in seiner Bildung begriffene Kernkörperchen hat sich an seiner Oberfläche noch nicht vollständig geglättet, da setzt schon eine neue Veründerung an dem Fadenwerke des liernes ein: Die Chromosomen fangen an, sich zu verdicken. Diese Dickenzunahme beginnt in der Mitte des Kernes und schreitet llach der Peripherie zu fort (Abb. 15) Oft kann man an einem und demselben Faden sehen, dass er in der Mitte des Kernes dicker ist, als am Rande. Am deutlichsten beweist die zentral beginnende Verdickung ein Vergleich der Abbildung 16, einer Calotte eines Kernes mit der die Mitte darstellenden Abb. 15. Die einzelnen Fäden in Abbildung 16 zeigen ausserdem wieder, dass sich das Fadengerüst des Kernes aus mehreren verschlungenen Fäden zusammensetzt. Sobald sich die Verdickung über den ganzen Kern ausgebreitet hat, ist die fünfte Periode der Kernveränderungen zum Abschluss gekommen.

Die beiden letzten ( $\mathrm{V} V$ und $\mathrm{V}$ ) Perioden scheinen eine erneute Chromatinaufnahme darzustellen, ähnlich der ersten Periode. Das zuerst aufgenommene Chromatin wird zur Bildung eines oder auch zweier Kernkörperchen verbraucht, das übrige lagert sich dann an dem Fadenwerk vom Zentrum nach der Peripherie hin fortschreitend ab.

Über die Stoffe, aus denen der Kern das Chromatin bildet, gibt uns auch in diesen Perioden das Eiprotoplasma keine Aufschlüsse; denn irgendwelche Einlagerungen finden sich in denselben nicht, es müste sonst die im Ei stärker hervortretende Körnung so ausgelegt werden (Abb. 15). Dazu ist meiner Ansicht nach keine Berechtigung vorhanden. 
Wit dieser fünften Periode ist die Ausbildung der Oocytenkerne in gewisser Weise zu einem Abschlusse gekommen. Bisher zeigte jede Periode bedeutende Veränderungen der Kernstrukturen. Dagegen nahm die Grösse der Eizellen im Vergleich mit dem in späteren Perioden erfolgenden Wachstum nicht bedeutend zu. Die Oocyten haben jetzt eine Durchschnittsgrösse von 0,013:0,030 mm, ein Keimbläschen von 9 bis $14,7 \mu$ und immer einen, einigemale auch zwei Keimflecken von 2 bis 3,5 "Grösse. Der Kern ist jetzt zur Ruhe gekommen. Ein sehr grosser Teil der Eikerne bleibt in diesem Stadium allerdings nicht lange stehen, sondern schreitet gleich zur Weiterentwicklung fort. Ein grosser T'eil erhält sich aber in dieser oder doch nur wenig verïnderter Form, in der wir selbst bei alten Legehühnern noch einen Teil der Oocyten vorfinden (Abb. 26). D'Hollander sucht in seiner Arbeit zu beweisen, dass es in der ganzen Wachstumsperiode der Oocyten des Huhnes kein Ruhestadium gibt. Meine Abbildungen 15 und 26 zeigen es sowohl beim jungen 8 Tage alten Hühnchen, bei dem die Oocyte gerade in die Ruhe eingetreten ist, wie beim zweijährigen Legehuhn, bei dem die Oocyte also ungefähr 2 Jahre in diesem Zustande verharrt sein muss. Unterschiede in der (irösse beider Eizellen bestehen nicht. Die Oocyte des achttaigigen Huhnes (Abb. 15) misst 0,0182:0,0276 mm, ihr Kern 10,5:14 $\mu$, ihr Kernkörperchen 2,9 $\mu$. Die Oocyte des 2 Jahre alten Huhnes (Abb. 26) hat einen Durchmesser von $0,028 \mathrm{~mm}$, ihr Kern misst $14 \mu$, ihr Kernkörperchen $3 \mu$. Das chromatische Kerngerüst zeigt auch keine wesentlichen Unterschiede, nur hat es sich bei der Eizelle des alten Huhnes von der Kernmembran vollständig auf die Mitte des Kernes zusammengezogen, wodurch der periphere Kernsaftraum entstanden ist. Dies stellt aber wohl ohne Frage eine ziemlich unwesentliche Veränderung des Kernes dar. Wie sie zustande kommt, werden wir noch sehen. Es muss nämlich bei der Weiterentwicklung der Oocyten unterschieden werden zwischen denjenigen, welche ohne längere Ruhepause sogleich die ganze Wachstumsperiode bis zur Reife durchlaufen, und denjenigen, welche in diesem Stadium bis zu späteren Legeperioden stehen bleiben und erst dann in die weitere Entwicklung eintreten.

Dieses Ruhestadium der Oocyte beschreibt $\mathrm{H}$ o $\mathrm{Il}$ als jüngstes Stadium der Eizellen des Huhnes. Bei ausgewachsenen Hühnern 
stellt es allerdings das jüngste im Ovar zu findende Stadium dar. Wie wir gesehen haben, hat die Oocyte aber schon zahlreiche, bedeutende Veränderungen durchgemacht, bis sie zu diesem Stadium gelangt. Die Maße, welche Holl für dieses Stadium angibt, stimmen mit den meinigen ziemlich überein. Auch $\mathrm{Holl}$ erwähnt schon, dass sich mit fortschreitender Entwicklung der Kerninhalt von der Kernmembran meist abhebt. Seiner Behauptung, dass immer nur ein Kernkörperchen vorkommt, kann ich nicht zustimmen; ich fand sogar ziemlich häufig zwei und ausnahmsweise selbst drei Kernkörperchen.

Ich habe die Entwicklung der Oocyten bis zu diesem Stadium in fünf Perioden eingeteilt. Jede derselben ist durch wichtige Veränderungen in der Kernstruktur charakterisiert, $z u$ denen dann noch einige nebensächliche Vorgänge hinzutreten. Die Charakteristika der einzelnen Perioden sind:

I. Chromatinbildung,

II. Anordnung des Chromatins am Fadenwerk des Kernes, also Verarbeitung des Chromatins,

III. Längsteilung der Chromosomen,

IV. Bildung eines Nukleolus,

V. Dickenwachstum der Chromosomen.

D'Hollander, der die Oogenese des Huhnes selur eingehend untersucht hat, stellt dagegen elf verschiedene Stadien auf. Meine Befunde decken sich so ziemlich mit den seinigen, von einigen wenigel wichtigen Punkten abgesehen. Seine Einteilung in elf Stadien lalte ich wohl für berechtigt, aber doch nicht für zweckmässig. Hierdurch werden unwesentliche Veränderungen den wichtigen vollständig gleichgestellt, dabei aber die leitenden Motive verschleiert.

Verfolgen wir zunächst die Oocyterkerne, welche bis zu späteren Legeperioden im Ruhestadium bleiben. Bei einem 21 Tage alten Huhne sehen wir (pag. 432) das chromatische Knäuel sich von der Kernmembran loslösen. Zunächst tritt nur ein schmaler halbmondförmiger spalt auf, der sich nach und nach um den ganzen Kern ausdehnt (pag. 433 f.). Dieser Spaltraum wird von dem hellen Kernsafte ausgefüllt. Bei einem zwei Monate alten Huhn (pag. 434) liegt das Knäuel schon vollständig frei inmitten des vom Kernsaft erfüllten Keimbläschens. Dasselbe zeigt eine Oocyte eines vier Monate alten Huhnes (Abb. 23). 
Diese Bilder zeigen zahlreiche Oocytenkerne alterer Hühner. Es dürfte als Beweis für die Erhaltung dieses Stadiums genügen, noch die schon erwähnte Oocyte des zweijährigen Huhnes anzuführen (Abb. 26), welche ein zentralliegendes chromatisches Knäuel mit einem Nukleolus und breitem ringförmigen Kernsaftraum zeigt. In welcher Weise geht diese Loslösung des chromatischen Knäuels von der Kernmembran vor sich? Beruht sie auf einer Retraktion des Knäuels oder auf einer Grössenzunahme des Kernes, während das Knäuel auf seiner bisherigen Grösse stehen bleibt? Eine Vergleichung der Maße der alteren Eier im Ruhestadium mit dem Ei in Abbildung 15 zeigt, dass beides der Fall ist. Das chromatische Knäuel hat anfangs die Grösse des Kernes, also 10,5:14 $\mu$. Das chromatische Knauel misst später durchschnittlich 10-12 1 , während der Kern 14-16 im Durchmesser hat. Das Knünel hat sich also etwas enger zusammengezogen und ist dadurch dichter geworden. Der Kern hat aber an Umfang wenn auch nur wenig zugenommen. Diese 'Zunahme beruht allein auf einer Vermehrung des hellen Kernsaftes. Da eine wesentliche Veränderung des chromatischen Kernbestandteiles nicht eingetreten ist, ist man wohl berechtigt, die Bilder aller dieser Kerne als ein Stadium aufzufassen, welches als Ruhestadium bezeichnet werden muss.

Bei der weiteren Entwicklung der Keimbläschen kann man anfangs, solange noch ein geschlossenes chromatisches Knäuel existiert, wohl noch unterscheiden, ob die Oocyte früher oder später aus dem Ruhestadium ausgetreten ist. Geht die Oocyte in ihrer Entwicklung gleich weiter, so füllt das chromatische Fadengerüst den Kern immer fast ganz aus (Abb. 17, 18, 19, 20,21 usw.). Tritt die Oocyte erst in späteren Legeperioden die Weiterentwicklung an, so bleibt um das chromatische Knäuel immer ein verschieden breiter, peripherer Kernsaftraum zu sehen (Abb. 24 und Eikern der Oocyte von 0,055:0,071 mm auf pag. 435). Mit dem Zerfall der Chromosomen verliert sich dieser Unterschied.

Der nun folgende Hauptteil der Wachstumsperiode der Oocyten des Huhnes ist schon mehrfach Gegenstand eingehender Untersuchungen gewesen. Die grössten und wichtigsten Arbeiten hierzu lieferten $\mathrm{Holl}$ und Loyez; einzelne Beobachtungen hierzu tinden sich noch bei anderen Autoren. An den Oocyten setzt jetzt ein ausserordentliches Wachstum ein, das sich auf den 
Eileib und auf den Kern erstreckt. Je weiter fortgeschritten das Kernstadium ist, in desto grösserem Maße nimmt das $\mathrm{Ei}$ an Umfang zu; es findet eine progressive Steigerung des Wachstums statt. In den letzten Stadien vor der Reifung nehmen die Eier ganz ausserordentliche Dottermassen auf; nach der Zahl der vorgefundenen grossen Follikel berechne ich die Zeit, in der dieselben von etwa $6-8 \mathrm{~mm}$ Durchmesser bis zur Reife mit einer ungeführen Grösse von $40 \mathrm{~mm}$ anwachsen, auf etwa eine Woche. Denn im Durchschnitt zeigten meine Hühner drei bis vier grosse Follikel. Ein nur einigermaßen gutes Legehuhn legt jedoch ebensoviel Eier in einer Woche: der Bestand an grossen Follikeln muss demnach in einer Woche vollstandig erneuert werden. Ein Follikel wichst also in dieser Zeit von $6-8 \mathrm{~mm}$ auf ca. $40 \mathrm{~mm}$ an.

VI. Die erste Periode nach dem Ruhestadium ist dadurch charakterisiert, dass der Kernsaft eine Veränderung eingeht. Auf pag. 430 ist eine Oocyte beschrieben, welche die ersten Zeichen der weiteren Entwicklung zeigt. Der Kernsaft verliert allmällich seine wasserhelle Beschaffenheit. Feinste Körnchen finden sich darin suspendiert. Gleichzeitig erhalten die chromatischen Fäden in ihrem Verlaufe körnige Verdickungen. Mit der Grössenzunahme der Eier treten diese Veränderungen immer deutlicher hervor (Abb. 17). Der Kernsaft wird immer dichter gekörnt und infolgedessen dunkler. Das chromatische Fadenwerk lässt jetzt von der Kernmembran los, sodass eine allerdings nur sehr schmale periphere Randzone entsteht, die nur von Kernsaft erfüllt ist. Die im Kernsaft enthaltenen Körnchen legen sich der Innentläche der Kernmembran in grösserer Menge an; infolgedessen nimmt die Körnung des Kernsaftes bald gegen die Kernmembran hin zu, hier entsteht ein schmaler dunklerer Streifen (pag. 431, Abb. 19). Bei gut fixierten Eiern (Abb. 19) ruft dieser Randsaum ganz den Eindruck hervor, als ob sich eine zweite Kernmembran zu der äusseren sich als einfache scharfe Linie zeigenden gebildet hat. D'Hollander beschreibt in diesem Stadium eine doppelte Kernmembran, eine innere cytoplasmatische, doppelt konturierte und eine äussere, sehr feine, häufig glänzende mit einfachem Kontur. D'Hollander beruft sich zum Beweis für die doppelte Kernmembran auf die gut erhaltenen Kerne, die keine Schrumpfung zeigen. Diese geben allerdings das Bild einer doppelten Kernhülle. In diesem Falle beweisen uns aber gerade die Schrumpfungsbilder 
(pag. 431), dass der Kernsaft und der dunkler granulierte Randsaum zusammengehören, dieser also ein Teil des Kernsaftes ist und nicht als Kernhülle aufgefasst werden kann. Holl und Loyez erwähnen in diesem Stadium noch nichts von einer doppelten Kernmembran.

Das Kerngerüst setzt sich aus mehreren einzelnen Fäden zusammen, in einzelnen Kernen lassen sich paarweise Verschlingungen derselben gut verfolgen (Abb. 15 und 18). Die Fäden werden immer unregelmüssiger und zeigen Verdickungen und Höckerchen (Abb. 17 und 18). Diese Aufrauhung und Quellung der Fïden nimmt immer mehr zu, sie zeigen sich bald in ihrem Verlaufe knotig verdickt. D'Hollander spricht in diesem Stadium ebenfalls von "Füden" der chromatischen Kette. Dagegen beschreibt Loyez einen besonders langen, verschlungenen und geknauelten Faden. Holl lasst es unentschieden, ob nur ein Faden oder mehrere das Kernnetz bilden. Im vorhergehenden Stadium spricht el von den Fiiden des Kernes, ebenfalls in spaiteren Stadien; es ist nach seiner Beschreibung nicht recht ersichtlich, weshalb el gerade in diesem Stadium mehr zu einem Faden hinzuneigen scheint. Nach meinen Präparaten halte ich es für fraglos, dass das chromatische Knäuel aus mehreren Füden zusammengesetzt ist, die sich auch wahrscheinlich alle paarweise verschlingen.

In dieser Periode habe ich bei allen Oocyten, welche im Ruhestadium nicht längere Zeit stehen blieben, immer mindestens einen Nukleolus gefunden (Abb. 15 und 18), einige Male auch zwei (Abb. 17). Auch Holl und d:Hollander schreiben dieser Periode ein Kernkörperchen zu. Loyez hat kein Kernkörperchen gefunden. Dies führe ich darauf zurück, dass sie wahrscheinlich nur ältere Hühner zu ihren Untersuchungen benützt hat, bei denen das Kernkörperchen früher zerfällt.

Die Grösse der Eier ist in dieser Periode bis auf etwa $0,060 \mu \mathrm{im}$ grössten Durchmesser angewachsen. Der Kern misst nur bis $25 \mu$. Auch das chromatische Knäuel hat sich entsprechend ausgedehnt; es füllt den Kern bis auf den schmalen verdichteten Randsaum aus. Die Verdichtung und Trübung des Kernsaftes und die körnige und variköse Beschaffenheit der Chromosomen tritt auch an Eikernen bei älteren Hühnern auf (Abb. 24 und Oocyte von 0,055:0,071 $\mathrm{mm}$ auf pag. 435). Bei diesen Oocyten sind die Maße etwas grösser. Das Kernkörperchen ist aus ihren 
Kernen meist schon verschwunden. Das chromatische Knäuel, welches sich nach dem Zentrum zusammengezogen hat, lockert sich mehr und mehr auf und sucht dadurch den Kernraum in grösserem Umfange auszufüllen. Einzelne Chromosomen lösen sich dabei häufig in grosser Länge ron dem Knäuel los und strecken sich füblerartig oft bis zur Fernmembran aus (Oocyte von $0,055: 0,071 \mathrm{~mm}$ auf pag. 435). Ich habe diese Präparate immer wieder untersucht und immer hatte ich den Eindruck, als ob in einigen Fällen die Chromosomen oder Teilchen von ihnen die Kernwand durchbohrten. Aussen lagen dem Kern an diesen Stellen dann chromatische Körner, Brocken etc., oder die Körnerringe mit hellem Zentrum an. Meine sämtlichen Untersuchungsbefunde hierüber schon jetzt $z u$ veröftentlichen, ist mir jedoch noch nicht möglich.

VII. Während die Chromosomen immer rauher und knotiger werden, fängt das Kernkörperchen an, zu zerfallen. Dieser Zerfall beginnt zu ganz verschiedenen Zeiten und zieht sich auch verschieden lange hin. Bei den Oocyten, welche sich längere Zeit im Ruhestadium aufhalten, setzt schon in diesen allmählich der Zerfall des Kernkörperchens ein. Bei frühzeitiger Weiterentwicklung beginnt der Zerfall dagegen erst dann, wenn der Kernsaft schon verdichtet ist und die Chromosomen angefangen haben, sich zu verändern. In beiden Fällen gestaltet sich der Zerfall des Kernkörperchens gleich. Bisher war der Nukleolus immer kugelrund oder ovoid und hatte eine glatte glanzende Oberfläche. Die ersten Veränderungen bestehen darin, dass die Oberfläche rauh wird. Es zeigen sich daran feine Körnchen und kleine Zacken und Spitzen (pag. 433 f,, Abb. 20, 21 und 24). $\mathrm{Ob}$ die Körnchen an seiner Obertläche schon als Zerfallserscheinungen aufzufassen sind, ist fraglich: es können auch Körnchen des Kernsaftes sein, die sich dem Kernkörperchen angelagert haben. Die Fortsätze werden oft sehr lang, einzelne kleinere oder grössere Stückehen trennen sich vom Kernkörperchen und bilden besondere chromatische Brocken (Abb. 24). In dieser Weise zerbröckelt das Kernkörperchen immer mehr. Schliesslich finden wir nur noch einen Haufen chromatischer Brocken (Abb.20,21). Reste des Kernkörperchens fand ich noch mit Sicherheit in einem Keln von $125 \mu$ (pag. 435). Der Kern zeigt schon Chromatinfadenstrannge. Holl gibt noch ein Kernkörperchen bei einem 
$81,6 \mu$ grossen Kerne an. Das von ihm in Fig. 7 aus einem 117 " grossen Kern gezeichnete strahlige Gebilde halte ich eher für einen Gerüststrang im Querschnitt, als für die Auflösungsfigur eines Nukleolus. Derartige strahlige Auflösung habe ich beim Kernkörperchen nie gefunden, sondern immer nur Zerfall in Bröckeln und Körnchen. Diese Bröckeln scheinen sich manchmal an ihrer Oberfläche abzuglätten und bilden dann Nukleolen (Abb. 20). Diese Zerfallsperiode des Kernkörperchens läuft neben den Veränderungen der Chromosomen zu Chromatinfadensträngen und deren Zerfall einher. Sie setzt in verschiedenen Stadien ein und hört dementsprechend auch zu verschiedenen Zeiten auf. Es lässt sich aber die Regel aufstellen, dass die früher zur Reifung fortschreitenden Oocyten ihr Kernkörperchen am längsten behalten, während sehr spät dazu übergehende Eier ihr Kernkörperchen schon verloren haben, wenn die ersten Veränderungen an den Chromosomen und die Trübung des Kernsaftes sich zeigen. Das drei Monate alte Huhn 93 zeigt schon zahlreiche im Ruhestadium verbleibende Oocytell, bei denen das Kernkörperchen schon Zerfallserscheinungen aufweist; bei einigen ist es sogar schon verschwunden.

VIII. Neben der Auflösung des Nukleolus einhergehend beginnt der Zerfall der Chromosomen. Die Körnung und knotige Verdickung derselben wird immer stitrker. Dabei zerfallen die Fäden in bröcklige Stückchen oder Kugeln, die aber noch zu einem fadenartigen Gebilde zusammengehalten werden. In einigen Füllen bilden sich vollständige Kugelreihen aus, die ganz wie Perlschnüre oder Streptococcen aussehen (Abb. 19). Dieser Querbau der Fäden in einem gewissen Stadium ist $\mathrm{Holl}$ aufgefallen. Seine Abbildung 4 zeigt ebenfalls diese Perlschnüre, nur beschreibt er sie nicht so. Loyez hat diese Periode gar nicht erwähnt. Sie scheint auch nur kurze Zeit zu bestehen und es finden sich gleichzeitig immer neben diesen Streptococcen noch Chromosomen der frïheren (Abb. 19) oder schon solche der nächsten Periode (pag. 437). Da diese Bilder nur selten im ganzen Kern rein auftreten, bilden sie nur ein schnell vorübergehendes Stadium in der ganzen Periode des Zerfalls der Chromosomen. Die Oocyten sind jetzt ungefähr bis auf $0,080 \mathrm{~mm}$, deren Kerne bis auf $30 \mu$ angewachsen; auch das chromatische Knäuel hat in demselben Maße an Umfang zugenommen. 
Die körnig-bröckligen, aus kleinen Stückchen oder Kiugeln sich zusammensetzenden Fadengebilde erhalten kleine Spitzen und Fortsätze, die sich nach allen Seiten erstrecken. Zunächst sind die Fortsätze nur fein und kurz (Abb. 20, 21 und pag. 434). Die Querfaserung wird etwas verschleiert durch die sehr feinen Körnchen, die sich den Fadengebilden angelagert haben. Die Anordnung der querfaserigen, körnigen Fadenzüge ist im Innern des Kernes regellos, nach dem Rande zu, ron dem sie durch die etwas breiter gewordene verdichtete Kernsaftzone getrennt bleiben, verlaufen sie in ringförmiger Anordnung der Kernmembranlinie parallel. Oft zeigen einzelne Fadengebilde scheinbare Verzweigungen. $0 \mathrm{~b}$ dies wirklich der Fall ist, möchte ich bezweifeln. Denn häufig genug kann man bei genügend dicken Schnitten zwei Gebilde eine längere Strecke verfolgen und sehen, dass sie sich parweise verschlingen, in derselben Weise, wie es die Chromosomen schon mehrfach in früheren Stadien gezeigt haben. Die Stellen, welche scheinbare Verzweigungen zeigen, tiuschen ohne Frage, da bei sehr feinen Schnitten die Chromosomengebilde nicht genügend lang verfolgt werden können, besonders nicht an den Kreuzungsstellen, an denen ja immer durch die Windungen der Fïden Verïnderungen in der Lage eintreten. Diese Gebilde, bei denen die (Querfaserung nur schmal und noch nicht vollständig ausgeprägt ist, finden sich in Eikernen von etwa 40-70, , die Oocyten messen bis ungefuhr $0,150 \mathrm{~mm}$. Wit fortschreitendem Wachstum bilden sich diese querfaserigen Chromosomen zu den bekannten Chromatinfadensträngen (Born) aus. Die Fasern und Fortsiitze erstrecken sich immer weiter in den Kernsaft hinein. Die anfangs noch ziemlich gestreckten Querfasern drehen und winden sich dann haarlockenähnlich durcheinander. In dem Gewirr derselben und infolge der starken Körnung des Kernsaftes verschwinden die freien Enden der einzelnen Fasern (Abb. 22). Die Körnung des Kernsaftes ist so stark geworden; dass häutig Körner als kleine Nukleolen erscheinen. Ein scharfer, dunkel gefürbter Acbsenfaden bildet die Grundlage der Chromatinfadenstränge, von dem nach allen Seiteu die verschlungenen und mit feirsten Körnchen bedeckten Fasern sich weit ausstrecken. An einzelnen Gebilden scheint der Achsenfaden sich aus ungefähr gleichlangen Stücken zusammenzusetzen. Ob die feinen Querfasern wieder noch Nebenästchen haben. oder ob diese nur durch die Verschlingungen 
der Fasern und durch die Übersäung mit Körnchen vorgetäuscht werden, lässt sich nicht entscheiden. Die Fasern scheinen sich in die feinsten Körnchen aufzulösen, die dann im Kernsaft frei auftreten. Auf dem Querschnitte zeigen sich die Chromatinfadenstränge als strahlige Flecken oder Punkte. Dass grösste Ei, welches diese Gebilde noch hinreichend deutlich, aber doch schon etwas verschwommen zeigte, maß 0,615:0,705 $\mathrm{mm}$ und hatte einen Kern von $125 \mu$ (pag. 435). Dieser Kern hat sich der Oberfläche des Eies noch nicht genähert. Am besten ausgebildet sind die Chromatinfadenstränge in Kernen von etwa $100 \mu$ Grösse. Holl beschreibt die Chromatinfadenstränge bei Oocyten des Huhnes von 0,292:0,491 mm, deren Kerne 81,6 und $117 \mu$ gross sind, als Gerüststränge. Loye $z$ beschreibt sie als filaments barbelés rayonnants, gibt aber gar keine Angaben über die Grösse der Kerne.

Diese unter den verschiedensten Bezeichnungen wie Chromatinfadenstränge, Gerüststränge, Flaschenbürsten, Lampenputzer etc. geschilderten Gebilde fand zuerst Flemming im Amphibienei. Rückert fand diese Gebilde bei Selachiern in paarweiser Verschlingung. Er schloss daraus auf eine Vereinigung derselben. In den Oocytenkernen des Huhnes habe ich diese paarweise Verschlingung in fast allen Stadien nach der Längsteilung der Chromosomen verfolgen können. Es handelt sich jetzt, wo die Chromatinfadenstränge dem vollständigen Zerfall entgegengehen, wohl nicht um eine Vereinigung derselben. Die paarweise Verschlingung hat sich bis jetzt von der Teilung her erhalten. Jedes Paar der Chromatinfadenstrănge ist aus einem Chromatinfaden entstanden.

Das Kernkörperchen hat sich in einzelnen Fällen noch bis zu dieser Periode erhalten, wenigstens in Überresten, meistens und immer bei sich später entwickelnden Oocyten ist es schon längst verschwunden. Der an Menge bedeutend vermehrte Kernsaft ist sehr stark gekörnt. Die einzelnen Körnchen von zum Teil bedeutender Grösse färben sich kräftig. Um das Knäuel der Chromatinfadenstrănge bleibt ein verschieden breiter, peripherer Saum, der nur von Kernsaft angefüllt ist. Die Kermembran zeigt sich als oft sehr starke, einfache Linie, die einen geraden oder schwach welligen Verlauf nimmt. Ihrer Innentläche liegen Körnermassen dicht an. Ich kann diesen Belag aber nicht als 
zweite Membran bezeichnen, wie Loyez, die in diesem Stadium von einer doppelten Membran spricht. Der Auffassung Holls, dass der unregelmässige Verlauf der Kernmembran in jedem Falle ein Kunstprodukt ist, kann ich mich nicht anschliessen. In allen früheren Stadien war bisher immer die Kernmembran vollständig glatt; sie zeigte dementsprechend keine Ein- und Ausbuchtungen. Dieser regelmässige Verlauf schwindet in diesem Stadium. Die Kernmembran erhält an ihrer Obertlache Eindrücke und Buckel, die im Querschnitt eine wellige Limie hervorrufen. Diese unregelmässige Beschaffenheit tritt immer stärker bei dem weiteren Wachstum hervor und die vollstindig einwandfrei fixierten und gut erhaltenen Eikerne nahezu reifer Follikel zeigen eine unregelmilssige und selbst gefaltete Kernmembran. Auch Loyez beschreibt einen unregelmässigen Verlauf der Kernmembran.

IX. Mit der fortschreitenden Entwicklung der Oocytenkerne verlieren die Chromatinfadenstränge immer mehr ihren faserigen Bau. Schon bei dem 165:190 $\mu$ grossen Kerne in Abbildung 25 zeigen sich keine Fasern mehr. Die Überreste der Chromatinfadenstränge stellen körnige, dunklere Flecken, Strassen oder Züge dar, die mehr oder weniger scharf begrenzt in den gekörnten Kernsaft übergehen. Diese Körnerzüge blassen allmüblich auch immer mehr ab. Sie erscheinen wie Schatten der Chromatinfadenstrănge (pag. 436). L o y z $z$ beschreibt diese lïrnerzüge ebenfalls als Reste der filaments rayonnants. Sie erklärt die Entstehung der Körnerzüge durch Zerfall und Verlust der Färbbarkeit der Chromosomen. Nur den ersteren Grund kann ich gelten lassen. Der körnige Zerfall der ursprünglich faserigen Gebilde tritt $\mathrm{zu}$ deutlich hervor. Die einzelnen Körnchen - das Zerfallsprodukt - zeigen sich in dem dunkler werdenden Kernsafte. Verlust der Farbbarkeit ist wohl nur eine Annabme, die sich gar nicht beweisen lässt. Holl zeichnet diese Körnerzüge in einem Kern von 129: מ1 $\mu$ einer 0,620 mm grossen Fizelle; er beschreibt sie als Reste der Gerüststränge. Auffallend ist hierbei, dass der Kern dieser noch relativ kleinen Oocyte schon nach der Oberfläche gerückt ist. Der Kern in Abbildung 25 und auch der auf pag. 436 haben sich beide der Oberfläche noch nicht genăhert, obwohl sie und auch die zugehörigen Eier bedeutend grösser sind, als das von $\mathrm{H}_{0} l l$ angeführte. Das kleinste Ei, dessen Kern in der Nähe der Oberfläche lag, hatte 
eine Grösse von 0,945:1,035 mm mit einem Kern von $192: 132 \mu$. Hieraus und aus dem Hollschen Befunde folgt, dass die Wanderung des Kernes zur Oberfliche des Eies zu ganz verschiedenen Zeiten eintritt. Diese ist deshalb wohl kaum von der Grösse des Eies oder des Kernes abhängig, sondern der Grund wird in den verschlechterten Ernährungsverbaltnissen, welchen der Kern inmitten des Eies ausgesetzt ist, zu suchen sein. Loyez macht keine Angaben darüber, wann der Kern sich der Eioberfläche nähert.

Die Auflösung der Chromatinfadenstränge schreitet noch weiter fort. Auch ihre letzten Reste - die körnigeren Züge und Inseln - verlieren sich immer mehr im Kernsaft. Damit sind die chromatischen Gebilde des Kernes vollständig in feinste Körnchen aufgelöst; die im Kernsaft verstreut liegen. Irgendwelche an Chromosomen erinnernde chromatische Bildungen treten bei keiner Färbung hervor. Die im liernsaft suspendierten Körnchen ordnen sich aber nun zu einer Art von Stützgerüst für den Kern all. Es entsteht ein körniges Netzwerk, welches den Kern vollständig durchsetzt (Abb. 27). Die körnigen Züge verlaufen vorwiegend in senkrechter Richtung; die Maschen des ganzen Netzwerkes werden von hellerem Kernsafte ausgefüllt. I)ieses stützgerüst erhält sich während der ganzen weiteren Wachstumsperiode und bildet die Grundlage jedes älteren Keimbläschens, blasst jedoch bei den alteren Kernen immer mehr ab. Holl erwähnt dieses körnige Netzwerk nur bei dem Kern eines $30 \mathrm{~mm}$ grossen Follikels. Lo ye $\mathrm{z}$ hat dieses Stadium des körnigen Zerfalls ganz übergangen. Sie lässt aus den diffusen Körnerzügen (den Resten der filaments rayonnants) die Chromosomen sich in Form feiner Fäden wieder herstellen.

Der Oocytenkern des Huhnes ist jetzt in einem Stadium feinster Chromatinverteilung angelangt, von Chromosomen zeigt sich nichts. Die Individualität der Chromosomen trifft also für die Oocyte des Huhnes nicht zu. Hierin muss ich den Untersuchungen und Schlüssen von Carnoy, Fick etc. bei anderen Arten zustimmen. $O b$ die Chromosomen bei einigen Arten, wie die Arbeiten Borns, Rückerts etc. ergeben haben, tatsächlich erhalten bleiben, kann nur durch erneute, eingehende Untersuchungen festgestellt werden. Die Grösse der Eier beträgt jetzt 
ungefähr 1 bis $1,5 \mathrm{~mm}$ im Durchmesser. Der Kern hat sich jetzt der Oberfläche genahert.

Haben wir dieses Aufsteigen des Kerns zur Eioberttache als eine wirkliche aktive Wanderung aufzufassen, oder beruht es darauf, dass das Keimbläschen spezifisch leichter wird als der Dotter? In den Eiern, bei denen der Kern die Oberflache eben erst erreicht hat, anch noch in Eiern von einigen Millimetern Durchmesser, findet man den Kern an den verschiedensten Stellen del Obertlache. Ich habe, um jede Verlagerung auszuschliessen, die Ovarien an dem darüberliegenden Stücke der Wirbelsăule gelassen und hieran hängend - also in normaler Lage - in die Fixierungstlüssigkeit gebracht. Da ich trotzdem das Keimbläschen an jeder Stelle der Obertliche fand, kann ich nur annehmen, dass es sich aktiv nach der Eioberfläche hin bewegt und wahrscheinlich immer nach dem zunächst liegenden Punkte derselben. Für Amphibien nehmen Fick und Stohmann auch eine aktive Wanderung des Keimbläschens zur Oberflüche an, da dasselbe beim Froschei immer am schwarzen Pol (Richtungspol) zu finden ist, selbst wenn dieser im Ovar nach unten oder seitwärts liegt. Das Keimbläschen der Hühneroocyte bleibt jedoch nicht an jeder beliebigen Stelle der Obertläche liegen. In ungefähr allen grossen Follikeln fand ich es am Stielpole oder höchstens $5-7 \mathrm{~mm}$ vom Stiel des Follikels entfernt. Welchen Gesetzen diese zweite Wanderung unterliegt, und ob sie überhaupt aktiv aufzufassen ist, ist mir nicht gelungen zu entscheiden.

Die vom Ruhestadium an bis zur vollständigen Auflösung der chromatischen Substanz verfolgte Entwicklung geht nur sehr langsam vor sich. In diesen Perioden des Zerfalls verbleiben die Eikerne lange Zeit. Das geht schon aus der sehr grossen Zahl der in den einzelnen Stadien dieser Perioden befindlichen Kerne hervor und aus der Mannigfaltigkeit der entstehenden Bilder. Die einmal zur Weiterentwicklung übergegangenen Eikerne schreiten dann rasch darin fort. Es scheint, als ob die bisher langsame Entwicklung ihren Grund in den schlechten Ernährungsverhältnissen des mitten im Ei liegenden Kernes hat. Jetzt hat der Kern die Obertläche erreicht und ist damit wieder in bessere Ernährungsverhältnisse gelangt. Nun schreitet auch die weitere Entwicklung fort. 
X. In den Eikernen wenig grösserer Oocyten wird das ganze Zentrum von tiefschwarz gefärbten, glänzenden, kugeligen Körpern - chromatischen Nukleolen - angefüllt (pag. 437, 441 und 445 ). Der Nukleolenhaufen ist nach aussen ziemlich scharf begrenzt und um denselben bleibt noch eine verschieden breite, nur von dem Kernsaft und seinem Netzwerke eingenommene periphere Zone frei. Diese Nukleolenbildung, wie sie bei vielen anderen Arten schon festgestellt ist, wurde bisher immer bei den Vögeln geleugnet. Auch L o ye z schreibt: Hier - bei den Vögeln gibt es keine Nukleolenbildung wie bei Reptilien. Die bedeutende Grösse, wie bei anderen Tieren, haben die Nukleolen in den Eikernen des Huhnes nicht, aber sie treten so deutlich und klar als kugelige Gebilde von 1 bis $1,5 \mu$ Grösse hervor, dass sie nur mit diesem Namen bezeichnet werden können. Über ihre Entstehung lässt sich nichts bestimmtes sagen. Es scheint, als ob die feinen Körnchen im Kernsaft zu Nukleolen anwachsen. Die Eier haben jetzt im grössten Durchmesser schon fast $2 \mathrm{~mm}$ erreicht.

XI. Schon ein Ei von 1,86:2,025 mm (pag. 438) zeigt die Neubildung von Chromosomen. Auch dieser Kern besitzt den zentralen Nukleolenhaufen. In demselben finden sich aber an verschiedenen Stellen nukleolenfreie Flecke, in denen die Chromosomenbildung vor sich geht. Diese zeigen sich anfangs nur als ganz zarte Körnerlinien; je zwei Chromosomen umschlingen sich sehr locker. Es ist wohl anzunehmen, dass die Chromosomen sich aus der Substanz der Nukleolen bilden; denn diese verschwinden in der Umgebung der neuen Chromosomen. Abbildung 32 und die Eikerne des 1,890:2,700 mm grossen Follikels (pag. 437), des 2,18:2,60 mm grossen Follikels (pag. 439), des 2,43:3,25 mm grossen Follikels (pag. 448), des 2,52:3,36 mm grossen Follikels (pag. 446), des 2,97:3,24 mm grossen Follikels (pag. 441) und des $3 \mathrm{~mm}$ grossen Follikels (pag. 439) zeigen diese zarten Chromosomen in dem Nukleolenhaufen. Die Chromosomen bilden sich bald zu feinen scharfen Fäden aus. Die chromatischen Nukleolen nehmen dabei an Menge ab. Die Verschlingungen der Chromosomen werden enger und dichter. Vorläufig liegen sie noch verstreut in dem Nukleolenhaufen (Eikerne des 3,054:4,644 mm grossen Eies auf pag. 436, des Follikels von $4,32: 5,13 \mathrm{~mm}$ auf pag. 445 und des Follikels von $5 \mathrm{~mm}$ auf pag. 442 ). 
Sobald sich die Chromosomen zu vollstandig glatten, tiefschwarz gefärbten, aber feinen Fäden ausgebildet haben, ziehen sich die Chromosomenpaare nach dem Zentrum des Eikernes zusammen. Der Nukleolenhaufen zieht sich gleichfalls zusammen und nimmt einen kleineren Umfang an. Die Chromosomenpaare liegen jetzt in einem dichten Haufen im Mittelpunkte des Kerns. Zunächst umgibt diese noch der verkleinerte Nukleolenlaufen (Abb. 28 und der Eikern des Follikels von $7 \mathrm{~mm}$ auf pag. 447). Der Nukleolenhaufen verschwindet nach und nach ganz. Die chromatische Substanz der Nukleolen wird zur vollständigen Ausbildung der Chromosomen verbraucht. Die Chromosomenpaare bleiben jedoch im Zentrum des Kernes, häufig zu einem Gewirr vereinigt, liegen (Eikern des Follikels von $9 \mathrm{~mm}$ auf pag. 445). Dieses Gewirre lockert sich nun etwas anf; die Chromosomenparre behalten aber ihre Lage in der Vitte des Kernes bei. Alle untersuchten Follikel von $11 \mathrm{~mm}$ auf pag. 445 , von $12 \mathrm{~mm}$ auf pag. 442 , von $13 \mathrm{~mm}$ auf pag. 440 (Abb. 29), von $1 \pm \mathrm{mm}$ auf pag. 447 , von $15 \mathrm{~mm}$ auf pag. 442 , von $16 \mathrm{~mm}$ auf pag. 440 , von $18 \mathrm{~mm}$ auf pag. 447 , von $19 \mathrm{~mm}$ anf pag. 446 zeigen dies. Nur steigt der Chromosomenkomplex etwas näher nach der OberHäche des Kernes zu auf. Die Chromosomenpaare umschlingen sich in ganz verschiedenen, unregelmässigen Formen; es entstehen dabei sehr weite (Abb. 35) und sehr enge Schlingen. Die Zahl der Windungen bei den einzelnen Chromosomenpaaren ist ganz verschieden. Häufig liegen die Paare nicht gestreckt, sondern stark gekrümmt und mit den Enden zusammengebogen. Die Zahl der Chromosomenpaare mit absoluter Sicherheit zu bestimmen, war mir trotz des grossen Materiales nicht möglich. Ich habe Schwankungen zwischen 8 und 16 Paaren erhalten. Am häufigsten fand ich 11 und 12 Paare. Es ist hiernach anzunehmen, dass die richtige Zahl der Chromosomenpaare 12 ist.

L o yez beschreibt die Chromosomenpaare als einen in Achtertouren stark um sich selbst gewundenen Faden. Es kommen allerdings einige Gebilde vor, die scheinbar aus einem Faden bestehen, aber viel zahlreicher sind die Fälle, in denen klar und deutlich die freien Enden der Fäden sichtbar sind.

Gleichzeitig lässt sich an dieser ganzen Reihe von Kernen verfolgen, wie sich der Kern mit der Grössenzunahme des Eies immer mehr abplattet, er nimmt ständig etwas an Breite zu und 
wird entsprechend dünner. Von einer Grössenzunahme des Kernes lässt sich wohl kaum reden; dagegen nimmt die Obertläche des Kernes bedeutend zu.

XII. Sobald die Grösse der Follikel über $20 \mathrm{~mm}$ hinausgeht, stellen sich neue Veränderungen an den Chromosomenparen ein. Die Fäden werden kürzer und dicker. Infolgedessen nimmt die Zahl der Umschlingungen ab, und wir sehen sie dann einfache elliptische Ösen bilden. An den Polen dieser Ösen zeigen sich anfangs noch die freien Enden der einzelnen Fäden. Bald verschmelzen diese aber und die Ösen enthalten dann an jedem Ende einen kurzen dicken Polfaden. Es ist also zu einer Vereinigung der beiden verschlungenen Chromosomen zu einem Gebilde gekommen. Ist dies die Amphimixis R ü ckerts? Jedenfalls ist die Vereinigung nicht im Sinne einer Selbstbefruchtung $z u$ deuten. Es findet nur die Wiedervereinigung der Chromosomen statt, die in einem früheren Stadium durch Lüngsteilung aus einem Faden entstanden sind. Diese Gestalt behält die chromatische Substanz bis zum Platzen des Follikels bei. Erst dann gehen die Verïnderungen der Reifungserscheinungen vor sich, zu deren Untersuchung ich leider kein allen Anforderungen entsprechendes Material erhalten konnte. Die Ösenbildung geht in Kernen von 20-27 $\mathrm{mm}$ grossen Follikeln vor sich, die einzelnen Stadien zeigen Abbildung 30, 34, 35 und die Eikerne des $22 \mathrm{~mm}$ grossen Follikels auf pag. 440 , des $26 \mathrm{~mm}$ grossen Follikels auf pag. 447 und des $27 \mathrm{~mm}$ grossen Follikels auf pag. 443. Die grösseren Follikel zeigen Ösen in den verschiedensten Graden der Ausbildung: Abbildung 31 und die Eikerne des $29 \mathrm{~mm}$ grossen Follikels auf pag. 446, des $30 \mathrm{~mm}$ grossen Follikels auf pag. 443, des $32 \mathrm{~mm}$ grossen Follikels auf pag. 441 und des ebenso grossen Follikels auf pag. 446. Holl hat die chromatischen Bildungen der 10 . bis 12 . Periode nicht gefunden. Die von ihm in dem 40:35 mm grossen Follikel gefundenen Stäbchen sind Falten der Kernmembran (cf. pag. $443 \mathrm{f}$.).

Loyez fand die Chromosomenschleifen und auch ihre Umbildung in elliptische Ösen. Durch einen in Rückbildung befindlichèn Kern liess sie sich jedoch verleiten, in ihrer fünften Periode Zerfall und vollständiges Verschwinden der chromatischen Substanz anzunehmen. In der sechsten Periode liess sie die Chromosomenpaare wieder entstehen und eine neue Veränderung 
eingehen. Die Unrichtigkeit der ganzen von Loyez aufgestellten fünften Periode habe ich durch die in Rückbildung befindlichen Eikerne des Huhnes 37 (pag. $448 \mathrm{f}$. und Abb. 36) nachgewiesen. Die Verfolgung der Kernreihen jedes einzelnen Huhnes von mir ergibt einen unumstösslichen Beweis für die fortschreitende Entwicklung der Chromosomenpaare, von einem Versch winden derselben zeigt sich nichts. Am Ende der Wachstumsperiode nimmt auch Loyez die Hollschen Stäbchen als vorhanden an, aber scheinbar (wenigstens ihrer Beschreibung nach zu urteilen) ohne sie gesehen zu haben.

Über die Grösse der am weitesten entwickelten Eikerne macht Loyez gar keine Angabe. Holl fand seinen grössten Eikern $315 \mu$ lang und $117 \mu$ hoch. His gibt an, dass ein ausgebildeter Eikern $380 \mu$ breit und $110 \mu$ dick ist. Der Eikern des grössten von mir gefundenen Follikels von $37 \mathrm{~mm}$ ist $455 \mu$ breit und $72 \mu$ dick. Er übertrifft demnach in seiner Abplattung und deshalb wahrscheinlich auch in seinem Entwicklungsgrade alle bisher beschriebenen Kerne.

Die gesamte Wachstumsperiode der Oocyte des Huhnes zerfullt in zwei Abteilungen. Die erste bildet die Entwicklungszeit des Oocytenkernes von seinem jüngsten Stadium bis zur Ruhe. In dieser Zeit werden die Chromosomen ausgebildet, es geht eine Längsteilung an diesen vor sich und es entsteht ein Kernkörperchen. Diese Entwicklungszeit lässt sich in folgende fünf schon auf pag. 456 angeführten Perioden zerlegen:

I. Chromatinbildung,

II. Anordnung des Chromatins am Fadenwerk des Kernes - also Verarbeitung des Chromatins,

III. Längsteilung der Chromosomen,

IV. Bildung eines Nukleolus,

V. Dickenwachstum der Chromosomen.

Die zweite Abteilung bildet die eigentliche Wachstumsperiode. Denn in ihr geht die ausserordentliche Grössenzunahme der ganzen Eizelle vor sich. Die Veränderungen der chromatischen Substanz des Kernes in dieser Periode können nicht die Veranlassung zum Wachstum der Eizelle geben, da sie Zerfallserscheinungen darstellen. „Der Kern ist mehr das ernährungsbedürftige, als das ernährende Element der Eizelle" (Lubosch). Das kolossale Wachstum der Eizelle verschlechtert die Ernährungs- 
verhältnisse des Eikernes unbedingt. „Die Erscheinungen am Keimblaischen sind demnach eine Anpassungserscheinung des Kernes an seine veränderten Lebensbedingungen zum Zwecke der Erhaltung seiner Erbmasse" (Lubosch). Der Erhaltungstrieb gibt die Veranlassung, dass die chromatische Kernsubstanz sicb bis zur feinsten Körnchenform auflöst und dass der Kern zur Eioberflache wandert, wo er bessere Lebensbedingungen findet. Infolge der besseren Ernährungsverhültnisse entstehen aus der chromatischen Substanz neue Chromosomen. Die Wachtumsperiode der Hühneroocyte (im engeren Sinne) lässt sich nach der Ausbildung der chromatischen Substanz in folgende Perioden (an die fünf Perioden der Entwicklungszeit anschliessend numeriert) einteilen:

VI. Veränderung des Kernsaftes,

VII. Zerfall des Kernkörperchens,

VIII. Umbildung der Chromosomen in Chromatinfadenstränge,

IX. Zerfall der Chromatinfadenstränge, überhaupt der gesamten chromatischen Substanz in feinste Körnchen. Wanderung des Kernes nach der Eiobertläche,

$\mathrm{X}$. Bildung chromatischer Nukleolen,

XI. Neubildung der Chromosomen,

XII. Umbildung der Chromosomen in ehromatische Ösen.

Meine Beobachtungen über den Dotterkern will ich noch hinzufügen, da sie insofern interessant sind, als sie zu einem Ergebnis über den Verbleib und vielleicht auch über den Zweck desselben geführt haben. In der Hühneroocyte ist der Dotterkern schon von vielen Autoren gefunden und beschrieben worden. Zuerst von Coste 1853 und Gegenbauer 1861, später von Cramer, Mertens, Holl, Schäfer, Legge, van Bambecke, Henneguy, vander Stricht, d'Hollander und L o y e $z$. Meine Untersuchungen an jungen Oocyten stimmen mit den Befunden der genannten Autoren überein. Danach ist der Dotterkern das von verschiedenen Mantelschichten umhüllte Centrosom der Eizelle. Ich übergehe es hier, dass eine grosse Zahl von Autoren alle möglichen anderen Gebilde im Eileibe für den Dotterkern gehalten hat. Das Centrosom liegt bei den jüngsten Oocyten ausserhalb des Kerns (Abb. 2). Falls es überhaupt je beim Huhne im Eikern gelegen hat, kann es also nur im Kern der Oogonie gelegen haben. Bei diesen fand es 
d'Hollander jedoch in derselben Form wie bei Oocyten. Als Gegensatz dazu will ich erwähnen, dass $\mathrm{B}$ a l b i a $\mathrm{n}$ i bei Araneiden die Ausstossung des Dotterkerns aus dem Eikern beobachten konnte. An dem Dotterkern der Hühneroncyte (corps vitellin de Balbiani) sind folgende Bestandteile zu unterscheiden (Abb. 2, 15, 17):

1. Das Centrosom ein tiefschwarzes, kleines Korn, welches

2. von einer dunklen, kngeligen Zone umgeben ist. I)ies Gebilde liegt

3. in einer hellen Intermediürzone von verschiedener Form.

4. Die Aussenzone oder Nantelschicht, dunkel gekörnt und dicht, wie die innere Zone, liegt dem Kern wie ein Schatten an und enthält das Centrosom an der breitesten Stelle.

Bei den jüngsten Oocyten umfasst die äussere Mantelschicht den Kern halbmondförmig (Abb. 2) oder auch ringförmig (pag. 425). Während der Entwicklung der Oocyte des Huhnes bleibt der Jotterkel'n in derselben Form mit dem darin befindlichen Centrosom erhalten (pag. 427 und 429); auch am Ende der Entwicklungsperiode der Oocyten zeigen ihn noch die Eier in Abb. 15 und 17 und das Ei von 0,0216:0,040 mm auf pag. 430 . In späteren Stadien konnte ich das Centrosom nicht mehr feststellen. Dagegen zeigten sich andere Gebilde in dem Dotterkernlager. Dieses umgibt das Keimbläschen jetzt häufiger ringförmig und verbreiter't sich gegen früher nur wenig an einer Kernseite (Abb. 17, 18, pag. 431).

In diesem Dotterkernlager finden sich jetzt die verschiedensten, scheinbar chromatischen Gebilde. Abb. 17 zeigt in einer 0,026:0,0315 mm grossen Oocyte melrere zarte Fäden: Pseudochromosomen. Diese Pseudochromosomen hat d'Hollander schon festgestellt, leider ohne Angabe, in welcher Periode der Oocytenentwicklung. Eine Oocyte von 0,0328:0,045う mm (pag. 431) enthält im Dotterkernlager dunkle, chromatische Brocken, Pseudochromosomen und helle Blasen; ebenso das Ei von $0,027 \mathrm{~mm}$ auf pag. 434. Ganz eigenartige Anschlüsse zeigt das Dotterkernlager der Oocyte von 0,0396:0,045 mm in Abb. 18 (pag. 432). Es finden sich drei grosse in einer Reihe liegende chromatische Brocken von hellen Hofe umgeben und in der Mantelschicht sehr deutliche einem verschlungene Pseudochromosomen. Bei einem Ei mit zwei Kernen 
(Abb. 23) quillt das Dotterkernlager seitwarts zwischen beiden Kernen hervor. Alle diese im Dotterkernlager gefundenen Gebilde stehen scheinbar zu der Dotterbildung in Beziehung. Eine Ausstossung dieser Substanzen aus dem Eikern scheint mir sehr wahrscheinlich. In einem nur wenig grösseren $\mathrm{Ei}$ von $0,054: 0,0684 \mathrm{~mm}$ (Abb. 21) hat sich das Dotterkernlager schon so weit vom Kern gelöst, dass es ihm nur als kugeliges Gebilde gerade noch anliegt. Ganz ebenso zeigt das $\mathrm{Ei}$ auf pag. 437 von $0,1008: 0,1278 \mathrm{~mm}$ das Dotterkernlager. In demselben sind keine der in kleineren Eiern so vielfach gefundenen Bildungen enthalten. Das Dotterkernlager hebt sich nur wenig dunkler gekörnt und schwach faserig aus dem Eileibe ab. Die Begrenzung ist nicht mehr so scharf wie ursprünglich. Bei dem 0,255:0,391 mm grossen Ei auf pag. 434 hat sich der Dotterkern vom Keimbläschen vollständig losgelöst und hebt sich nur wenig inmitten des Eileibes hervor. Bei grösseren Eiern wird er wieder deutlicher. In seinem Innern tritt ein immer stärker werdendes Faserwerk auf, das sich netzartig verflechtet. An seiner Peripherie fasert er sich in dem Dotter des Eies auf. In dieser Weise zeigen ihn das 0,960:1,275 mm grosse $\mathrm{Ei}$ auf pag. 438, das 1,860:2,025 mm grosse $\mathrm{Ei}$ auf pag. 438 . In dem 2,700:2,916 mm grossen $\mathrm{Ei}$ auf pag. 441 bat sich das Gebilde insofern verändert, als in den Maschen zwischen den netzartig angeordneten Fasern helle Blasen aufgetreten sind. Am weitesten ausgebildet fand ich das Dotterkernlager bei einem $11 \mathrm{~mm}$ grossen Follikel (Abb. 33). In dem faserigen mit hellen Blasen durchsetzten, ovoiden Gebilde von $350 \mu$ Länge und $250 \mu$ Breite hat sich ein kugeliges, gekörntes, eosinophiles Zentrum von 50 " Durchmesser gebildet. Es ist wohl anzunehmen, dass dies Gebilde im Zentrum des Eies liegen bleibt und im reifen Ei die Latebra (Purkyne) darstellt.

Wir haben verfolgen können, wie sich das ursprüngliche Dotterkernlager vom Kern vollständig loslöst. Frei, inmitten des Eies liegend, bildet es hier den Punkt, um den sich der Dotter ablagert, es wird zum Dotterzentrum. Ob das Dotterzentrum hierbei einen aktiven Einfluss auf die Dotterkugeln ausübt, oder ob sie sich demselben als haltbietendem Körper anlagern, vermag ich nicht $z u$ entscheiden. Es wäre denkbar, dass das Centrosom eine anziehende Kraft ausübte. Dieses habe ich aber schon in keinem Ei, welches das Ruhestadium überschritten hatte, mehr 
nachweisen können. Ich konstatiere hiermit nur die Tatsache, dass der Dotterkern zum Dotterzentrum (Latebra) wird. Diese Funktion des Dotterkerns vermuteten schon Allen Thomson und Henneguy.

Die vorliegende Arbeit verpHlichtet mich, allen denjenigen zu danken, welche mir ihre Unterstützung dabei haben zuteil werden lassen. Mein hochverehrter Chef, Herr Professor Dr. Schmaltz, derzeitiger Rektor der Königl. Tierärztlichen Hochschule, hat mir die Mittel des anatomischen Institutes zur Ausführung der Cntersuchungen zur Verfügung gestellt. Herr Professor Regenbogen unterstützte mich bei meinem Brütversuch. Die Herren Kreistierarzte Krüger und Giraud haben mir bei Beschaffung des sehr reichhaltigen Materiales geholfen. Meiner Schwester verdanke ich die grosse Zahl sehr schöner Abbildungen. Die Firma Voigtländer, Braunschweig, lieh mir zur Anfertigung der Zeichnungen einen Apochromaten. Allen sei an dieser Stelle mein bester Dank ausgesprochen.

\section{Literaturverzeichnis.}

1. Balbiani: Sur l'origine des cellules du follicule et du noyau vitellin de l'oeuf chez les Geophiles. Zoolog. Anzeiger. 6. 1883.

2. Derselbe: Centrosom et Dotterkern. Journal de l'anatomie et de la physiologie, T. 29. 1893.

3. van Bambecke, Ch.: Contributions à l'histoire de la constitution de l'oeuf. I. Rapport médiat de la vésicule germinative avec la périphérie du vitellus. Archives de Biologie, T. IV, pag. 803. Paris 1883, und: Bulletin de l'academie royale des Sciences. 3 série, VI, pag. 813, Brüssel 1883.

4. Derselbe: Contributions à l'histoire de la constitution de l'oeuf. II. Elimination d'elements nucléaires dans l'oeuf ovarien de Scorpaena scrofa. Bulletin de l'academie royale des Sciences. 3 série, XXV. Brüssel 1893.

j. Derselbe: Recherches sur l'ovocyte de Pholcus phalangoides. Archives de Biologie, T. XV. Paris 1897.

6. Derselbe: Contribution à l'étude du noyau vitellin de Balbiani dans l'ovocyte de Pholcus phalangoides. Bulletin de l'Academie Royale de Belgique. 3 série, XXXIV, Nr. 4. Brüssel 1897.

7. B o r n, G.: Die Entwicklung der Geschlechtsdrüsen. Ergebn. der Anatomie u. Entwicklungsgesch., Bd. IV 1894, pag. 593. Wiesbaden 1895. 
8. Derselbe: Die Struktur des Keimbläschens im Ovarialei von Triton taeniatus. Archiv f. mikr. Anatnmie, Bd. 43, pag. 1. Bonn 1894.

9. Bornhaupt: Untersuchungen über die Entwicklung des Urogenitalsystems beim Hühnchen. Riga 1867 (war mir unzugänglich).

10. B orsenkow: Zur Entwicklungsgeschichte des Eies und des Eierstockes beim Huhn. Bulletin Soc. imp. natur. Noscon., T. 42, P. 1, pag. 221. 1869.

11. Derselbe: Über die Entwicklung des Eierstockes beim Huhn etc. Ebenda, T. 44, P. 2, pag. 11.1872.

12. v. $\cdot \mathrm{Brunn}$ : Rückbildung nicht ausgestossener Eierstockseier bei den Vögeln. Beiträge zur Anatomie und Embryologie als Festgabe für Henle, pag. 1. Bonn 1882.

13. Carnay et Lebrun: La vésicule germinative et les globules polaires chez les Batraciens. La cellule, T. XII 1897, T. XIV 1898, T. XVI 1899.

14. Cramer: Beitrag zur Kenntnis der Bedeutung und Entwicklung des Vogeleies. Verhandl. d. phys. med. Gesellsch. zu Würzburg, N. F. I., pag. 129. 1869:

15. Durante, Fr.: Sulla struttura della macula germinativa della novo di gallina. Ricerche nel Laboratorio di Anatomia della R. Università di Roma , war mir unzugänglich).

16. Eckert, H.: Beiträge zur Kenntnis der weiblichen Geschlechtsteile and ihrer Produkte bei den Vögeln. Dissert. Dorpats, 1861.

17. Eimer: Untersuchungen über die Eier der Reptilien, II. zugleich Beobachtungen am Fisch- und Vogelei. Archiv f. mikr. Anatomie, Bd. 8, pag. 416. Bonn 1872.

18. Fick: Mitteilungen über die Eireifung der Amphibien. Verhandl. d. Anatom. Gesellsch. auf der 13. Vers. in Tübingen, Mai 1899. Ergänz.Heft zu Bd. 16 des Anatom. Anzeigers, pag. 68 und 132. Jena 1899.

19. Gasser: Eierstocksei und Eileiterei des Vogels. Sitz.-Ber. d. Ges. z. Beförderung d. ges. Naturw., pag. 84. Marburg 1884.

20. Gegenbauer: Über den Bau und die Entwicklung der Wirbeltiereier mit partieller Dotterteilung. Archiv f. Anatomie u. Physiologie 1861, pag. 491.

21. Derselbe: Zur Frage vom Ban des Vogeleies. Jenaische Zeitschrift f. Med. u. Naturw., Bd. I, pag. 113. 1864.

22. Häcker: Das Keimbläschen, seine Elemente und Lageveränderungen. I. Über die biologische Bedeutung des Keimbläschenstadiums und über die Bildung der Vierergruppen. Archiv f. mikr. Anatomie, Bd. 41 , pag. 452. Bonn 1893.

23. Derselbe: Das Keimbläschen, seine Elemente und Lageveränderungen. II. Über die Funktion des Hauptnukleolus und über das Aufsteigen des Keimbläschens. Archiv f. mikr. Anatomie, Bd. 42, pag. 279. Bonn 1893.

24. Derselbe: Die Vorstadien der Eireifung. Archiv f. mikr. Anatomie, Bd. 45, pag. 200. Bonn 1895.

25. Harper, E. H. : Fertilisation in the Pigeon's egg. Science N. S. Vol. XV, No. 379, pag. o226. 1902, u. Amer. Journ. Anat. Vol. III, No. 4, pag. 349. 1904. 
26. Henneguy, L. F.: Note sur la vésicule de Balbiani. C. R. Soc. de Biologie, s. 8. t. IV., pag. 68. Paris 1887.

27. Derselbe: Le corps vitellin de Balbiani dans l'neuf des vertébrés. Journ. de l'anatomie et de la physiologie. 29, pag. 1. Paris 1893.

28. Hertwig, 0.: Über das Vorkommen spindeliger Körper im Dotter junger Froscheier. Morphol. Jahrb. X., pag. 337. 1884.

29. Hertwig, R.: Über die Bedeutung der Nukleolen. Sitz.-Ber. d. Ges. f. Morphol. u. Physiol. München Bd. 14, pag. 92. 1898.

3(). His, W.: Untersuchungen über die erste Anlage des Wirbeltierleibes. I. Die Entwicklung des Hühnchens im Ei. Leipzig 1868.

31. Ho 11, M.: Reifung der Eizelle des Huhnes. Sitzungsbericht d. k.Akademie der Wiss. in Wien, mathemat.-naturw. Klasse Bd. 99, Abt. III, pag. 311. Wien 1891.

:32. Derselbe: Über die Reifung der Eizelle bei den Säugetieren. Verhandl. d. Anatom. Ges., 7. Vers. in Göttingen 1893, pag. 122.

33. Derselbe: Über die Reifung der Eizelle bei den Säugetieren. Sitzungsher. d. k. Akad. d. Wiss. in Wien, mathemat.-naturw. Klasse. Bd. 102, Abt. III, pag. 249. Wien 1893.

34. D'Hollander, F.: Recherches sur l'ovogénése et sur la structure et la signification du noyau vitellin de Balbiani chez les oiseaux. Commun. prélim. Ann. de la Soc. de Méd. de Gand. 3 fasc. 1903.

3. Derselbe: Recherches sur l'ovogénése et sur la structure et la signification du noyau vitellin de Balbiani chez les oiseaux. Arch. d'Anat. microse., T. VII, pag. 117. Paris 1904.

36. Derselbe: Les "pseudochromosomes" dans les ovogonies et les ovocytes des oiseaux. Bibliogr. anat., T. XIII, pag. 1. 1904.

37. Derselbe: Le noyan vitellin de Balbiani et les pseudochromosomes chez les oiseaux. Verhandl. d. Anatom. Ges. auf der 16. Vers. Halle 1902. Ergänzungsheft zu Bd. 21 des Anatom. Anzeigers, pag. 168. Jena 1902.

38. H of $\mathrm{m}$ an n, C. K.: Etude sur le dé veloppement de l'appareil urogénital des oiseaux. Verhandl. d. Koninkl. Akademie van Wetenschappen te Amsterdam (II. Sectie) Deel I, Nr. 4. Amsterdam 1892.

39. Hoyer: Über die Eifollikel der Vögel, namentlich der Tauben und Hühner. Archiv f. Anatomie u. Physiologie 1857, pag. 52.

40. Janosik, I.: Histologisch-embryologische Untersuchungen über das Urogenitalsystem. Sitzungsbericht d. k. Akademie d. Wissensch. zu Wien, Mathemat.-naturw. Klasse, Bd. 91, Abt. III, pag. 97 und 147. 1885.

41. Derselbe: Bemerkungen über die Entwicklung des Genitalsystems. Ibidem Bd. 99, pag. 260, Abt. III. Wien 1890.

42. Klebs: Die Eierstockseier der Wirbeltiere. Virchow's Archiv. Bd. 21, pag. 362. 1861. Bd. 28, pag. 301. 1863.

43. Kohlbrugge, J. H. F.: Die Entwicklung des Eies rom Primordialstadium bis zur Befruchtung. Archiv f. mikr. Anatomie, Bd. 58, pag. 376. Bonn 1901.

44. Koster, W.: Remarque sur la signification du jaune de l'oeuf des oiseaux comparé avec l'ovule des Mammifères. Archives néerlandaises des sciences exactes et naturelles. I. pag. 472. 1866. 
45. Legge, F.: Seconda contribuzione alla conoscenza dell'Uovo ovarico nel Gallus Domesticus: Il nucleo vitellino. Boll. Acad. med. Roma XIII. pag. 338. 1887.

46. Lereboullet: Recherches sur l'anatomie des organes génitaux des animanx vertébrés. Verhandl. d. kais. Leopold.-Carol.-Akademie der Naturforscher (Vol. XXIII). 15. Bd., Abteil. 1. Breslau 18j1. Bd. 1.

47. Loise1, G.: Origine et fonctionnement de la glande germinative chez les embryons d'oiseaux. C. R. l'Assoc. Anat. Sess. 5, pg. 204. 1903.

48. Loyez, N.: Sur la constitution du follicule ovarien des Reptiles. C. R. de l'academie des Sciences de Paris. T. 130.1900.

49. Derselbe: Sur les transformations de la vésicule germinative chez les Sauriens, ibid. T. 133, pag. 1025. 1901.

50. Derselbe: Sur la présence des formations elgasto-plasmiques dans l'épithélium folliculaire des oiseaux. ibid. T. 136, pag. 312.

כ1. Derselbe: Les premiers stades du développement de la vésicule germinative chez les Reptiles. Bull. Soc. Philom. Paris. S. 9, T. 4, pag. 63.

52. Derselbe: Note sur les transformations de la vésicule germinative des Reptiles. C. R. de I'Assoc. d'Anat. IV, session 1902.

53. Derselbe: L'épithelium folliculaire et la vésicule germinative de l'oeuf des oiseaux. C. R. de l'Assoc. d'Anat., pag. 81. Liege 1903.

54. Derselbe: Recherches sur le développement ovarien des oeufs méroblastiques à vitellus nutritif abondant. Arch. anat. microsc., T. VIII, pag. 69. Paris 1905.

5. Lubosch, W.: Über die Eireifung der Metazoen, insbes. über die Rolle der Nukleolarsubstanz und die Erscheinung der Dotterbildung. Ergebn. der Anatomie- und Entwicklungsgeschichte v. Merkel-Bonnet, Bd. XI 1901, pag. 709. Wiesbaden 1902.

56. Derselbe: Über die Nukleolarsubstanz des reifenden Tritoneneies nebst Betrachtungen über das Wesen der Eireifung. Jenaische Zeitschrift N. F, Ba. 30., pag, 217. 1902.

57. Ludwig, Hub.: Über die Eibildung im Tierreich. Arbeiten aus dem zool.-zootom. Inst. in Würzburg, Bd. I, pag. 287. Würzburg 1874.

58. Meckel yon Heusbach: Die Bildung der für partielle Furchung bestimmten Eier der Vögel etc. Zeitschr. f. wiss. Zoologie, Bd. IIJ, pag. 420.1851.

59. Nertens, H.: Sur la sphére attractive dans l'ovule des oiseaux. Bull de la Soc. de med. de Gaud. 1893.

60. Derselbe: Recherches sur la signification du corps vitellin de Balbiani dans l'ovule des mammifères et des oiseaux. Arch. de Biol. T. 13, pag. 389. Paris $1893 / 94$.

61. Miescher, Fr.: Histochemische und physiologische Arbeiten dess., gesammelt $u$. herausgegeben von seinen Freunden. Bd. II. Leipzig 1897. Kerngebilde im Dotter des Hühnereies, pag. 24. Über das Ei, pag. 108.

62. v. Mihalkovics, G.: Untersuchungen über äie Entwicklung des Harnund Geschlechtsapparates der Amnioten. Int. Monatsschr. f. Anatomie und Histologie, Bd. 2. 1885. 
63. Nussbaum, M.: Zur Entwicklung des Geschlechts beim Huhn. Verhandl. d. Anat. Ges., 15. Vers. in Bonn 1901, pag. 38. Jena 1901.

64. Oellacher, J.: Beiträge zur Geschichte des Keimbläschens im Wirbeltierei. Arch. f. mikr. Anatomie, Bd. 8, pag. 1. Bonn 1871.

65. Rathke, H.: Über die Entwicklung der Geschlechtsteile bei den Vögeln. Schriften der Naturf. Ges. in Danzig, Bd. I, Heft 4. Halle 18:5.

66. Rauber, A. : Über das Schicksal der Granulosa des Vogeleies. Sitz.-Ber. der naturf. Ges., Leipzig, 3. Jahrgang. pag. 3. 1876.

67. Rückert: Zur Entwicklungsgeschichte des Ovarialeies bei Selachiern. Anatom. Anzeiger, Bd. 7. Jena 1892.

fił Derselbe: Über die Verdoppelnng der Chromosomen im Keimblischen der Selachier. Anatom. Anzeiger, Bd. 8. Jena 1892.

65). Ruge, G.: Vorgänge am Eifollikel der Wirbeltiere. Jahrb. Bd. 15, pag. 491. Leipzig 1889.

7). Samter, I.: Nonnulla de evolutione ovi avium donec in oviductum ingrediatur. Diss. inang. Halis 1853.

71. Schäfer, E. A.: On the structure of the immature ovarian ovum in the common Fowl and in the Rabbit etc. Proc. of the Roy. Soc. of London 1880, Vol. XXX. Yo. 202, pag. 2:37.

72. Schütz: Über den Dotterikern. Inaug.-Dissert. Bonn 1882.

73. Seidlitz, H.: Die Bildungsgesetze der Vogeleier. Leipzig 1869.

74. Semon, R.: Die indifferente Anlage der Keimdrüsen beim Hühnchen und ihre Differenziernng zum Hoden. Jena 1887.

75. de Sommer, E.: Les premiers stades de la vitellogenése dans l'ovules de la Poule. Ann. Sic. Med. de Gand. Vol. 8̆. $190 \check{\text { o. }}$

76. Skrobansky, K. V.: Zur Frage über den sog. ,Dotterkern" (corps Balbiani) bei Wirbeltieren. Arch. f. mikr. Anatomie, Bd. 62, pag. 194. Bonn 1903 .

77. Strasser: Regeneration und Entwicklung. Rektoratsrede. Bern 1899.

78. Van der Stricht, 0 : Contribution à l'etude du noyau vitellin de Balbiani dans loocyte de la Femme. Verhandl. d. Anat. Ges., 12. Vers. in Kiel 1893.

79. Derselbe: Le noyau vitellin de Balbiani et les pseudochromosomes chez les oiseaux. Verhandl. d. Anatom. Ges., 16. Vers. in Halle 1902, pag. 168.

80. Derselbe: La structure de l'oeuf des mammifères. Arch. biol., T. 21, pag. 1. $190 \check{0}$.

81. Stricker, S.: Beiträge zur Kenntnis des Hühnereies. Sitz.-Ber. d. k. Akad. d. Wiss. in Wien, mathem.-naturw. Klasse, Abt. 2, Bd. 54, pag. 116. 1866.

82. v. la Valette St. George: Über den Keimfleck und die Deutung der Eiteile. Archiv f. mikr. Anatomie, Bd. 2, pag. 57.1866.

83. Walde yer: Eierstock and Ei. Leipzig 1870.

84. Derselbe: Die Geschlechtszellen, in O. Hertwig (Handbuch der Entwicklungslehre der Wirbeltiere). Jena 1901. 


\section{Erklärung der Abbildungen auf Tafel XIX-XXII.}

Die Zeichnungen sind mit ${ }^{1 / 12}$ hom. Ölimmersion von Zeiss und Leitz und mit einem Apochromaten ( $3 \mathrm{~mm}$ hom. Immersion) von Voigtländer angefertigt. Von den Abbildungen $290,30 \mathrm{~d}, 34 \mathrm{a}, 35 \mathrm{~d}$ ist links, von Abbildung $36 \mathrm{e}$ rechts ein Drittel des vollständigen Kernquerschnittes fortgelassin.

H whn 81 (sofort nach der Geburt getötet):

1. Zwischenzellen aus dem Ovarium eines 6 Tage alten Huhnes (90) (pag. 421).

2. Oocyte von 0,012:0,016 mm mit einem Kern von 6 u, mit Dotterkern (pag. 424). Vergr. 2000.

3. Oocytenkern von 7 a (pag. 425). Vergr. 2000.

4. Oocytenkern von $7: 7,8,4$ (pag. 425). Vergr. 2000.

5 . Oncytenkern von 8 " (pag. 426). Vergr. 2000 .

6. Oocytenkern ron $8 u$ (pag. 426). Vergr. 2000 ).

Huhn 82 (4 Stunden nach der Geburt getötet):

7. Oocytenkern von 8:9" (pag. 426). Vergr. 2000.

8. Oocytenkern von $9 "$ (pag. 126 ). Vergr. 2000.

9. Oncytenkern von 9,8" (pag. 427). Vergr. 2000.

Huhn 8.) (3 Tage alt):

10. Oocytenkern von $10 \mu$ (pag. 427). Vergr. 2000

11. Oocytenkern von $10, \mu$ (pag. 428). Vergi. 2000 .

12. Oocytenkern von $10 u$ (pag. 428). Vergr. 20010

Huhn 90 ( 6 Tage alt):

13. Oncytenkern von 10 " (pag. 428). Vergr. 2000 ).

Huhn 68 ( 8 Tage alt):

14. Zwei Oocyten von 0,017:0,0198 und 0,018:0,0206 $\mathrm{mm}$ (paty, 429). Ver(gr. 200).

15. Oocyte von 0,018: :0,0276 mm mit einem Kern von 10,5:14," mit Dotterkern und Epithelhülle (pag. 430). Vergr. 2000

16. Abschnitt eines Oocytenkernes (pag: 430).

Huhn 74 (14 Tage alt):

17. Oocyte von 0,026:0,0315 mm mit einem Kern von 16,2:18 a mit Dotterkern (pag. 431) Veror. 2000

18. Oocyte von 0,0396:0,045 mm mit einem Kem yon 19.8:21.6 "s mit Dotterkern (pag. 432). Vergr. $10(0)$.

19. Oncytenkern von $26: 27,3 \mu$ (pag. $4: 32$ ). Vergr. 1000 ).

Huhn 91 (21 Tage alt):

20. Oocytenkern von 45 " (pag. 433). Vergr. 1000 .

21. Follikel mit zwei Eiern von 0,054:0,0684 and 0,0654:0,108 $\mathrm{mm}$ (pag. 433). Vergr. 1000.

H a h 93 (3 Monate alt):

22. Oocytenkern ron 85:98.6" (pag. 434). Vergr. 1000).

Huhn 58 (4 Monate alt):

23. Oncyte mit zwei Kernen yon 13 und 16.9:18,2 "(pag +35). Vergr. 1000.

Arohiv t. mikrosk. Anat. Bd. 79. 
Huhn 1 ( 6 Mronate alt):

24. Oocytenkern von 27:37,8 a (pag. 435). Vergr. 1000.

$\mathrm{H}$ uhn 3 ( 6 Monate alt):

25. Oocytenkern von 165:190 $\mu$ (pag. 436). Vergr. 500

Huhn 22 (2 Jahre alt):

26. Oocytenkern von 14 " (pag. 4:37). Vergr. 1000.

27. Oocytenkern von 122,4:272 " (pag. 438). Vergr. 300.

$\mathrm{H}$ uhn 32 :

28. Oocytenkern eines Follikels von $6^{1 / 2} \mathrm{~mm}$ (pag. 439). Vergr. 500 .

29. Oocytenkern eines $13 \mathrm{~mm}$ grossen Follikels (pag. 440 ). Vergr. 500 . Huhn 50 ):

30. Oocytenkern eines $21 \mathrm{~mm}$ grossen Follikels (pag. $44-2$ ). Vergr. 500.

31. Oocytenkern eines $37 \mathrm{~mm}$ grossen Follikels (pag. 443). Vergr. 500. Il uhn 64

32. Oncytenkern eines Follikels von $3,13: 3,40 \mathrm{~mm}$ (pag, 445). Vergr. 500. Von $32 \mathrm{f}$ ist nur die rechte Kernhälfte wiedergegeben.

33. Dotterzentrum eines $11 \mathrm{~mm}$ grossen Follikels (pag. 4ti). Vergr. 100.

34. Oocytenkern eines $26 \mathrm{~mm}$ grossen Follikels (pag. 4t6). Vergr. 300. II uhn 6̆ :

35. Oncytenkern eines $22 \mathrm{~mm}$ grrossen Follikels (pag. 447). Vergr. 310. Huhn 37 :

36. Oocytenker'n eine's $23 \mathrm{~mm}$ grossen Follikels (pag. 448). Vergr. jo0). 


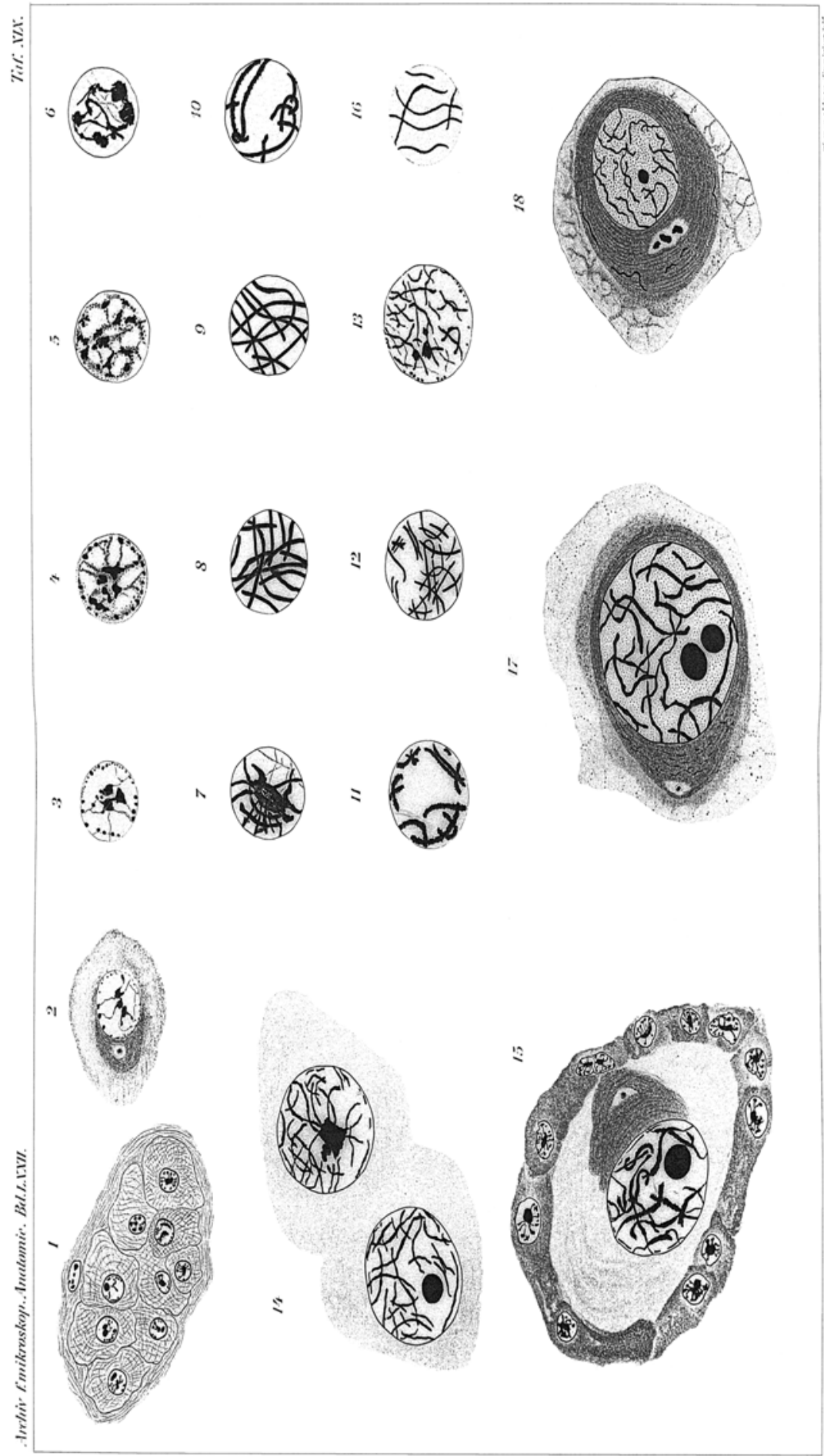




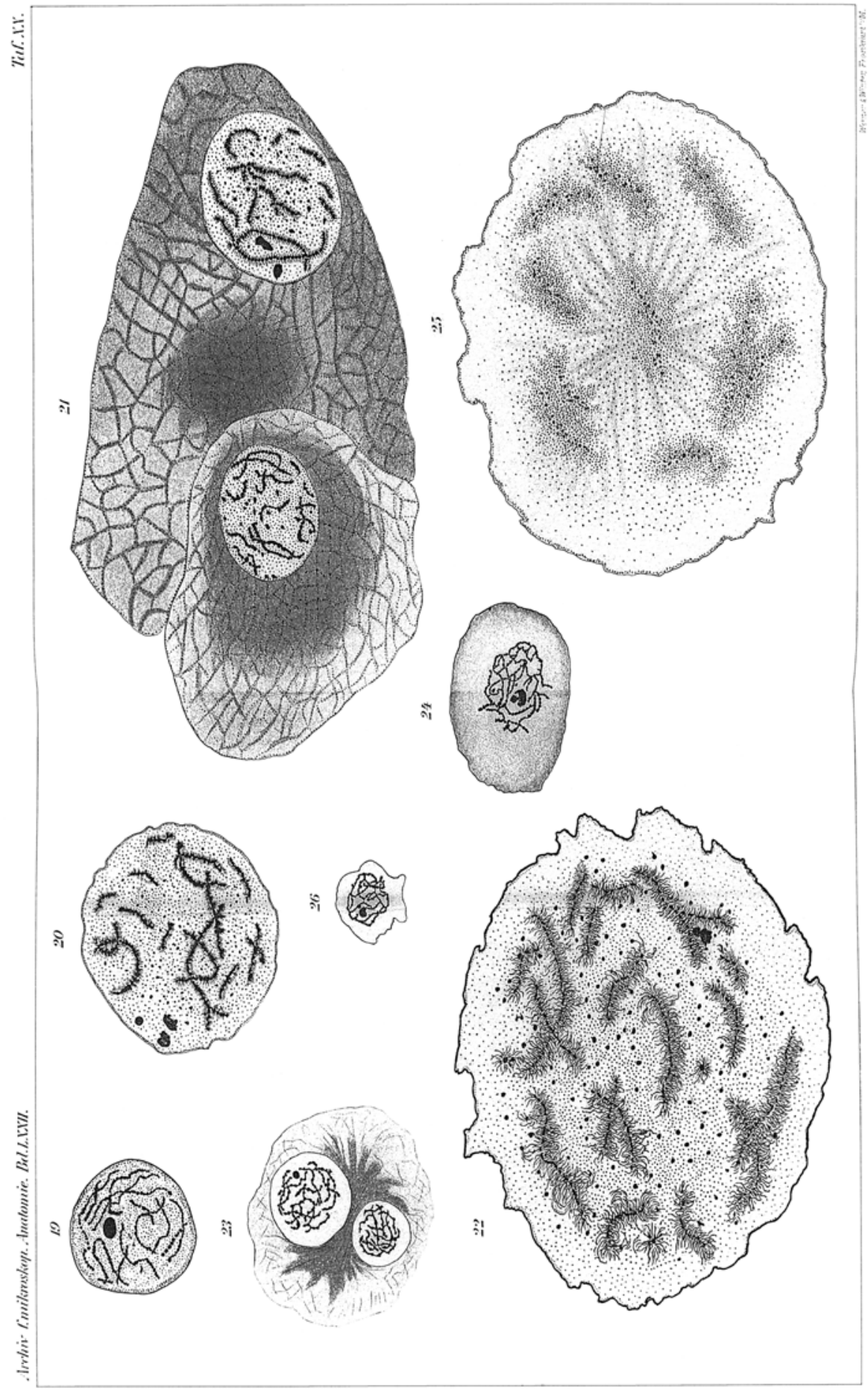




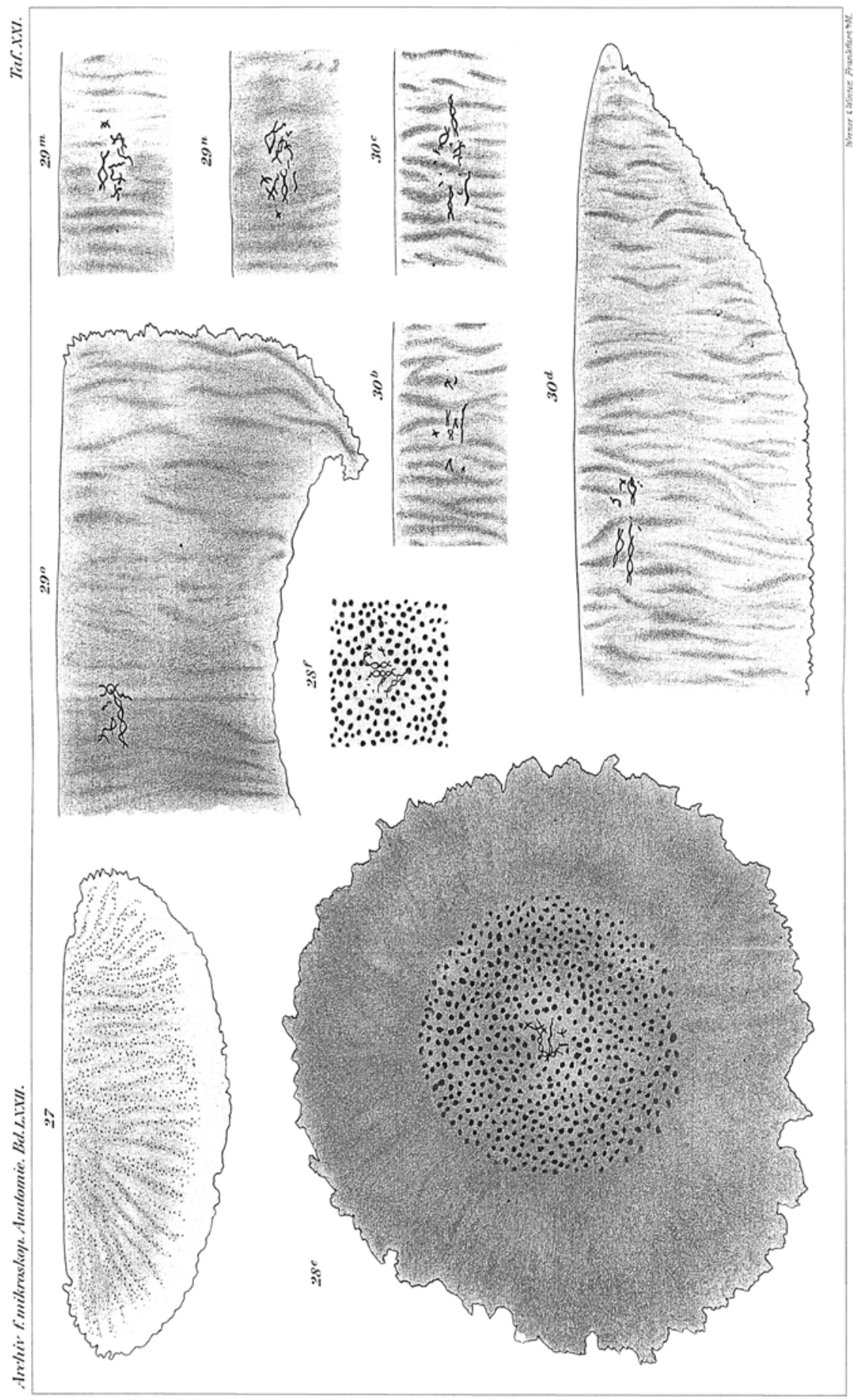




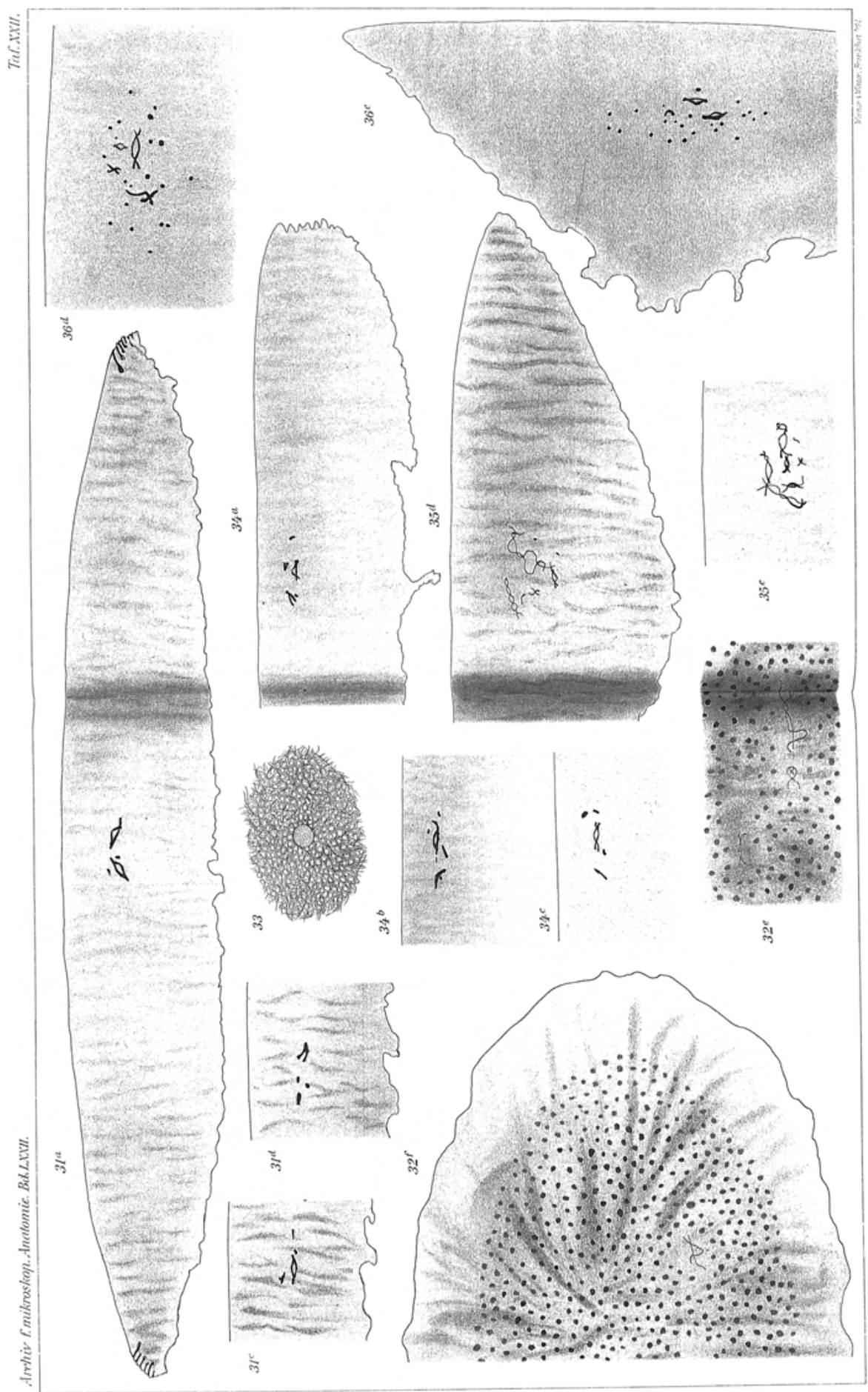

